\title{
Alexander von Humboldt and nineteenth-century ideas on the origin of American Indians
}

\author{
Michael Anthony Wadyko \\ West Virginia University
}

Follow this and additional works at: https://researchrepository.wvu.edu/etd

\section{Recommended Citation}

Wadyko, Michael Anthony, "Alexander von Humboldt and nineteenth-century ideas on the origin of American Indians" (2000). Graduate Theses, Dissertations, and Problem Reports. 1225.

https://researchrepository.wvu.edu/etd/1225

This Dissertation is protected by copyright and/or related rights. It has been brought to you by the The Research Repository @ WVU with permission from the rights-holder(s). You are free to use this Dissertation in any way that is permitted by the copyright and related rights legislation that applies to your use. For other uses you must obtain permission from the rights-holder(s) directly, unless additional rights are indicated by a Creative Commons license in the record and/ or on the work itself. This Dissertation has been accepted for inclusion in WVU Graduate Theses, Dissertations, and Problem Reports collection by an authorized administrator of The Research Repository @ WVU.

For more information, please contact researchrepository@mail.wvu.edu. 


\title{
ALEXANDER VON HUMBOLDT AND NINETEENTH-CENTURY IDEAS ON THE ORIGIN OF AMERICAN INDIANS
}

\author{
Michael Anthony Wadyko \\ Dissertation submitted to the Eberly College of Arts and Sciences \\ At West Virginia University \\ In partial fulfillment of the requirements \\ For the degree of \\ Doctor of Philosophy \\ In \\ History
}
Gregory Good, PhD., Chair
John C. Super, PhD.
Stephen C. McCluskey, PhD.
A. Michal McMahon, PhD.
Helen M. Bannan, PhD.

Department of History

Morgantown, West Virginia

2000

Keywords: Indian origins, Alexander von Humboldt, origins debate, Bering Strait Theory Copyright 2000 Michael Wadyko 


\title{
ABSTRACT \\ Alexander Von Humboldt and Nineteenth-Century Ideas On the Origin Of American Indians
}

\author{
Michael Anthony Wadyko
}

This dissertation revolves around Alexander von Humboldt's research on Indian origins. Humboldt conducted investigations on Indians during his precedent-setting scientific expedition to Meso- and South America during the years 1799-1804. Officially sponsored by the Spanish crown, the main purposes for this expedition were twofold: to examine, evaluate, and discredit Buffon's "degeneracy" claims about America and its inhabitants, and to gather empirical evidence on geography, climate, flora, fauna, and the indigenous cultures. From these results Humboldt published three major works about the expedition, particularly a thirty-volume work condensed to two volumes, Vues de Cordillerès et monuments des peuples d'Amerique.

From this work on Indian cultures and origins, this dissertation focuses on the Indian origin theory he created and the varied roles Humboldt played in the origins debate. Concomitant with these roles is Humboldt's influence and authority with various types of empirical and speculative researchers who cited him. As the origins debate evolved towards mid-nineteenth century, Humboldt's roles in the debate became more indirect. Humboldt turned to other sciences, while various researchers kept his influence alive in the debate into the $1830 \mathrm{~s}$ and 1840s.

After his death, knowledge of his work was eclipsed, and much of his contributions suffered neglect. One purpose of this dissertation is to revive this very important work. The dissertation analyzes his main work on Indian origins, plus works of other researchers from various fields who cited his works. These researchers often differed as much from one another as from Humboldt, and often used his citations to oppose his hypotheses and create their own. Included are investigators from the older speculative tradition who continued to work concomitantly along the newer empiricists from various disciplines. Those of the speculative tradition often cited Humboldt during the course of the debate during the first half of the nineteenth century. Included is the controversy that built up about the origins of a separate race of Mound builders apart from the American Indians. This controversy remained unresolved well into the late nineteenth century. 


\section{ACKNOWLEDGEMENTS}

To those people friends, mentors, and associates who have knowingly or unknowingly enabled me to complete this personal venture to ascend the academic mountain.

To: My Frau Judy, who endured academic work for almost a decade

My loving sister and friend, Valerie who supported my endeavor

My long term Freunden, Lawrence B. Kort, Joan, Teresa, and Elizabeth

My telecourse co-ordinator at CMC, Herr David Kohls

My newly minted friend, Reverend Bill Smith, Ph.D.

My Chief of Nursing at Pittsburgh VAMC, Mrs. Ernestine Marsh

My ICU Supervisor and Nurse Manager, Ms. Nancy Snyder

My VAMC director in Colorado, Dr. Kurt Schlegelmilch, who provided the permission for an early retirement to complete my research

My career-counselor and friend, Dr. Dennis Pad

Abbot Dr. Martin and all at Mt. Saviour Monastery

My mother, Mrs. Ann Dworak Wadyko the Neva Daniel family

My dissertation committee membership headed by Dr. Gregory Good the Late Dr. John Maxwell, the Late Dr. Robert Colodny,

Dr. Robert Maxon, and

Dr. Elizabeth Fones-Wolf and Dr. Helen Bannan, who were not formally on my committee

My students and friends who actively encouraged me:

Ms. Karen Marsh

Ms. Rose Marie Schlegelmilch-Bauman

Ms. Janet Girardy

Mrs. Thelma Dinge

Ms. Laurel Little

Amy and Fran Sirianni

Mr. and Mrs. Dennis Boyd

Mark Kavasch, Jeff Carlson, the Parrish family, choir and staff of Good Shepherd Lutheran

Ms. Helen and Dr. Robert Ives, who assisted me with research efforts

Dr. Joe and Mrs. Jurene Phaneuf

Dr. and Mrs. Pentti Nupponen

Herr Doktor Walter Fuchs, retired physicist, (and Frau Alice Fuchs)

Dr. Jim Forrester from West Liberty State College

Mrs. Carol Crum, RN

Mrs. Sarah Oliver, MS, CNS

Dr. Al Saliman, GMA

Dr. Holly Phaneuf

Mike and Robin Spencer

the Late Dr. Richard Roberti

Dr. Orisya Karapinka

the Late Dr. Carl Beck

Members of Ohr Shalom Congregation

WVU Support Staff: Kathy Fletcher, John Hagen, Carol Hando, Nancy McGreevy, Karla Vaughan

Herr John McCormick, Ms. Lynn Sabloff, Sean Vetter, OT, Ms. Lori Adams

Pope John Paul II 


\section{CONTENTS}

\section{Introduction}

Page 1

\section{Chapter One}

Alexander von Humboldt's

Investigations on Indian Origins

Page 14

Section 1 - Prelude to Theory

Section 2 - Humboldt's Methodology

Section 3 - Bases of Humboldt's Origin

Theory in Views and Monuments

Section 4 - Humboldt's Emphasis on Archaeological Remains

Section 5 - The Toltecs

Section 6 - Humboldt's Analyses of Astronomical-Astrological Calculations and Calendars

Section 7 - Final Comments

\section{Chapter Two}

Ancient Texts and Myths as Historical Record: Atlanteans, Lost Tribes, and Other Ancient Traditions

Page 48

Section 1 - Ancient Sources versus Existing Evidence

Section 2 - Atlantean Origin Theory

Section 3 - Biblical Origin Theories

Section 4 - James Adair on Lost Tribes

Section 5 - Joseph Smith and the Ten Lost Tribes as Scripture

Section 6 - Variations on the Lost Tribes' Theme 
Section 7 - Links with Other Ancient Peoples

Section 8 - Combination Theories

Section 9 - Welsh and Scandinavian Theories

Section 10- Conclusion

\section{Chapter Three}

Philology Addresses Asian Origins

Page 105

Section 1 - Introduction: Philologists

First of the Empiricists

Section 2 - Those Who Laid the

Groundwork

Section 3 - Benjamin Smith Barton

Section 4 - Johann Vater

Section 5 - Thomas Jefferson

Section 6 - Albert Gallatin

Section 7 - Lewis Cass

Section 8 - Conclusion

\section{Chapter Four}

Gentlemen Scholars and Theorists

\section{Page 138}

Section 1 - Basic Themes

Section 2 - Physician-Climatologists

Williamson and Murray

Section 3 - Scholars Who Kept Humboldt's

Ideas in the Debate

J.H. McCulloh and B.H.Coates

Section 4 - Other Inconclusive Scholars

C.S. Rafinesque Alexander Bradford

Section 5 - Separate-Origin Theorists

Section 6 - Summary and Conclusions 


\section{Chapter Five}

Mound Builders and the Origins Debate

Page 168

Section 1 - Differentiation in Research

Methods

Section 2 - Organized Investigations

Section 3 - McCulloh and Priest on

Mound Builders

Section 4 - The Phrenologists:

Samuel Morton

Section 5 - Advent of Sophisticated

Archaeology:

Squier and Davis

Section 6 - Conclusion

\section{Conclusion}

Page 177 


\section{INTRODUCTION}

\section{Basic Themes}

This dissertation involves Alexander von Humboldt's attempts to resolve, by scientific methodology, elements of a dilemma introduced by Columbus's landing in America. A dilemma for Europeans developed from their treatment of the native peoples. This posed questions about their origins, because that affected the treatment accorded them. If Europeans resolved this issue of origins to their satisfaction, then they were able to justify actions. Other reasons for interest in origins arose from scholarly, exploratory, religious, and curiosity reasons.

As fierce competition among investigators and nations in Europe intensified, the number and type of speculations on origins grew. Errors in assessing origins increased, because investigators lacked sufficient evidence, knowledge, and methodology to about the subject. Absence of recorded histories and visible remains posed a significant obstacle in the assessment of origins. Many American Indian cultures featured rich oral traditions about migrations and heritage. Conquistadorés had plundered and destroyed archaeological remains and written records of the major Indian civilizations of Mexico and Peru, ignorant of the evidence that these may have contained about origins. Ecclesiastical destruction accompanied this pillage, as clerics viewed the remains as intrinsically evil. Elsewhere in North America, burial grounds, cultural remains, villages, and artifacts incurred desecration and devastation by the European invaders.

Three centuries after Columbus, Europeans still possessed limited climatic and geographic knowledge about the New World. More colonists settled in the Americas. Explorers continued mapping the continents. Many purely speculative accounts acquired a more sophisticated bent as a result of updated information. Lee Huddleston's Origins of the American 
Indians, European Concepts 1492-1729 (1967) covers the range of origin speculations, hypotheses, and theories from the Columbus era through $1729 .{ }^{1}$ These included mythical, legendary, and contrived sources from Atlantis to the Ten "Lost Tribes" of Israel, Phoenicians, Egyptians, Welsh, Scandinavians, northeastern Asians, Mongolians, and a host of other possible sources.

Interests in the origins of the indigenous peoples by explorers, missionaries, travelers, and indigenous peoples went back at least to Biblical times. Various creation stories attempted to trace genealogies and migrations of tribes and nations through a mixture of fact and fiction. After the expeditions of Columbus, Europeans renewed their interest in indigenous peoples, particularly those of the New World, mistakenly termed "Indians" by Columbus. With the revival of learning experienced during the Renaissance, Europe quickly accepted the challenge of investigating the origins of the New World's inhabitants. Since few facts and little concrete evidence existed, myths, legends, oral traditions, and speculations sufficed to explain origins. By the mid-eighteenth century, attempts to resolve the "dilemma" had reached a virtual stalemate.

In his analysis of origin theories up to 1729, Huddleston focuses on key investigators, including José de Acosta, Edward Brerewood, Hugo Grotius, Ioannes, DeLaet, and George de Hornn. They provided valuable insights for future theorists and sparked origins discussions during this speculative period. Their largely unsubstantiated hypotheses about a northeastern Asian origin for the Indians revolved around the belief that America abutted Asia in the northernmost regions of the globe. Such a short distance projected in the "Straits of Anian," provided a feasible entry from Asia to America.

\footnotetext{
${ }^{1}$ Lee Huddleston, Origins of the American Indians, European Concepts, 1492-1729, London and Austin: University of Texas press, 1967.
} 
Serious efforts to gather empirical evidence and hypothesize from it began well after the cutoff date (1729) for Huddleston's examination of origins by Europeans. The 1770s marked the period when explorers precisely mapped out the northernmost regions of North America, while American missionaries and explorers gathered information about languages, customs, practices, and remains of the American Indians. By the late 1800s, the age of the empirical investigator and scholar had dawned with a new impetus for discovering not only American Indian origins, but humanity's origins as well.

A prominent figure of scientific and Enlightenment thought arose from the Prussian aristocracy and bureaucracy during the last decade of the century - Alexander von Humboldt. With his vast knowledge and education, he emerged as a consolidating force for a new empirical approach in many areas of scientific investigation that replaced the more narrow and exacting "positivistic" approach of the eighteenth century. With the development of a universalistic, comprehensive approach to science and forms of empirical evidence, Humboldt initiated the Indian origins debate of the first half of the nineteenth century. Humboldt's research efforts, varied interests, persona, philosophy, and reputation as scholar, scientist, and traveler, formed the matrix that connected all of the diverse elements of the origins debate. He moved to the forefront of empirical investigation in the quest for Indian origins, because of his precedentsetting scientific expedition to Meso- and South America. With the knowledge and evidence gained from the expedition and thereafter, the period from 1790 until his death in 1859 can be properly termed, "the Age of Humboldt." 2 During this period many of the sciences developed in the investigations of origins acquired their scope, methodology, validity, and established

\footnotetext{
${ }^{2}$ Margarita Bowen, Empiricism and Geographical Thought from Francis Bacon to Alexander von Humboldt, London, New York, Sydney: Cambridge University Press, 1981, pp. 210, 211. Bowen mentions that to call the epoch 1790-1859, the "Age of Humboldt" may not be as accurate as the "Age of Newton," a century earlier. Adolf Meyer-Abich, Alexander von Humboldt 1769/1969, Bonn: Bad Gotesberg, 1969, p. 33, mentions that the motives
} 
themselves in institutions of learning and research because of Humboldt's efforts. Humboldt dedicated his energies to these developments of sophistication and institutionalization by providing leadership himself in the fields of geography, botany, anthropology, and archaeology, key disciplines for investigating human cultures and their beginnings.

Humboldt's universalistic position as a natural scientist, his leadership in the sciences, and reputation in the scientific world paradoxically also led to his decline. His reputation was eclipsed rapidly after his death in 1859 (the same year that heralded Darwin's publication of Origin of Species). First, subsequent neglect occurred in areas of marginal interest to Humboldt in his later years, such as the further investigation of Indian origins and validation of the Bering Strait Theory he created. By 1830 Humboldt had ceased research and writing on the subject. His role in the origins debate he initiated developed into an indirect one perpetuated by scholars active in the debate. They continued to cite his authority and findings, when he had already turned to the pursuit of other scientific interests.

To explore and revive scholarly interest in this neglected area of assessing Indian origins and the dominant roles Humboldt played during the first half of the nineteenth century in the debate is the main reason for this dissertation. A secondary reason derives from the explicit importance of Humboldt and his achievements for America:

for Humboldt's expeditions were purely scientific with no intended political agenda taking priority over his research. Susan Faye Cannon, "Humboldtian Science," Science in Culture: The Early Victorian Period, New York: Dawson and Science History Publications, 1978, p. 74, suggests that the activities of several scientists in the early nineteenth century matched up to Humboldt's schema fairly precisely. From 1800 to 1840, he drew the attention of many European scientists, especially the younger generation, to a conglomerate of interests, for which there has never been a completely satisfactory phrase. 
If one wishes not only to understand what Alexander von Humboldt accomplished . . . one ... must trace Humboldt's influence in America. For Humboldt is certainly by far the most important of all the Germans who ever worked in America and for America. He was the greatest naturalist of Goethe's day and also the last universal scholar in the field of the natural sciences, with whose contemporary results he was thoroughly familiar. . . However, in the American history of ideas Humboldt's importance is far greater and he has the status of a tradition whose influence is felt today. ${ }^{3}$

To explore and revive scholarly interest in this primary area of neglect on Indian origins and the dominant part he played in the origins debate he initiated, provides the main motivation behind this dissertation. The research questions the dissertation explores derive from the influence of Enlightenment thought and the reputation Humboldt achieved in French social, philosophical, and scientific circles. Paris of the late eighteenth century represented the center of European scientific activity. Humboldt's background and achievements enabled him to mingle easily in Paris society. His peculiar pattern of evolution from the norms set by the Prussian nobility into a pan-European intellectual and adherent of Enlightenment principles, resulted in a controversial path towards investigation of various phenomena, including Indian origins.

Humboldt hailed from the Prussian nobility and bureaucracy embellished by Enlightenment circles in Berlin and steeped in the knowledge of the natural sciences, especially geography. Born of a French mother, Humboldt spoke and wrote more fluently in French than German. His mother raised him and educated him for a career in the Prussian bureaucracy along with his older sibling, Wilhelm.

Humboldt thus entered the heart of the "polemic" about the supposed inferiority of America and its inhabitants advocated by Enlightenment philosophe Georg Buffon and his disciples, Raynal and DePauw. ${ }^{4}$ In this controversy Humboldt first appeared as a European

\footnotetext{
${ }^{3}$ Adolf Meyer-Abich, "Introduction," Alexander von Humboldt 1769/1969, Bonn/Bad Gotesberg: Internationes, 1969, p. 1.

${ }^{4}$ Otis E. Fellows and Stephen F. Milliken, Buffon, New York: Twayne Publishers, Inc., 1972; Daniel Webb, Selections from M. Pauw, with Additions by Daniel Webb, Esq.; London and Bath: R.Cruttwell, 1795. See also
} 
champion for the American cause and conceived his idea for a scientific expedition to America for evaluating the validity of these "degeneracy" claims by Buffon and his disciples. The "polemic" helped to create a strong interest In American Indians and their origins. The overriding purpose for Humboldt's Meso- and South American expedition and consequent writings developed from his determination to disprove these claims. These particular philosophes proposed that all of the plant and animal species and the land itself were "inferior" to those of Europe and the rest of the Old World. They cited climatic differences, absence of large land animals, the "degraded' state of the indigenous peoples' cultural development, and the consequent decline of humans and domesticated animals upon their arrival in America. Humboldt inadvertently played into the dynamics of the "polemic" by introducing pronouncements into his thesis about the "savage" nature of the American Indians and the degree of "advancement" American civilizations had achieved compared to European standards. ${ }^{5}$

Humboldt's expedition resulted in three basic works about his and Aimé Bonpland's travels and investigations throughout the regions. The main emphasis on investigations and assessments of Indian origins constituted his original thirty volume work, Vues de cordillerès et monuments des peuples d'Amerique (French, 1810, English, 1814). ${ }^{6}$ This work contains the material from which Humboldt created his origin theory - the Bering Strait Theory - which numerous scholars and researchers from both sides of the origins debate cited. This controversial work, with its numerous findings, hypotheses, and contradictions, sparked the Indian origins debate of the first half of the nineteenth century. For various reasons, the original

Antonello Gerbi, The Dispute of the New World, The History of a Polemic 1750-1900, Pittsburgh: University of Pittsburgh Press, 1983.

${ }^{5}$ Marie Louise Pratt, Imperial Eyes, Travel Writing and Transculturation, London and New York: Routledge, 1992, p. 134; Antonello Gerbi, The Dispute of the New World: History of a Polemic, 1983, pp. 409-411; On p. 410, Gerbi states that Humboldt dealt Buffonian theory a "stunning" blow. 
version and its translations into English experienced neglect, before and after Humboldt's death. Historians Marie Pratt and Margarita Bowen provide insights for the decline of its scientific importance. The purposes of this dissertation involve his main work on origins, the title of which Marie Pratt appropriately shortens to Views and Monuments. ${ }^{7}$ Her reasoning about the work's diminished importance underlie the use of the shorter, but still comprehensive title. Pratt emphasizes that the popular two-volume version carved from the original thirty volumes, readily lost the second half of its title shortly after publication, because readers and commentators alike never fully appreciated the "richness" of the archaeological essays' contents. These were consequently forgotten and the work acquired the shortened half title of Views of the Cordilleras. Other factors contributed to the eventual neglect: First, the work appeared as a popular companion to Humboldt's Ansichten der Natur (Views of nature) published in German in 1808, which emphasized the image of America as primal nature. Also, the archaeological writings posed a potential threat to explode the myth of primal America and its concomitant views about the American Indians held by idealistic-minded Europeans. Learning about the cultures and histories of the principal American Indian civilizations contradicted pre-conceived images of "savages" in the forest primeval, as Humboldt himself had deemed them as "indigenous hordes." ${ }^{\prime}$ Classification of the work as "travel literature," written for popular consumption prevented its acceptance as a bona fide scientific work. The various views of nature scenes emphasized throughout both volumes certainly gave that impression of a picturesque travel account with little scholarly content. Contemporary authors as Douglas Botting still fail to consider this work as a scholarly endeavor, because he views it as a heterogeneous collection of

\footnotetext{
${ }^{6}$ Alexander von Humboldt, Researches, Concerning the Institutions and Monuments of the Ancient Inhabitants of the Americas, with Descriptions and Views of Some of the Most Striking Scenes in the Cordilleras! Translated by Helen Maria Williams, Vols. 1, 2, London: Longman, Hurst, Rees, Orme, Brown, J. Murray, and H. Colburn, 1814.

${ }^{7}$ Marie Louise Pratt, Imperial Eyes, Travel Writing and Transculturation, p. 132.
} 
descriptions and illustrations of mountain views and Aztec art. ${ }^{9}$ Humboldt's other two works about the expedition, Political Essay on the Kingdom of New Spain (French, 1810 and English, 1811) and Personal Narrative of Travels to the Equinoctial Regions of the New Continents during the Years 1799-1804 (French, 1811 and English, 1815) fit within the classification of travel literature. They were basically travel logs and statistical accounts of the regions' inhabitants. ${ }^{10}$ Pratt includes Views and Monuments in travel literature, though she interprets the work as a more serious piece of scholarship.

Humboldt never intended to create an incongruent mixture of writings, but rather a work that interwove essays on America and its inhabitants into a cohesive collection that reflected harmony and connection. His presentation of the monuments of the indigenous American tribes and the views of the mountains they inhabited, demonstrated that the "climate, soil, plant physiognomy, and the view of beautiful or of savage nature had influenced the progress of the arts."11

Humboldt wanted to emphasize the Mexican pyramids ("teocalli”), manuscripts, and other artifacts. European excavations in Egypt uncovered lost remains from ancient civilizations, which provided a precedent for such an archaeological discovery of America. The discovery of the Rosetta Stone must have motivated Humboldt's investigation of American hieroglyphic findings, the material essence for his longest and most erudite essays in Views and Monuments. Pratt finds Humboldt "fascinated" and inspired by his archaeological finds. She also sees his observations on the American Indians' history as remarkable, even prophetic. Pratt maintains

\footnotetext{
${ }^{8}$ Marie Louise Pratt, Imperial Eyes, Travel Writing and Transculturation, p. 134.

${ }^{9}$ Marie Pratt, Imperial Eyes, travel Writing and Transculturation, p. 133; Douglas Botting, Alexander von Humboldt, Biographie Eines Grossen Forschungs Reisenden, München: Prestel Verlag, 1989, p. 202.

${ }^{10}$ Alexander von Humboldt, Political Essay on the Kingdom of New Spain; Vols. 1, 2, 3, 4, Translated from the French by John Black, London: Longman, Hurst, Rees, Orme, and Brown, Paternoster Row and Colburn, 1811; New York: AMS Press, 1966.

${ }^{11}$ Marie Louise Pratt, Imperial Eyes, Travel Writing and Transculturation, p. 133.
} 
that Humboldt disparaged the achievements of American Indian civilizations in comparison with those of the classical Mediterranean ones:

American architecture . . can cause no astonishment, either by the magnitude of its works, or the elegance of their form, but it is highly interesting, as it throws light on the history of the primitive civilizations of the mountains of the new continent. ${ }^{12}$

Pratt also challenges Humboldt's emphasis on the harmony of culture and nature in America, because it guaranteed an inferior status for the American Indians. Humboldt supposedly believed the "more "savage"" the nature, the "more "savage"" the culture. 13 This emphasis on the harmony of culture and nature in America challenged by authors, such as Pratt, necessitates a clearer understanding of Humboldt's periodic perspective when he wrote Views and Monuments, and what he hoped to achieve through its publication. Humboldt consistently demonstrated his attempts for objectivity, despite his cultural biases exhibited during the course of his five-year Meso- and South American expedition. He conducted a demanding program of research in the best empirical tradition of the time by collecting specimens, correcting geographical-geological records, and gleaning archaeological data, while investigating languages and the practices of the American Indian cultures he encountered. Humboldt was careful to label himself as a scientific traveler, not as an explorer, who accurately investigated what explorers had erroneously observed and reported. Humboldt's expedition used the latest instruments of measurement available to him. ${ }^{14}$ The separation of natural science and history into individual components does not appear possible in the viewpoints expressed by Humboldt and the intent of this dissertation. The term "natural history" represented a misinterpretation of

\footnotetext{
${ }^{12}$ Alexander von Humboldt, Views and Monuments, Vol. 2, p. 9.

${ }^{13}$ Marie Louise Pratt, Imperial Eyes, Travel Writing and Transculturation, p.133; Alexander von Humboldt, Views and Monuments, Vol. 1, pp. 39, 40.

${ }^{14}$ Margarita Bowen, Empiricism and Geographical Thought from Francis Bacon to Alexander von Humboldt, London, new York, Sydney: Cambridge University Press, 1981, pp. 224, 225; Susan Faye Cannon, "Humboldtian
} 
the meaning Humboldt intended in his works, including Views and Monuments. Natural history as a comprehensive study still makes sense to an historian of the sciences, of which Humboldt was among the first. The historian of science evaluates records from human cultures in context of the natural environment, exactly what Humboldt attempted to do in his work on origins. Humboldt emphasized the intrinsic value of historical research with its scrupulous comparison of dates and related documents. He intended to stretch the limits of a narrow empiricism. On this expedition, Humboldt investigated varied types of evidence, ignoring a restricted, exacting, positivistic approach, which enabled him to selectively gather evidence and abandon irrelevant forms of evidence. He demonstrated this, when he examined hieroglyphic paintings and various sources to tell of the Mexicans' histories and migrations, thus enacting the role of an historian. ${ }^{15}$

Humboldt earned the role of "transculturator," because he transferred knowledge acquired from his expedition to Europe, rather than just introducing European ways and thinking to America. This, in turn, created new reservoirs of European knowledge influenced by nonEuropean sources. The label of "transculturation" specifically fit Humboldt's Views and Monuments, but could have applied to all travel writing of the period. Questions about the effects and directional flow of "transculturation" are often difficult to assess from within the framework of "bourgeois-author centered ways of knowing texts.",16

The knowledge obtained from a traveler's awareness and astute observations significantly reflected the interpretations and experiences of their homeland readership, filtered through their Weltenschauung or conceptual worldview. Pratt's assessment poses a further point about

Science," Science in Culture: The Early Victorian Period, New York: Dawson and Science History Publications, 1978 , p. 75.

${ }^{15}$ Margarita Bowen, Empiricism and Geographical Thought, pp. 224, 225, 231, 232.

${ }^{16}$ Marie Louise Pratt, Imperial Eyes, Travel Writing and Transculturation, p. 135, asks two questions: 1) "To what extent was Humboldt a transculturator, transporting to Europe knowledges American in origin; producing European knowledges infiltrated by non-European ones? 2) "To what extent within relations of colonial subordination, did 
assessing Humboldt's influence with European scholars and American investigators, who inevitably belonged to the educated middle and upper classes of their respective societies. Assessment of Humboldt's work must take this factor into account, no matter how advanced his views may have been for the times and a person from his background. ${ }^{17}$

A few comments are in order here about the English translation by Helen Maria Williams (1762-1827) of Humboldt's Views and Monuments used exclusively in this dissertation.

Translation from the original French version represented (and still presents) a formidable task. To achieve the exact meaning and precise terminology intended by Humboldt is never easy. His tendency towards verbosity and complexity added to the dating of the language and further compounded the task. The dissertation draws primarily from the translation by Helen Maria Williams because Humboldt interacted with her directly to accomplish this task. Humboldt personally made the corrections needed. Later translations, such as the one by Thomasina Ross in 1851 exist, but are farther removed from the context in which he wrote. Various critics, however, still find fault with Williams's translations.

Historian Margarita Bowen claims that Williams omitted information, changed meanings, and erroneously transcribed phraseology. Her comments do not pertain directly to Views and Monuments, but to other works from Humboldt's expedition translated by Williams, especially a later personal account of Humboldt's experiences during the American expedition, Relation historique du voyage, written in French in 1814 and translated into English in 1818. Various historians, on the other hand, particularly Marie Louise Pratt, uphold the validity of Williams's English translation of Views and Monuments and derive their assessments from it. Pratt mainly

Americans inscribe themselves on him, as well as he on America?" These questions are key factors in evaluating Humboldt's work on Indians and their origins.

${ }^{17}$ Marie Louise Pratt, Imperial Eyes, Travel Writing and Transculturation, pp. 135, 136. 
quotes from Williams's 1814 translation, considering it the most authentic of the translations ${ }^{18}$

The biggest point of controversy about translation occurred about the incorrect translation of “natural science" as "natural history," two completely distinct fields. Various disciplines contributed to natural history, whereas natural science focused on scientific investigations of both nature and humanity. ${ }^{19}$

A second term relevant for Humboldt's analyses of Indian origins that proved problematic in its literal translation from French to English was "Geographie physique." English usage of the term by the nineteenth century implied a study of the earth's surface features, such as mountains and rivers. Humboldt interpreted it more broadly as an all-inclusive geography of living and non-living matter. This represented a key distinction underlying the interpretation and analysis of his main work on origins, Views and Monuments. Bowen's implied criticism of the accuracy with which Williams translated Views and Monuments certainly appears misdirected or irrelevant. $^{20}$

With the emphasis of these factors that form the approach to interpretation and analysis of his main work on origins, Views and Monuments, an orientation to the work and an analysis of it follows in the first chapter. A sketch of Humboldt's life and experiences provides a background for understanding how Humboldt and his work influenced the nineteenth-century Indian origins debate he initiated. The summary of prior Indian origin theories provided a foundation on which empiricists, especially Humboldt, based their investigations and developed their empirically oriented theories. Finally, this dissertation illustrates the dual legacy of the

\footnotetext{
${ }^{18}$ Marie Louise Pratt, Imperial Eyes, Travel Writing and Transculturation, p. 240.

${ }^{19}$ Margarita Bowen, Empiricism and Geographical Thought, pp. 231-233.

${ }^{20}$ Margarita Bowen, Empiricism and Geographical Thought, pp. 230, 231. On p. 230 Bowen mentions it is important to note that the problem of geography continued to occupy Humboldt during the composition of his works about the expedition. On p. 219 Bowen first introduces Humboldt's idea of a "universal" or "natural science."
} 
speculative tradition that co-existed and intertwined itself with the research and theories of the Indian origins debate of the first half of the nineteenth century. 


\section{CHAPTER ONE}

\section{Alexander von Humboldt's}

\section{Investigations on Indian Origins}

\section{Overview}

This chapter examines Humboldt's writings about American Indian origins and his methods of investigations. His analyses built on origin speculations before the latter part of the eighteenth century. This period witnessed numerous geographical explorations and serious empirical investigations on American Indians. This discussion focuses on four objectives and relies heavily on the English translation (1814) from the original French version, Vues de cordillerès et monuments des peuples indiginès d' Amerique (1810), by Helen Maria Williams (1762-1827), as does historian Marie Louise Pratt. Williams, a renowned English radical and advocate of Enlightenment thought, collaborated directly with Humboldt in the translation of his work. Humboldt personally corrected her errors. ${ }^{1}$ Her translation came close to the original meaning. Humboldt emphasized that his principal objective for writing was to throw light on a "universal" or "natural" science which had only been sketched and vaguely referred to as Physique du Monde, Theorie de la Terre or Géographique physique. ${ }^{2}$ Williams's translations of Humboldt's works from French into English are the most authentic and reliable versions available.

\footnotetext{
${ }^{1}$ Marie Louise Pratt, "Notes," Imperial Eyes, Travel Writing and Transculturation, London and New York: Routledge, 1992, p. 240. Pratt mentions that she primarily quotes from Williams's 1814 English translation. She also refers to Williams as the "well known English radical" of the times on p. 119. Humboldt wrote mostly in French.

${ }^{2}$ Margarita Bowen, Empiricism and Geographical Thought from Francis Bacon to Alexander von Humboldt, London, New
} 
Williams translated Humboldt's French into the English of the times. Her translation of his Vues des Cordillerès et monuments des peuples indigenès d' Amerique would have been the most familiar to Americans around 1820. Americans read these editions, which formed the background for the reception and interpretation of Humboldt's ideas. Other translators' versions also proved useful to American readers, especially John Black's translation of Humboldt's other two works about his expedition. John Black (1783-1855) translated Political Essay on the Kingdom of New Spain (1811) and Personal Narrative of Travels to the Equinoctial Regions of the New Continent during the Years 1799-1804 (1822). ${ }^{3}$ Different translations introduced a wider range of perspectives for interpreting Humboldt's ideas.

This chapter features seven sections about Humboldt's Meso- and South American expedition and writings on indigenous Americans. It first introduces Humboldt's "official" report for the Spanish government on his expedition. This sets the stage for his later and more voluminous works about American Indian investigations other than those conducted for official political purposes. Next follows analyses of Humboldt's methodology found in writings about the expedition. In this section the focus shifts to Views and Monuments. ${ }^{4}$

The third section underscores the empirical bases of Humboldt's origin theory, whereas the fourth focuses on Humboldt's archaeological investigations. The fifth examines the controversy about the Toltecs' origins and the challenge it presented to Humboldt's origin theory.

York, Sydney: Cambridge University Press, 1981, p. 231.

${ }^{3}$ Marie Louise Pratt, "Notes," Imperial Eyes, Travel Writing and Transculturation, endnote no. 15. In constructing her assessment of Humboldt's Personal Narrative, Pratt relies solely on the translation by Williams published in 1822 .

${ }^{4}$ Marie Louise Pratt, Imperial Eyes, Travel Writing and Transculturation, p. 132. Pratt suggests this abbreviated title rather than Views of the Cordilleras, Because it includes both the physical and human geography. The commonly used abbreviation Views of the Cordilleras omits the human side entirely. 
The sixth section explores the Humboldt's comparative analyses of Mexican astronomy and astrology and comparisons of Mexican religious practices with those of other peoples. Section seven represents a summary and commentary of Humboldt's discoveries

\section{Section 1}

\section{Prelude to Theory}

In the Political Essay on the Kingdom of New Spain (1810 in French, 1811 in English), his official work about the Meso- and South American expedition, Humboldt previewed his later work on American Indian cultures and origins, Views and Monuments (1810 in French, 1814 in English). In Views and Monuments, he elaborated on ideas from the Political Essay. The main argument of this section centers on the reserved position Humboldt presented on American Indian origins in the Political Essay and the Personal Narrative (1814 in French, 1822 into English).

In these two works he touched on the travels of a few groups of indigenous peoples in the Americas. Translator John Black (1783-1855) predicted that Humboldt would be consulted as an authority on the subject of Indian origins. ${ }^{5}$ This statement of Black's reflects the essence of the key theme for the entire dissertation: Humboldt exerted both a direct and indirect influence on investigators who followed him, whether or not they agreed with him or ever established contact with him.

\footnotetext{
${ }^{5}$ Alexander de Humboldt, "Preface," Political Essay on the Kingdom of New Spain, Vol. 1, translated from the original French by John Black, London: Longman, Hurst, Rees, Orme, and Brown, 1811, pp. Iv, v: "M. de Humboldt belongs to a higher order of travellers to whom the public have of late been very little accustomed ....".
} 
In the Political Essay he first questioned Indian origins as related to the pattern of continual population flow from north of the Gila River in Arizona southward. Where did these peoples originate? In this work, he did not take a stand on the origins of the various Mexican Indian cultures:

We are ignorant whether that [region north of the Gila River] was their primitive country, or whether they came originally from Asia or the Northwest coast of North America ... Where is the country from which the Toultecs [sic] and Mexicans issued? ${ }^{6}$

Humboldt conveniently dodged the origins issue in this work by stipulating that the matter went "beyond the limits of history and philosophy."7 This aloof stand often resulted in hypotheses snarled with contradictions. He declared no one could assume whether or not all of American Indians had originated from Asia. It may have simply meant that such a statement required proof. If the Toltecs, for example, had actually come from Asia, insufficient evidence existed to generalize about the whole from a few of its parts. Humboldt cautioned against making hasty generalizations. ${ }^{8}$

Humboldt emphasized that few pre-European contact human remains existed north of the Gila River or into northern Canada. ${ }^{9}$ In anticipation of Views and Monuments, Humboldt intentionally avoided discussion on similarities between eastern Asian and American Indian languages. In the Political Essay he downplayed the investigations of Benjamin Smith Barton

\footnotetext{
${ }^{6}$ Alexander de Humboldt, The Political Essay on the Kingdom of New Spain, pp. 132, 133. Humboldt separated the Toltecs from successive waves of Mexican peoples, but the Toltecs represented the first wave of migration of indigenous peoples into Mexico.

${ }^{7}$ Alexander de Humboldt, The Political Essay on the Kingdom of New Spain, p.135.

${ }^{8}$ Alexander de Humboldt, The Political Essay on the Kingdom of New Spain, pp. 134-136.

${ }^{9}$ Alexander de Humboldt, Political Essay on the Kingdom of New Spain, p. 134.
} 
(1766-1815) based on word comparisons between Old World languages and American Indian tongues. $^{10}$

Humboldt's key statements on origins in the Political Essay contradicted northeastern Asian speculations. He evaded the origins question by relegating authority on the matter to earlier Spanish historians:

$\ldots$ we shall confine ourselves to the accounts of Spanish historians ... ${ }^{11}$

In the Political Essay Humboldt defined other issues, such as the north to south pattern of Indian migrations and comparisons of Indian language idioms, mannerisms, cultural norms, physical stature, and intellectual capacities. Humboldt rationalized that the keen European interest in American Indian cultures contained a moral theme that bolstered humanity's integrity. ${ }^{12}$ In this official report to the Spanish government, Humboldt purposely neglected to analyze the varied types of remains, which he believed resembled those of most civilizations:

To give an accurate idea of the indigenous inhabitants of New Spain ... we must go back to a remote period, when ... the nation could display its energy ... These researches are reserved for the historical account of our expedition to the tropics ... ${ }^{13}$

The bulk of data and evidence Humboldt gathered for the Spanish bureaucracy consisted of population statistics, regional distributions of peoples and mineral resources, geographical and geological measurements, architectural assessments in Mexico City, miscellaneous forms of data, and recommendations on a variety of subjects discussed.

\footnotetext{
${ }^{10}$ Alexander de Humboldt, Political Essay on the Kingdom of New Spain, p. 136.

${ }^{11}$ Alexander de Humboldt, Political Essay on the Kingdom of New Spain, p. 136.

${ }^{12}$ Alexander de Humboldt, Political Essay on the Kingdom of New Spain, p. 136.
} 
The Political Essay's objective reflected Humboldt's fulfillment of his obligation to the Spanish authorities for sponsorship of his expedition. The work analyzed human society in an impersonal manner through statistical and demographical description with a social analysis based on an environmental determinism. It did not create a myth of primordial nature, as did his nature writings. The Political Essay, however, shared two components of those works: a historicity and the absence of culture. Scholars still value it as a source in the history of slavery and race relations. It geographically complemented his "aestheticized" nature writings that depicted South America. It read like a bureaucratic report that followed guidelines established by colonial bureaucracies. The main concern reflected the ideological contrast of the work which regarded New Spain as "more advanced" than South America. Humboldt wrote succinctly:

Nothing struck me more forcibly than the contrast between the civilization of New Spain and the meagre physical and moral culture of these areas which I had just passed through ... ${ }^{14}$

Humboldt wrote that he believed that the native inhabitants of Mexico came out of the Northwest and successively infiltrated Mexico. The Toltecs arrived first in the Valley of Mexico about 544 AD, followed by various peoples: the Chichimecs, Cirimecs, Zapatecs, and Aztecs. The Aztecs represented the last wave of migration (1170 AD), established their capital on an island in Lake Texcoco, later drained to build Mexico City. All of the successive waves of migration left ruins or "monuments," as they ventured southward. He believed that the Mayans in Yucatan derived from various indigenous peoples from adjacent Central and South American areas.

In the Personal Narrative of Travels to the Equinoctial Regions of the New Continent

\footnotetext{
${ }^{13}$ Alexander de Humboldt, Political Essay on the Kingdom of New Spain, p. 140.

${ }^{14}$ Marie Louise Pratt, Imperial Eyes, Travel Writing and Transculturation, pp. 131, 132. The quote covers both pages. Pratt mentions bluntly that Humboldt's attitudes about New Spain's progress directly worked their way into Views and Monuments.
} 
during the Years 1799-1804 (1815), Humboldt summed up his chief purpose for writing Views

and Monuments:

... [to] throw some light on the ancient civilization of the Americans, from the study of their monuments of architecture, their hieroglyphics, their religious rites, and their astrological reveries $\ldots{ }^{15}$

The Personal Narrative's overall purposes differed significantly from Views and Monuments and the Political Essay. Its four volumes (Humboldt never completed the fourth) read like a travel account in which Humboldt cited observations of natural phenomena, including geological formations, flora and fauna, indigenous peoples, and encounters with European scholars and missionaries in narrative form. Unlike Views and Monuments, Humboldt made few in-depth analyses and hypotheses in the Personal Narrative.

\section{Section 2}

\section{Humboldt's Methodology}

Before an analysis of Views and Monuments and the question of ultimate origins, an abstract of Humboldt's methodology of science is necessary to understand his almost neglected work on Indian origins. In the 1790s, Humboldt's writings displayed a new concern with "analogies" or contrasts between animate and inanimate matter, which developed into an entirely new science. Humboldt challenged the prevailing positivistic approach to science characteristic of the eighteenth century during this formative period. He viewed nature as a whole, not as an

\footnotetext{
${ }^{15}$ Alexander de Humboldt and Aimé Bonpland, "Introduction," Personal Narrative of Travels to the Equinoctial Regions of the New Continent during the Years 1799-1804, translated by Helen Maria Williams (1762-1827), Philadelphia: M. Carey, 1815, pp. xxii, xxiii.
} 
aggregate of compartmentalized sections for separate study. He thereby laid the foundation for the growth of the natural sciences. His efforts lead historians to refer to "Humboldtian Science" and the "Age of Humboldt." ${ }^{16}$ Humboldt adapted divergent components with which he built his method. Although he rejected the particular form of positivistic empiricism, his search for connections was ultimately empirical. Humboldt extended and modified the Baconian scientific tradition by adding elements derived from Hegel and the German school of Naturphilosophie, dominated by Goethe and Johann Gottfried von Herder. Until his death, Humboldt firmly believed that Kant's concept of the boundless universe formed the foundations for natural science. To label Humboldt a "natural philosopher" is a misnomer. He initially worked from within Naturphilosophie, but significantly diverged from it to develop the natural sciences. ${ }^{17}$

Naturphilosophie and natural philosophy were hardly identical disciplines. The latter, an English term used from the seventeenth to the nineteenth century, meant physical science. The former, a German term, represented a particular form of romantic science around 1800.

Humboldt's work with the framework of Naturphilosophie led to his concept of a universal science, though he concerned himself with the problem of developing such a vast study on a specifically empirical basis to demonstrate harmony in nature. Studying nature from diversified viewpoints with an emphasis on physical observations, Humboldt concluded:

I have conceived the idea of universal science (physique du monde); but the more I feel its need, the more I see how slight the foundations are for such a vast edifice. $^{18}$

\footnotetext{
${ }^{16}$ Margarita Bowen, Empiricism and Geographical Thought, 1981, p. 210.

${ }^{17}$ Margarita Bowen, Empiricism and Geographical Thought, 1981, pp. 214-224: Quote from Humboldt is p. 224. Humboldt claimed that he welcomed the strides made in scientific endeavor by "natural philosophy," and constantly affirmed that the strict empirical investigator should not work in opposition to the philosopher. Humboldt eventually realized his stance necessitated a reassessment of the empirical method as understood by the positivist exact sciences. See also Antonello Gerbi, Dispute of the New World, 1983, pp. 356-370.

${ }^{18}$ Quoted in Margarita Bowen, Empiricism and Geographical Thought, pp. 214-220. Quote from Humboldt is p. 220.
} 
Understanding Humboldt's methodology provides a clearer understanding of what Humboldt hoped to achieve through Views and Monuments. Humboldt consistently demonstrated this method during his five year Meso- and South American expedition. He carried on a demanding program of research in the best empirical tradition by collecting specimens, correcting geographical-geological records, mapping, and gleaning archaeological data. But he also emphasized the connections and wholeness of nature. Moreover, he illustrated humanity as integral with the whole of nature. An investigator could not examine physical nature apart from human cultures. ${ }^{19}$

The separation of natural science and history into isolated compartments does not appear realistic or possible in the viewpoints of Humboldt and the intent expressed in this dissertation. Humboldt indicated his concern to go beyond the limits of a restricted realm of scientific investigation. He examined evidence from diverse sources, such as hieroglyphic paintings and oral traditions to tell of the Mexicans' histories and migrations. ${ }^{20}$ The crux of this argument points out that Humboldt did not restrict himself to an exacting positivistic empirical format. Such an approach undoubtedly motivated him to gather all available types of evidence and to selectively abandon irrelevant forms.

In his writings Humboldt employed dual methodologies of both the natural scientist and the historian. Humboldt's format followed a pattern of: 1) description of phenomena, 2) suggesting possible explanation(s), 3) review of evidence in favor of this explanation(s),

\footnotetext{
${ }^{19}$ Margarita Bowen, Empiricism and Geographical Thought, pp. 224, 225.

${ }^{20}$ Margarita Bowen, Empiricism and Geographical Thought, pp. 224, 225, 231, 232.
} 
4) review of evidence inconsistent with his explanation(s), and 5) making a final decision on relative strength of the explanation(s). With his pattern of investigations, Humboldt discredited suppositions championed by Buffon in the infamous "querelle d' Amerique," the prolonged dispute among European intellectuals about the relative size, value, and variety of American flora and fauna. Buffon considered American plants and animals inferior to those of Europe and the Old World. He claimed that species transplanted from the Old World to the New "degenerated." Moreover, Buffon and his disciples proposed multiple origins for humanity, which posed longreaching implications for origins of various peoples, especially the American Indians. The issue forced every thinker to take sides in the debate. Humboldt did not directly focus on this issue in Views and Monuments. ${ }^{21}$ Humboldt's enthusiasm for American nature represented an indirect involvement implicitly disproving the "degeneracy" claims with consequent vindication of America and refutation of Buffon's multiple origins theory. It supported a single origin theory for all of humankind. ${ }^{22}$

Humboldt supported the single origin theory through his postulates: First, American Indians derived from Old World sources, especially northeastern Asia, whose inhabitants they most resembled. Second, these peoples crossed over Bering Strait into the Americas and spread from north to south throughout the continents. Third, the American Indians represented a single, major prehistoric wave of migration that created a unified race throughout the Americas. These postulates formed the core premises of Humboldt's origin theory. Before the 1770s, no firm evidence existed about the Bering Strait region, so earlier investigators foreshadowed Humboldt's theory with vague speculations. Humboldt claimed he had discovered irrefutable, concrete

\footnotetext{
${ }^{21}$ Marie Louise Pratt, Imperial Eyes, Travel Writing and Transculturation, note 16, p. 240.

${ }^{22}$ Margarita Bowen, Empiricism and Geographical Thought, p. 257.
} 
evidence to support his hypotheses. This evidence came from his Meso- and South American expedition and from earlier explorers and researchers of his time.

Humboldt tried to avoid the pitfalls of other theorists and investigators, who constructed elaborate hypotheses based on diverse possibilities: Chinese and Egyptian colonization in America, Celtic dialects in America, and facsimiles of the Phoenician alphabet. Instead, he proposed groups as varied as the Etruscans, Egyptians, Tibetans, and Aztecs all shared apparent similarities. He saw each society as a separately functioning system generated within a specific locality, but sharing characteristics of the human condition with all societies. Humboldt declared that the historian's objective must illustrate these, despite difficulties to assess information precisely. He warned investigators not to generalize without precise data. ${ }^{23}$

His methodology incorporated a purely moral intent to contradict the stereotypes that Europeans held of "savage" life with his presentation of New World cultures in a distinct contrast with these notions. Members of the American Philosophical Society agreed with his ideas about cultural similarities among diverse societies. With support from Barton's ideas, Humboldt refuted a popular theory in Views and Monuments, that humankind had originated very recently. Barton reinforced Humboldt's hypothesis of a much earlier origin and consequent migration for America's first inhabitants. ${ }^{24}$

\footnotetext{
${ }^{23}$ Alexander von Humboldt, Researches Concerning the Institutions and Monuments of the Ancient Inhabitants of the Americas, with Descriptions and Views of Some of the Most Striking Scenes in the Cordilleras!, translated by Helen Maria Williams, Vols. 1 and 2, London: Longman, Hurst, Rees, Orme, and J. Murray Brown, and H. Colburn, 1814, pp. 1-11.

${ }^{24}$ Margarita Bowen, Empiricism and Geographical Thought, p. 227. Her perspective of Humboldt's sympathetic image contrasts drastically with Pratt's disparaging outlook that reinforced European concepts about "savage indigenous hordes"; Antonello Gerbi, Dispute of the New World, pp. 409-411.
} 


\section{Section 3}

\section{Bases of Humboldt's Origin Theory}

Humboldt introduced assumptions that were part of his origin theory. He formed these assumptions piecemeal from his evidence and from others' speculations and research. Most of these appeared to be integral conclusions from Humboldt's research and the last one a methodological assumption, similar to "actualism" or "uniformitarianism" in geology. The thread of the argument specified that all these assumptions or conclusions of his research reached back to empirical evidence obtained through the physical senses. He saw no room for abstract thought or possible forms of speculative or evidence touted by the speculative tradition, such as myths and legends. These were incapable of investigation through scientific methodology. The underlying assumptions included: American Indians comprised a single unified race. Both American Indians and Mongolians featured a more regimented social structure than did Europeans or Asians. American Indian languages provided only partial evidence for the relationship of Old World to New World peoples. Past communications between the Old World and the New definitely existed. Civilizations in the Old and New Worlds may have developed domestically or derived from other sources. A "superior" civilization existed in the Americas prior to the arrival of the Indians. Remains of the past world civilizations accurately reflected their achievement levels.

In his assessment of racial characteristics, Humboldt invariably used the broad designation "Tartaric" or "Tartar" to characterize all eastern Asian peoples from the east-central areas of Mongolia into northeastern Asia. This imprecise terminology signified a distinct departure from his usually precise and detailed use of language. Throughout his work, Humboldt never clarified the limits of the definition of "Tartar", nor did any of his contemporaries. From 
this broad generalization about race, Humboldt also concluded that all of American Indians comprised one race and all humanity one species. ${ }^{25}$

Humboldt believed that American Indian languages indicated organizational unity, just as physical features did racial unity. He demonstrated that various American tropical dialects resembled those of the polar region. This strengthened his core conclusions, that the American Indians originated from a common source, had followed a north to south migration pattern, and comprised a unified race. He deduced that American Indian languages derived from very ancient times, so the migrations must have occurred prehistorically - a concept rejected by previous scholars. $^{26}$

Archaeological evidence of past communication between native groups from northeastern Asia and America underscored Humboldt's theory. Humboldt believed that hieroglyphic paintings and sculptures, "cosmogonies" (astrological-astronomical calculations), institutions, and practices presented more trustworthy forms of evidence than did language. Throughout the remainder of Views and Monuments he tried to justify that these communications preceded division of Asiatics into subgroups. ${ }^{27}$ (American Indians derived from "Tartars.") He observed how the Old and New World civilizations had developed:

The civilization of the people is almost always in inverse relation to the fertility of the land which they inhabited. The more that nature presents difficulties to be surmounted, the more rapid the development of their moral faculties. ${ }^{28}$

\footnotetext{
${ }^{25}$ Alexander von Humboldt, Views and Monuments, pp. 13-19. The generalization enabled him to conveniently and physically contrast American Indians across a wide spectrum with Arabs, Persians, and Slavs, all included in the Caucasian race. From his analogy he deduced that all American Indians formed a single race despite nominal and physical differences.

${ }^{26}$ Alexander von Humboldt, Views and Monuments, p. 21.

${ }^{27}$ Alexander von Humboldt, Views and Monuments, p. 24. Subgroups of Chinese, Mongolians, Asians of the subcontinent, and the numerous northeastern Asian peoples fell under the classification, "Tartaric".

${ }^{28}$ Margarita Bowen, Empiricism and Geographical Thought, p. 225. Marie Pratt, Imperial Eyes, p. 133, argues from
} 
Humboldt noted that civilization's growth pattern, like migration, moved from north to south. He never conclusively clarified whether an aboriginal people already lived in America or when cultures that came later influenced them. Various peoples may have come before or after the American Indians. Humboldt insisted that even the most advanced American civilizations failed to match the achievements of the Greeks and Romans that underlay the institutions of European civilization. He concluded that eastern Asian peoples provided the sources for the myths and traditions of American Indian civilizations, since both existed at an equal lower level of achievement compared to European standards. ${ }^{29}$

Humboldt believed that remnants from "highly advanced" civilizations revealed "actual" works of art, whereas "less advanced" ones created historically significant "memorials". He categorized all works as memorials from east of the Tigris-Euphrates Basin to Asia's easternmost limits together. ${ }^{30}$ "Monuments" of "partially" civilized peoples reflected a psychological significance that enabled scholars to calculate the "universal progress of the human mind." ${ }^{31}$ Humboldt placed the Mexican works between those of Scythia and those of "Hindustan" (India). ${ }^{32}$

her interpretation of Humboldt's intention "the more savage the culture," effectively guaranteed an inferior level of achievement for Native American cultures. Bowen echoes similar statements from Pratt.

${ }^{29}$ Margarita Bowen, Empiricism and Geographical Thought, p. 227: Humboldt pointed out that the records and monuments of the Indian civilizations before the Conquest compared favorably with those of most civilized societies. The destruction of their hieroglyphics deprived them of the means for transmitting their knowledge, leading to a sharp decline in the quality of their civilization.

${ }^{30}$ Alexander von Humboldt, Views and Monuments, pp. 35-38; Marie Louise Pratt, Imperial Eyes, p. 133: Humboldt intended to show the great influence environment had on the progress of the arts.

${ }^{31}$ Margarita Bowen, Empiricism and Geographical Thought, p. 227: To this effect Humboldt believed that the development of American cultures must be considered part of the general progress of the human mind.

${ }^{32}$ Alexander von Humboldt, Views and Monuments, pp. 35-42. 
Humboldt introduced another factor to demonstrate the interrelationship of the development of American Indian civilizations. He believed that the northeastern Asians, or "Tartars," originally had an alphabet. He observed that both the "Tartaric" peoples and the American Indians lacked a "real" alphabet in his time. Humboldt thought that the northeastern Asian "Tartars" lost their alphabet, because they neglected to use it, when they reverted to a prior stage of existence comparable to the European "Dark Ages." Humboldt postulated that actual communication between northeastern Asia and America resumed after the dawn of history, when the Christian Nestorians reintroduced the alphabet to the northeastern Asian peoples. Humboldt concluded this sequential reasoning process that a prehistoric migration still pre-dated alphabet's arrival in Northeast Asia. ${ }^{33}$

The controversy over the time of crossing failed to shake the foundations of Humboldt's origin theory. But a complete turnabout concerning the location of the crossing would have shaken the theory to its very foundations. A firmly established premise about the origin of indigenous peoples within the Americas would have completely contradicted the theory. Thomas Jefferson in Notes on the State of Virginia (1797) had already introduced this possibility. ${ }^{34}$ The fact that Humboldt left the timing of the migration undecided weakened his theory. His controversial stance on the Mound Builders' origins sowed further seeds of doubt about the validity of his theory. He displayed ambivalence about these issues, because he thought the evidence was not yet adequate.

\footnotetext{
${ }^{33}$ Alexander von Humboldt, Views and Monuments, pp. 35-42.

${ }^{34}$ Thomas Jefferson, Notes on the State of Virginia, Chapel Hill, N.C.: University of North Carolina, 1955, pp. 102104.
} 


\section{Section 4}

\section{Humboldt's Emphasis on Archaeological Remains: Similarities between Asians and American Indians}

Although Views and Monuments discussed both nature and humanity, natural phenomena were peripheral to his analysis of Indian origins in this book. Humboldt's comparisons of American artifacts with Old World artifacts were, however, at the center of that analysis. Archaeological remains provided concrete evidence for his origin theory. Humboldt emphasized that the intrinsic nature of the comparisons did not provide strong support for his hypotheses. Such evidence in Views and Monuments did, nevertheless, help Humboldt to support the already developed hypotheses and rule out some others. Although, he declared that far-fetched comparisons crumbled quickly under detailed scientific scrutiny, he integrated several tenuous conjectures from other investigators into his theory. Humboldt often exaggerated his "analogies" through comparisons of artifacts remotely similar with ones in other parts of the globe. He compared items as diverse as features from Aztec statues, bas reliefs, and hieroglyphic paintings with supposedly related examples in the Old World. He noted that Aztec pyramidal structures resembled varied structures in the Old World such as Egyptian pyramids, Babylonian ziggarats, and northeastern Asian structures. ${ }^{35}$ After Humboldt had collected detailed data from pyramids at Cholula and Xochicalco, he established parallels with Egyptian pyramids. Why did Humboldt provide such precise measurements, detailed structural comparisons, and intricate analyses of the

\footnotetext{
${ }^{35}$ Alexander von Humboldt, Views and Monuments, pp. 43-52: For example, Humboldt compared the Aztec pyramid at Cholula with the Babylonian temple at Belus and an Aztec statue with a Greek statue of Isis - very farfetched comparisons. Both the Aztec pyramids and the Old World pyramids served multiple purposes as tombs, temples, and defense arsenals.
} 
pyramid at Cholula or Xochicalco, when he had already decided that the American Indians had derived from the Old World? He wanted to establish where in the Old World they had originated. His findings pointed to an Asian origin, specifically from northeastern Asia. Comparisons with Asian pyramids revealed two things for Humboldt: 1) Civilizations at certain stages around the world exhibited certain common elements of civilization, 2) The Egyptian pyramids appeared more "advanced" than the Mexican ones, which related more closely to the structures found in northeastern Asia in stage and time of development. ${ }^{36}$

Humboldt discovered the remains of astronomical observatories on the pinnacles of pyramids in both the Old and New Worlds. This revealed another connection between Old and New World structures. He noted that frequently pyramids served only as burial places, as did the Tibetan, Chinese, Canadian, Indian, Peruvian, and the Virginian structures. He realized the Mexican pyramids served multiple purposes, so Humboldt revised his original thinking about singular versus dual uses for pyramids. Another parallel sealed the comparison with the Old World pyramids for him. Like other Mexican pyramids, he noted that Xochicalco served both as a place of worship and defense, as did Asian temples from earliest times. With intricate descriptions of several pyramidal structures, he narrowed the scope of origins. American works, such as Cholula and Xochicalco exactly resembled those in eastern Asia built by "Tartaric" peoples. Humboldt failed to specify or elaborate on such structures in eastern Asia that he claimed represented almost daily discoveries constructed by "Moguls" [sic] or Mongolians. The interchangeable and amorphous usage of the terms "Mongolian" and "Tartaric" by Humboldt and

\footnotetext{
${ }^{36}$ Alexander von Humboldt, Views and Monuments, 1814, pp. 81-91. Humboldt attributed Cholula's construction to the Toltecs, who preceded the Aztecs into Mexico by over 500 years.
} 
his contemporaries introduced questions about the structures and who built them. ${ }^{37}$

Humboldt intended that his comparisons strengthen his origin theory. His description, for example, of a bas relief in Oaxaca underscored his methodology. The caricature featured alien characteristics, such as oversized noses, uncommon among the Mexicans of his time. From this he extrapolated similarities between this type of relief and hieroglyphic paintings found on the northwestern American coast. He speculated that the hieroglyphics might have represented Carthaginian inscriptions and Phoenician monuments. This speculation was not consistent with his ideation, when compared to prior statements about Phoenician type alphabets. An alphabet implied a more sophisticated means of communication than hieroglyphics. Humboldt failed to trace out the implications of these extrapolations for his theory. ${ }^{38}$

Humboldt discussed the Mexican paintings and reliefs for two purposes: First, they shed light on the mythology and history of America's first inhabitants; second, the paintings revealed a connection with writings from the Old World. Throughout his work Humboldt reaffirmed these similarities of artifacts of the New World and Old with two ideas in mind: to support his evidence on American Indian origins and to verify that communication occurred in the distant past between peoples that had been separated by mountains or seas. Humboldt explained the relevance of hieroglyphic paintings to his investigations, thus illustrating his version of Bering Strait Theory:

If tribes of the Tartar race have passed over to the northwest coast of America; and thence to the south and east, ... we should be less surprised at finding, ... idols and monuments of architecture, a hieroglyphic writing, and exact knowledge of the duration of the year, ... recalling to our minds the sciences,

\footnotetext{
${ }^{37}$ Alexander von Humboldt, Views and Monuments, pp. 109-114.

${ }^{38}$ Alexander von Humboldt, Views and Monuments, 1814, pp. 126-134.
} 
the arts, and religious opinions of the Asiatic nations. ${ }^{39}$

Humboldt reinforced northeastern Asian hypotheses of José de Acosta and Edward Brerewood in the seventeenth century. Humboldt concluded that American Indians originated from northeastern Asian peoples, who crossed over the Anian or Bering Strait connection during an unknown time as a single unified race that spread from north to south in the Americas. He struggled to establish a common point of origin and migration time for so many diversified cultures with so many languages in America.

Humboldt thought it absurd to assume that wherever pyramids and hieroglyphics were found, migration of Egyptians had occurred. On the other hand, he marveled at similarities in manners, arts, language, and traditions among peoples so far removed from one another geographically. These two extreme points provide one reason that Humboldt did not draw from conclusions on all aspects of Indian origins. ${ }^{40}$

The apparent similarities between Mexican and Egyptian pyramids and hieroglyphics initially presented a problem for Humboldt. He doubted that Egyptians had traveled to the Americas, and argued that the similarities were fewer than they seemed. Egyptian hieroglyphics stood for entire thoughts, while those in America did not. The pyramids may have served the same purposes as temples and tombs, but structurally the Mexican pyramids did not epitomize the structure of the pyramidal shape. Although Mexican pyramids were used for defense, few, if any, Egyptian pyramids in the Valley of the Kings showed any evidence of ramparts or other fortifications for defense. Comparing the Egyptian and Mexican pyramids probably presented no conflict for Humboldt. He knew about the time gap between construction of the two: the

\footnotetext{
${ }^{39}$ Alexander von Humboldt, Views and Monuments, 1814, pp. 146, 147.

${ }^{40}$ Alexander von Humboldt, Views and Monuments, 1844, pp. 147, 148.
} 
Egyptian almost 3000 BC., the Mexican ones supposed no earlier than 500 AD., quite a gap for them to have been constructed by the same people. The northeastern Asian structures were much closer to the Mexican formations. ${ }^{41}$

Humboldt further questioned the sources of American hieroglyphic paintings. These led to further questions that complicated the issues of the early nineteenth-century origins debate. $\mathrm{He}$ declared that he had discovered no evidence anywhere in central or northeastern Asia of a people who used hieroglyphics for communications, as the Mexicans had done since at least the seventh century AD. So, he left unresolved the issue, whether a "Tartaric" people acquainted with the exact duration of the year, introduced the hieroglyphic system independently:

If we do not find in the Old Continent any nation, that has made so extensive a use of painting as the Mexicans, it is because we discover neither in Europe nor in Asia a civilization so advanced, without the knowledge of an alphabet, or substitute, .... ${ }^{42}$

Humboldt explained why the Mexicans and northeastern Asians both needed to use hieroglyphics. He reasoned that such "advanced" civilizations needed hieroglyphic characters to compensate for their lack of an alphabet, so they could further develop their respective civilizations. This reasoning implied that in various aspects of their respective civilizations, both peoples had already outpaced their development of communications, especially writing. ${ }^{43}$

For Humboldt investigation of archaeological remains provided the most reliable concrete forms of evidence with which to support and develop hypotheses. These represented existing

\footnotetext{
${ }^{41}$ Alexander von Humboldt, Views and Monuments, 1814, pp. 148, 154: Humboldt generalized that all American Indian characters resembled "Tartaric" characters, because a stone found near Montreal, Quebec supposedly featured Manchurian characters. Humboldt never viewed it directly, and no one ever proved if the inscriptions were even authentic.

${ }^{42}$ Alexander von Humboldt, Views and Monuments, pp. 167, 168.

${ }^{43}$ Alexander von Humboldt, Views and Monuments, pp. 167, 168.
} 
visible remains from which more was derived empirically than from such sources of evidence as legends, ancient texts, oral traditions, and even languages. Humboldt loved to make comparisons with similar types of evidence in the rest of the world. The common aspects found in remains of civilizations around the world defeated the possibility of multiple origins. This demonstrated that all of humankind shared in this capacity to develop civilizations, though at differing developmental stages from one another. These common elements of the human condition and capabilities represented the progress Humboldt believed all races of humankind were capable of. The multiple- origins theory proposed a permanent status for each race. Humboldt helped to set a trend that led to archaeology coming to the forefront of scientific investigations by the midnineteenth century. Archaeologists investigated unchanging, visible remains of cultures. Humboldt, for example, conducted his investigations during the time of the first empirical researchers, the philologists. Humboldt placed minimal faith in forms of evidence that were living and changing. He applied the same standard to physical characteristics, customs, practices, and movements of peoples, all of which represented changing variables, difficult to evaluate on a permanent basis. Pyramidal structures and other artifacts provided clear and constant means for evaluation of cultures. Hieroglyphics etched in stone, parchment, or wood told about the history of migrations, ceremonies, and origins. Unfortunately for Humboldt and future investigators, the Conquistadors, accompanied by zealous missionaries, destroyed or confiscated numerous writings. This made possible only a spotty, incomplete reconstruction of the culture's history and civilization. Art works, particularly, sculptures and reliefs, represented a complementary form of visible remains that Humboldt assessed in conjunction with the art of other ancient worldwide cultures. He attempted to categorize these works according to his perspective about the level of civilization achieved and their subsequent utilization. Humboldt, with his comprehensive 
assessment of various forms of tangible evidence, initiated the trend to gather data about existing, unchanging visible forms of evidence that has prevailed to this day.

\section{Section 5}

\section{The Toltecs}

The migrations of the Mexican peoples allowed Humboldt to develop a more detailed chronology of the migration from northeastern Asia. He thought specifically that the Toltecs represented the first part of a migration wave from the Northwest into Mexico around 544 AD. This was consistent with thinking that the Indians comprised a single major wave of migration from northeastern Asia, but it provided more detail about them. The Toltecs arrived from an immediate location north of the Gila River (Huehuetlapallan) with their hieroglyphic paintings that described their annual waves of migration from that region to areas south of the Gila River into Mexico. Humboldt suggested that the names of the cities that they built derived from their former settlements in the North Country. Humboldt believed that such a correlation would ultimately point to the origins of the Toltecs and later successive peoples, such as the Chichimecs, Cirimecs, Alcohuans, and Aztecs. To establish those origins, investigators needed to locate a people or peoples in the north of America or Asia who understood the place names.

Humboldt observed that the two northern peoples, the Hurons and Iroquois, inscribed hieroglyphics on wood. From this observation, he deduced that the Toltecs had intermixed with these peoples on the way into central and South America. He also postulated that the Toltecs 
were the Incas' ancestors. If an investigator uncovered the Toltecs' origins, this evidence was insufficient to determine the derivations of the peoples east of the Mississippi River, with whom the Toltecs intermingled. Besides, Humboldt had little evidence of the route the Toltecs took to South America. ${ }^{44}$

The migrations definitively occurred before the Inca period. To establish when they occurred, Humboldt reiterated his claim about prior Christian influences on the American Indians. He maintained that the Mexican "cosmogonies" (astrological-astronomical calculations) and the resultant calendar derived from the Nestorians, who had intertwined Christian principles with Buddhist and Shamanistic traditions:

. . . I may affirm, . . . in order to explain these resemblances of traditions. . . are found both among the followers of Brahma, and among the Shamans of the eastern steppes of Tartary ...45

According to Humboldt, they spread their beliefs among the northeastern Asians who later crossed the Strait into America. Humboldt asserted that the Toltecs descended directly from these peoples, though he assumed that other first Americans had arrived long before the dawn of Christianity. ${ }^{46}$

For Humboldt careful investigation always introduced exceptions to a theory. He differed from well meaning investigators, who often arranged data to fit the parameters of a pet theory. The complexities of Humboldt's ideas on peoples' histories stemmed from this evidence. For example, the original cultures of different native groups were often modified by later cultural

\footnotetext{
${ }^{44}$ Alexander von Humboldt, Views and Monuments, pp. 170-178. Humboldt speculated that Toltec migration penetrated the southern hemisphere via the plains east of the Andes.

${ }^{45}$ Alexander von Humboldt, Views and Monuments, p. 199.

${ }^{46}$ Alexander von Humboldt, Views and Monuments, p. 198. Humboldt believed the Nestorian supposition more plausible than the one which assumed Judeo-Christian traditions came to America from Scandinavian colonies established since the eleventh century.
} 
influences. This represented a finely tuned distinction within his theory. This left open the possibility for numerous migrations spread over a wide time span.

Humboldt's basic premise that Asian peoples had migrated across the Strait before the rise of Christianity required an ancient, prehistoric arrival of the American Indians' ancestors from northeastern Asia. Humboldt presented a dilemma for later interpreters, because he argued that the origins of both peoples and their original culture were the same, being modified during a later period of time. He expressed distinctions repeatedly throughout his arguments.

Humboldt's theory included contradictions and complexities, but it also revealed a degree of systematic continuity and consistency in both his conclusions and methods. Humboldt concluded that the cultural characteristics existing in American Indian cultures revealed a path taken towards achieving civilization distinct from that of Europeans:

... I think I discover in the methodology of the Americans, ... the descendants of a race of men, which early separated from the rest of mankind, has followed a . .. peculiar road in the unfolding of its intellectual faculties, and in its tendency toward civilization ... ${ }^{47}$

\section{Section 6}

\section{Humboldt's Analyses of Astronomical-Astrological Calculations, and Calendars}

Humboldt included comparisons of religious practices within the scope of his investigations. He posed questions about astronomy, astrology, mythology, chronology, and their relationships to Mexican religious practices. He started from his basic assumption that the

\footnotetext{
${ }^{47}$ Alexander von Humboldt, Views and Monuments, p. 200.
} 
Mexicans had originated from Asia, and turned his focus on the rite of human sacrifice.

Humboldt mentioned striking similarities between the Mexican practice and that of the Hindus, but he thought that these similarities were coincidental. Humboldt concluded similarly about a mask worn by Mexican priests that resembled the trunk of an elephant, an animal associated with Asia. He questioned the primary origin of such customs:

Had the people of Atzlan [Aztecs] sprung from Asiatic origin, presented some vague notions of elephants? ... did their traditions go back to the period when America was yet peopled with those gigantic animals, the petrified skeletons of which are found ... even on the ridge of the Mexican Cordilleras? ${ }^{48}$

He argued that the delay between migration and the establishment of the two main Indian civilizations meant these masks did not originate in eastern Asia. The remote mountainous location further reinforced this conclusion. Rather, Humboldt went on, the Indian civilizations created the elephant masks independently, based on a tradition about mammoths, which still lived in northwestern America during their migration southward.

The evolution of "cosmogonies," along with differentiation observed in other practices, led Humboldt to strongly support a domestic development for the American Indian civilization. ${ }^{49}$ Differentiation drawn from study of languages strengthened his suspicions. Humboldt previously minimized the value of vocabulary comparisons to assess origins, but he found them acceptable as secondary evidence. Humboldt not only reiterated the importance Johann Vater (1771-1826) and Benjamin Smith Barton (1766-1815) had placed on word comparisons in the assessment of origins, but he elaborated on points he had introduced about comparative analysis of American Indian languages with those of the Old World. This led him to propose an extensive delay

\footnotetext{
${ }^{48}$ Alexander von Humboldt, Views and Monuments, p. 212.

${ }^{49}$ Alexander von Humboldt, Views and Monuments, p. 213.
} 
between migration from Asia and the establishment of the Mexican and Peruvian settlements:

... It cannot be doubted that the greater part of the nations of America belong to a race of men, who isolated ever since the infancy of the world from the rest of mankind, exhibiting the nature and diversity of language ... incontestable proofs of an early and complete separation ... ${ }^{50}$

He contradicted his previously mentioned supposition that cultural influences on the American Indians took place across the Strait, either at such an early time that these minimally affected cultural development, or so recently (Christian era), that they may have been integrated into a well established cultural structure. Humboldt remained unclear throughout his writing about his position. He further pointed out that American Indian languages differed as much from one another, as they did from the "Tartaric" tongues. Humboldt's inability to establish connections between Tartaric and American Indian languages did not undermine the possibility of ancient communications of Americans with Asia. He contended that tribes who derived from the same roots, and then separated over a lengthy period of time from each other, retained scattered elements of their respective dialects. ${ }^{51}$

Humboldt discussed other kinds of evidence that supported his hypothesis about a domestic origin for the two major American Indian civilizations. He firmly believed, despite possible cultural transmissions across the Strait, that the Aztecs and Incas developed their cultures in the Western Hemisphere. Other investigators, particularly Barton, had already struggled with this question and resolved it in favor of domestic development, as did Jefferson. Humboldt introduced further evidence favoring a "home-grown" civilization through comparison of the ratio of similarities and differences he found with Old World civilizations. The American

\footnotetext{
${ }^{50}$ Alexander von Humboldt, Views and Monuments, pp. 249, 250.

${ }^{51}$ Alexander von Humboldt, Views and Monuments, p. 306.
} 
civilizations overwhelmingly differed from them in various key respects: foods, agricultural techniques, technology, absence of technological devices commonly found in the Old World, and a paucity of domesticated animals. Animals domesticated as "beasts of burden" (excepting llamas) appeared in America only after the arrival of Europeans during the Conquest.

Humboldt studied chronology derived from the American Indian civilizations to support the possibility of cultural transmissions having taken place across the Strait at a very early period. Humboldt oscillated on this subject with vague proposals, pro and con. He studied chronology derived from their astrological-astronomical calculations, but failed to understand adequately them adequately. Humboldt studied the data on time divisions or "intercalations" of the Aztec calendar. He presented intricate tables and incomprehensible explanations in Views and Monuments in attempts to assess origins and migrations. His far-fetched similarities, remote connections, and ridiculous interpretations puzzled readers. Humboldt's inability to read Nahuatl, the Aztec native tongue, may have played a role. He lost the advantage of first-hand personal interpretation, and relied on translations by others. The vast destruction of Nahuatl works during the Conquest and the lack of a Rosetta Stone for comparison of it with a known entity, resulted in poorly translated works from Nahuatl by earlier Spaniard scholars. So, both he and earlier scholars may have interpreted evidence in Nahuatl incorrectly. During the time elapsed between translations of the Nahuatl works and Humboldt's investigations, Spanish had itself evolved, introducing subtle differences in meanings. ${ }^{52}$

Humboldt argued that chronologies (calendars) served a threefold purpose in analyzing origins. They suggested the sequence of migration and settlement and showed that cultural

\footnotetext{
${ }^{52}$ Alexander von Humboldt, Views and Monuments, pp. 276-281. On p. 278, Humboldt said Fernando de Alvarado discovered manuscripts in Nahuatl on the history of Aztec ancestors. Humboldt was unable to decipher these transcripts.
} 
influences had crossed over the Strait into America. Also, they ranked among the most important "monuments" or evidence demonstrating the advanced civilization of the Mexicans before European contact. Through the comparisons of different systems of American chronology, Humboldt and other contemporary investigators hoped to further evaluate past communications between "Tartaric" and Hindu peoples and those of the New World. He cited the sixteenthcentury scholar, Gama, to compare Toltec, Aztec, and Inca years with those of various Asian peoples. ${ }^{53}$ Humboldt concluded that the Mexican "intercalations" correlated closely with those of the Hindus, Tibetans, Chinese, Japanese, and other "Tartaric" peoples. The calendars, thirdly, accounted for lunar, solar, and seasonal cycles. Years and cycles varied in length, but were based on similar astronomical phenomena. Each culture's signs of the zodiac named years after animals. Names for gods and goddesses represented days or "small periods. ${ }^{54}$

In the remainder of Views and Monuments, Humboldt examined Mexican astrology and chronology. He interspersed references to Persian, Hindu, Tibetan, Mongolian, and Japanese chronologies to demonstrate links between Old World and New World peoples. These similarities indicated complex interrelationships. The Indians of Chiapas used a chronology similar to the Aztecs'. Among the signs for their days appeared the name, "Votan," or "Wodan." Wodan was a god of the Goths and the Celts - the Wods and the Odins. Based on prior research, Humboldt thought that Odin and the Buddha (Siddhartha) were identical. He observed that Boudvar, Wodansdag (Wednesday), and Votan denoted "a day of a small period" in India,

\footnotetext{
${ }^{53}$ Alexander von Humboldt, Views and Monuments, p. 288. Gama postulated that the Peruvians had not descended from the Toltecs, contrary to Humboldt. Gama based this on evidence from the Inca calendar.

${ }^{54}$ Alexander von Humboldt, Views and Monuments, pp. 282-289. On p. 288, Humboldt wrote specifically about causes of confusion concerning the Mexican year.
} 
Scandinavia, and Mexico, respectively. ${ }^{55}$ This analogy manifested itself, he argued, in time division, periodic sequences, and astrological signs for days and years. He tried to illustrate this by his intricate templates and detailed explanations. He thereby concluded that the methods used to calculate the American chronologies were exactly the same ones used in the Asiatic chronologies. Humboldt used data from his tables to reinforce his argument.

Throughout his analysis Humboldt pointed out that American and Asian peoples shared chronological features, such as the names for the years in a cycle and male and female elements of the zodiac. Each analogy he made presented a "striking revelation" for him. ${ }^{56} \mathrm{He}$ examined, for example, the relationship between the denomination of the Mexican days and the supposedly similar signs of the "Tartaric" zodiacs. In the correlation he had discovered the relationships he wanted, but the results of the investigations on time divisions proved vital to accurately confirming the existence of past communications among peoples.

Humboldt focused on differences in the zodiac constellations of the various eastern Asian peoples who had conquered one another successively. The effects of the resulting intermixture manifested themselves the most in northeastern Asia. There the languages differed so extensively from each other, that they defied any systematic attempt to classify them. He noticed the farther the distance from India and Tibet, the more varied were the languages, knowledge, civil institutions, and religious traditions. Because northeastern Asian cultures were so tenuously connected to the southern Asian cultures, it was no surprise to Humboldt to discover numerous differences like these among American groups. Humboldt wrote:

When nations of Tartar or Mongol origin mingled with the indigenous hordes

\footnotetext{
${ }^{55}$ Alexander von Humboldt, Views and Monuments, pp. 319, 320.

${ }^{56}$ Alexander von Humboldt, Views and Monuments, 1814, pp. 321-325.
} 
of America have found a road toward civilization with great difficulty, their languages, their mythology, their divisions of time, everything assumes a character of individuality that almost effaces the primitive type of the physiognomy. ${ }^{57}$

Humboldt knew about Thomas Jefferson's theory of a truly indigenous American people, but rejected it. Humboldt had read Jefferson's Notes on the State of Virginia. ${ }^{58}$

Humboldt seemed to say: Some time in the distant past an unknown people crossed over from northeastern Asia via Bering Strait and spread out over North and South America, representing a single major migration. This people formed one unified race from the northernmost part of North America to Cape Horn. They developed independently for a long period of time. At a later time Tartaric peoples crossed the Strait into America bringing their genes and traits and intermingled with those who led the first wave of migration. These all blended into one people who further evolved, developing "home-grown" civilizations in Mexico and Peru. Humboldt's suppositions allowed for the existence of a prior, "more advanced" race of Mound Builders whom Squier and Davis in the 1840's believed formed an extinct American Indian subgroup. Humboldt remained uncommitted about who preceded whom.

\footnotetext{
${ }^{57}$ Alexander von Humboldt, Views and Monuments, p. 358.

${ }^{58}$ Gerbi Antonello, Dispute of the New World, 1983, p. 404;Thomas Jefferson, Notes on the State of Virginia, edited by William Peden, pp. 102-104.
} 


\section{Section 7}

\section{Final Comments}

Humboldt's conclusive statements in Views and Monuments demonstrated his idealism, extensive learning, and intensive analysis. Often, he used data and beliefs of other scholars to form his conclusions. Humboldt, however, developed most of his ideas through personal research efforts:

... all we have hitherto learnt respecting the ancient state of the natives of the New Continent is nothing, in comparison with the light which will be shown on this subject, if we succeed in bringing together the materials now scattered over both worlds, that have survived the ages of ignorance and barbarism . . ${ }^{59}$

The evidence Humboldt compiled for his origin theory began the path towards a new way of seeing American-Indian origins. He insisted that extended comparisons of American and Asian cultures proved necessary before any conclusions could be drawn. He left many questions open, because he considered them irresolvable at the time.

Humboldt focused on another question that had concerned previous scholars and his contemporaries alike - the extent to which various Indian cultures had progressed towards "civilization" as measured by Greco-Roman-based European standards. Humboldt still could not divorce himself from his culture or era. Some authors of the late twentieth century have not taken this into account and have analyzed Humboldt from a current perspective; that is, they have criticized Humboldt out of historical context. Humboldt shared some common views of his culture, but diverged significantly through his continuous questioning of ideas of other scholars about American Indian cultures.

Other scholars rendered every society that failed to conform to their own cultural styles of

\footnotetext{
${ }^{59}$ Alexander von Humboldt, Views and Monuments, 1874, p. 397.
} 
"civilization" as "barbarous," "inferior," or "savage." Although Humboldt used such terminology, he at least partially refuted such preconceptions and accorded American Indian civilizations a more "advanced" degree of culture than others had supposed. This respect for the achievements of the Indian civilizations derived in part from his appreciation of the significant archaeological losses incurred during the Spanish Conquest. Philanthropists were American Indian sympathizers who appreciated Indian cultures, wanted to save them from destruction, and educate them for assimilation into European-American society. These included Jefferson, Barton, and Gallatin on the American scene, and Rousseau, Goethe, and Vater on the European scene. It was more difficult for Americans to sympathize with Indians, because they often came in conflict with Indians over ownership of lands. Humboldt analyzed individual cultural traits of the Indians and compared them carefully to those of Asian and other cultures. He clearly expounded on his method in this regard:

... the state of the nations or individuals is the same; ... the whole faculties of the mind unfold themselves but gradually so, in the former, the progress of civilization does not manifest itself at once in the amelioration of public and private manners, in taste for the arts, and the form of general institutions . . ${ }^{60}$

Humboldt also clarified his perspective by negating others' notions about the essential elements required for development of civilization. He claimed that the philosophes De Pauw and Reynal (disciples of Buffon) and the British historian William Robertson (1721-1793) reluctantly acknowledged that not all American Indian societies were "barbarous." Humboldt went one step further and rejected the categories as simplistic:

We cannot admit these abrupt distinctions into barbarous and civilized nations . . ${ }^{61}$

\footnotetext{
${ }^{60}$ Alexander von Humboldt, Views and Monuments, 1814, p. 397.

${ }^{61}$ Alexander von Humboldt, Views and Monuments, 1814, p. 397; Antonello Gerbi, Dispute of the New World, 1983 , p. 380. Gerbi states: "Robertson described the 'brutalization' of the American population as both true and shocking". Humboldt thought Robertson as the most judicious of historians on America.
} 
Humboldt countered with his viewpoint:

... whatever we ourselves have been able to discover respecting the ancient nations of this New Continent, we have endeavored to combine the features by which they seem to be connected with different groups of Asiatics . . ${ }^{62}$

On this philosophical note, Humboldt concluded that his assessments about the nature of American Indian civilizations compared favorably with those of the Old World.

In Views and Monuments Humboldt concluded that he had analyzed sufficient evidence, formed hypotheses, and affirmed and reaffirmed results. This comprised the matrix for his theory. He analyzed a wide variety of remains, including architectural "monuments" (pyramids, tombs, and other edifices), hieroglyphics, artistic works, "cosmogonies," and religious practices. Throughout Views and Monuments, he repeated descriptions of various remains and reiterated points. Humboldt's poetic and repetitive style in Views and Monuments made it popular, but has hindered scholarly appreciation of its important role in the history of ideas on the origin of American Indians.

Humboldt's writing style presented difficulties for interpretation, but Views and Monuments clearly illustrated the successive steps he took in the formulation of his origin theory and the evidence he gleaned for its support. It rested on four central premises. The American Indians originated in the Old World, crossed over the Bering Strait into America during prehistoric times, represented one major migratory wave (though he allowed for both prior and later crossings), and comprised a single unified branch of the human family from North to South America. Humboldt also supported a single origin for all of humankind, which contradicted the notion that the American Indians may have formed a separate, inferior, and indigenous

\footnotetext{
${ }^{62}$ Alexander von Humboldt, Views and Monuments, 1814, p. 308.
} 
race, or a distinct "subspecies" of humanity.

Did Humboldt actually formulate the currently accepted version of the Bering Strait Theory, or have it uppermost in his mind among the numerous possibilities introduced in Views and Monuments? Yes, the theory's central premises totally originated from his analyses. Moreover, Humboldt focused on the Bering Strait thesis, even before he made his expedition to Meso- and South America. In Views and Monuments he established the theory as a valid and serious explanation of Indian origins. 


\section{CHAPTER TWO \\ Ancient Texts and Myths as Historical Record: \\ Atlanteans, Lost Tribes, and Other Ancient Traditions}

\section{Section 1}

\section{Ancient Sources vs. Existing Evidence}

During the early nineteenth century, two very different approaches to the investigation of the origin of American Indians co-existed. One group based its inquiries on ancient sources and recorded myth, another on observation of still existing evidence: language structure, archaeological remains, and physical characteristics. This chapter examines the former, while later chapters discuss the latter. All of them interacted on some level with Humboldt. The origins debate followed a parallel course by pitting scientific theory against lay and religious hypotheses. ${ }^{1}$ These ancient sources formed a specific tradition, which not only co-existed with empirical investigations, but which interacted with empirical traditions. This interrelationship of seemingly opposed traditions contributed a vitality to the origins debate, which helped to prevent the debate from developing a skewed, one-sided perspective.

These earlier writings influenced investigators into the nineteenth century, including Humboldt. None of these origin theories deviated from the Biblical time frame or the belief in a single origin for humans. The newer, Enlightenment worldview questioned these theories.

Humboldt and his contemporaries emulated the new perspective. Many of the old theories from

\footnotetext{
${ }^{1}$ Robert Wauchope, Lost Tribes and Sunken Continents, Myth and Method in the Study of the American Indians, Chicago and London: University of Chicago Press, 1962, pp.1, 2; Edward Lee Huddleston, Origins of the American Indians, European Concepts 1492-1729, Austin and London, University of Texas Press, 1967. Huddleston amply covers the history of theories about Indian origins up to 1729 .
} 
mythological and historical suppositions often survived into the nineteenth century under new guises.

\section{Section 2}

\section{Atlantean Indian Origin Theory}

One such origin theory derived from the Legend of Atlantis, the "lost continent." By 1799 the theory sparked renewed interest. It culminated with Ignatius Donnelly's popular version in the 1880 's. ${ }^{2}$ As early as 1535 , the legend specified Atlantis as the place of origin for the American Indians. This concept continued, though scholars repeatedly refuted the theory.

The Atlantis theory supposed that an advanced civilization flourished around 11,000 B.C. on an island in the Atlantic Ocean. Atlantis sent out colonists to America before a cataclysm that sank the island beneath the ocean. ${ }^{3}$ The legend itself originated with Plato, who wrote in Timeaus of a conversation between long-dead Egyptian priests and his ancestor, Solon. They raved about a country located in the western sea larger than Asia Minor and Libya combined, where a magnificent civilization emerged. In Critias Plato elaborated further on Atlantean rule, its achievements, and its final destruction. A witness testified 300 years before Solon, that an earthquake swallowed an island the size of Africa. All inhabitants perished. Up to the seventeenth century, a large island in the Atlantic appeared on maps. For centuries, legends had told of islands located beyond the Strait of Gibraltar: stories of Arabian geographers and tales of the Greek Fortunate Islands, the Welsh Avalon, the Portuguese Isle of Seven Cities, the Irish Isle of St. Brendan, and Antilia. No wonder that Atlantean theory persisted well into the nineteenth

\footnotetext{
${ }^{2}$ Robert Wauchope, Lost Tribes and Sunken Continents, pp. 4, 28.

${ }^{3}$ Robert Wauchope, Lost Tribes and Sunken Continents, p. 29.
} 
century. It only needed a boost from a sensationalized work to perpetuate it. Such legends provided the least amount of evidence to assess Indian origins. Primary sources proved unavailable, while archaeologists could not identify any remains. ${ }^{4}$ Such classical-mythological theories offered no empirical foundation, but they still attracted methodical empirical investigators.

One such investigator, Charles Stephen Brasseur de Bourbourg (1814-1874), abandoned his research for concrete evidence on Indian origins and introduced his version of the theory. A serious scholar, Brasseur sought out long-neglected records, such as Mexican documents in the Vatican, described by Humboldt in Views and Monuments. ${ }^{5}$ He traveled throughout the Americas in the 1840's, studying Mexican traditions, religion, and artifacts. He developed into a meticulous, systematic archaeologist-anthropologist. Nevertheless, Brasseur embraced mysticism and a zealous belief in Atlantean theory. In Quatre Lettres (1868), he promoted the idea that Egyptian and Mexican pyramids derived from Atlantis. American settlers from Atlantis created the great civilizations of the Old World. Many of his contemporaries respected him despite his promotion of Atlantean theory. A few agreed with him. His version with its variations, especially Egyptian derivation from the Indians, attracted enthusiasts. ${ }^{6}$

\footnotetext{
${ }^{4}$ Robert Wauchope, Lost Tribes and Sunken Continents, pp. 29, 30. Josiah Priest, American Antiquities and Discoveries in the West, Albany, N.Y.: Hoffman and White, 1834.

${ }^{5}$ Marie Pratt, Imperial Eyes, condensed version of the title for Humboldt's main work on Indian origins.

${ }^{6}$ Robert Wauchope, Lost Tribes and Sunken Continents, pp. 45-48. See chapter 2, pp. 7-27.
} 


\section{Section 3}

\section{Biblical Origin Theories}

A popular origin theory of classical antiquity derived from the Scriptural roots of the Judeo-Christian tradition. It proposed that the American Indians descended from the "Ten Lost Tribes" of Israel mentioned in the Old Testament, who widely dispersed from Israel. Sixteenthand seventeenth-century explorers and scholars often referred to it. Hebrew eschatology from the Old Testament represented the most documented source about life in ancient times (before the advent of Greece and Rome). The Bible definitively shaped these scholars' worldview.

The theory represented an important step towards the formation of empirically based origin theories during the first half of the nineteenth century. It reflected a real attempt by earlier scholars to establish a single, unified origin theory. Its spin-offs persisted well into the nineteenth century. These correlated precisely with the definition of "speculative comparisons of Indians to peoples of classical antiquity." The theory about the "Ten Lost Tribes" persisted, because many nineteenth-century investigators worked from a Biblical framework. The framework remained largely intact, despite inroads made by eighteenth-century Unitarians and "Freethinkers." Their perspectives derived from the Enlightenment "use of reason." Europeans still adhered to the basic Biblical beliefs. The theory also appealed to a conservative group of Old Testament antiquarians. ${ }^{7}$ Biblical scholars contributed most to revive the theory in accord with newer, more empirically based theories.

\footnotetext{
${ }^{7}$ Robert Wauchope, Lost Tribes and Sunken Continents, p. 28.
} 


\section{Section 4}

\section{James Adair on the Ten Lost Tribes}

James Adair (1709- c.1783) approached the subject of the Ten Lost Tribes from an empirical view as historian and anthropologist. Little is known about Adair. He came to America in 1735 to trade with the Indians in the Southern colonies. There he lived among them observing their culture. ${ }^{8}$

In The History of the American Indians (1775), Adair argued from an anthropologicallinguistic perspective that the Indians had descended from the Jews. This dualistic approach revealed itself in the five main arguments he presented about similarities in tribal organization, symbols, language, and spirituality. This included worship of one God. He compared the Hebrew name for God, "Jehovah", and the corresponding Indian (Choctaw) name, "Yohewah". Adair emphasized the resemblance of the Indian practice of monotheism with that of the Jews, instead of the polytheism practiced among ancient peoples. The Indians, like the Israelites, believed that they represented God's chosen people. He illustrated the Israelites' belief in angels and the Indian awareness of witches, wizards, evil spirits, and angelic apparitions. In both belief systems the angels chased out evil forces and replaced them with their own presence. From a comparative linguistic viewpoint, Adair hypothesized that Indian languages and dialects all derived from Hebrew, the primordial idiom, and shared the same syntax. ${ }^{9}$

\footnotetext{
${ }^{8}$ Allen Johnson, "Adair, James, (c. 1709 - c. 1783)," Dictionary of American Biography, Vol. 1, New York, 19271936, pp. 33, 34.

${ }^{9}$ Samuel Cole Williams, Adair's History of the American Indians [1775], Johnson City, Tennessee: Wautauga Press, 1930, pp. 11-40.
} 
The remainder of Adair's arguments focused on specific practices common among both Hebrews and Indians. These included practices carried on in isolated circumstances by each people. Through his quasi-empirical methods and quasi-theological approach, Adair established legitimacy for the theory of the Ten Lost Tribes. This exerted a significant influence on eighteenth and nineteenth-century rabbinical oriented writers. Jewish scholars, historians, rabbis, and theologians primarily composed this group, but others sympathetic to their beliefs also belonged. Charles Hudson's article, "James Adair as Anthropologist," demonstrates the dramatic influence Adair exerted on eighteenth-century writers. ${ }^{10}$

Various nineteenth-century authors often referred to Adair. John McIntosh, Origin of the North American Indians (1843), believed that Adair had acquired an expertise on the subject of Indian origins. He had supposedly discovered an affinity between the American Indians and the Jews based on nationality. McIntosh remained unconvinced whether or not Adair had actually spent forty years with the Indians, yet he strongly supported Adair's ventures:

... that few or none have gone or come after him, who witnessed what he witnessed, or viewed the Indians as he viewed them. . . ${ }^{11}$

McIntosh's contemporaries, including Humboldt, proved more critical of Adair's assumptions that reflected Indian origins derived from a long lineage dating back to Noah's sons, Ham and Japhet.

Adair's investigations contributed to the development of systematic, scientific methods used to formulate newer origin theories. Adair consolidated the theory about the Ten Lost Tribes

\footnotetext{
${ }^{10}$ Charles Hudson, "James Adair as Anthropologist," Ethnohistory, Vol.24, No.1. (Winter 1977), Tempe, Arizona: Publication Services, Inc., 1978, pp. 311-328, pp. 311, 312. Hudson maintained that James Adair's History of the American Indians represented a major source for the ethnohistory of the Indians living in the southeastern United States during the eighteenth century.

${ }^{11}$ John McIntosh, The Origin of the North American Indians, New York: Nafis and Cornish, 1843, p. 79.
} 
of Israel as ancestors of the American Indians. His systematic method of inquiry may have been sound, but his theorizing proved erroneous. Scholars of his era and later disputed his theory, and challenged Adair's comprehension of the complexities of Indian culture and society.

Adair contributed to history and science through investigating ancient sources and his empirical anthropological research among the Indians, which he intertwined to form his conclusions. Foremost, his knowledge of the Old Testament and the classics provided him a comprehension and awareness of antiquity, when European intellectuals were only beginning to systematically investigate the remote past. Scholars may have discredited his conclusions, but Adair ranked among the first to arrive at them by use of the scientific method and the first to contribute to a general understanding of classical antiquity. His systematic research among the Indians consisted of observation, data collection, assembling and categorizing evidence, and comparative analysis. He hypothesized from these forms of evidence. He based theoretical assumptions on his interpretation of ancient texts, particularly the Bible. He employed this methodology in support of the theory about the Ten Lost Tribes.

\section{Section 5}

\section{Joseph Smith and the Ten Lost Tribes as Scripture}

Adair's consolidation of the Indians' derivation from the Ten Lost Tribes helped to promote acceptance of this belief. For the Church of Latter Day Saints the belief represents more than dogma, but Scripture divinely revealed and incorporated into their holy manuscript, The Book of Mormon. Joseph Smith (1805 - 1844), prophet and founder of the Mormon faith, lived 
and preached in the United States. His followers accept Smith's teachings as a restoration of the original Christian faith. One of these, written down in the Book of Mormon, included his revelation about the American Indians' derivation from the Hebrews.

Born in Sharon, Vermont, the prophet Smith led a short, dynamic life that ended in martyrdom at the hands of a "lynch" mob in Carthage, Illinois in 1844. Between 1820 and 1827, he experienced revelations about his proposed mission as chosen prophet to restore Christ's Church on earth. ${ }^{12}$ The Book of Mormon records Smith's visions of God's interactions with ancient American inhabitants. It summarizes how the Indians descended from the Hebrews with an account of the Israelites' travels across "large waters" to America before the time of Christ and their consequent settlement. The Book of Mormon is primarily a testament about the ancient inhabitants of America. One civilization that originated in Jerusalem around 600 BC separated into two nations, the Nephites and the Lamanites. Before the formation of this one civilization, tribal Hebrew peoples, the Jaredites, came to America shortly after the destruction of the Tower of Babel around roughly 3000 - 4000 BC. They were destroyed in the second century BC. ${ }^{13}$ The Book of Mormon specified that the Nephites survived the scourge of the Lamanites. The Lamanites spread to America and established the principal lineage for the American Indians. It specifies why the two nations separated:

The Nephites separate themselves from the Lamanites, keep the Law of Moses and build a temple - Because of their unbelief, the Lamanites are cursed, receive a skin of blackness, and become a scourge unto the Nephites ... ${ }^{14}$

\footnotetext{
${ }^{12}$ Dumas Malone, "Smith, Joseph," Dictionary of American Biography, Vol. 9, 1935, 1936, pp. $312,313$.

${ }^{13}$ Robert Wauchope, Lost Tribes and Sunken Continents, p. 59.

${ }^{14}$ Joseph Smith, "Introduction," Book of Mormon, (pages not numbered), the "First Book of Nephi," p. 1, 65. Quote found on p. 65. It may be added that the Indians would have fallen with a classification of darkness or "blackness" of complexion.
} 
America represented the new "promised land" for the Jewish tribes and the descendants of Laman (the Lamanites). These represented the direct ancestors of the Indians. The book referred to these events in context with the later discovery of America by the Europeans, although both the Nephites and the Lamanites arrived in America sometime between 600 BC and the time of Christ. The Jews had crucified their God, and dispersed widely, until they finally believed in him. ${ }^{15}$ The book elaborates on Jesus's ministry to the Israelites in America and the Lost Tribes' return to Israel with the advent of the New Jerusalem. ${ }^{16}$

Mormon Scripture focuses on the migration to America of two Israeli peoples or "Lost Tribes," the Lamanites and the Nephites. They saw Christ shortly after his resurrection and created the lineage from which the American Indians derived. For members of the Church of Latter Day Saints, this testament represents an incontestable truth found in Scripture, rather than a dogma or theory.

\section{Section 6}

\section{Variations on the Lost Tribes}

Other variations about the Ten Lost Tribes had appeared since the seventeenth century. The theory's essential element outside of Mormon theology featured the story about the enslavement of the tribes around $721 \mathrm{BC}$. The Assyrians failed to enslave all of the tribes. Some wandered off, or the Assyrians carried them off them to unknown destinations, whereby they disappeared from recorded history. By some accounts the "lost" tribes arrived in America and founded various ancient civilizations.

\footnotetext{
${ }^{15}$ Joseph Smith, Book of Mormon, "Third Book of Nephi," p. 427 for quote.

${ }^{16}$ Joseph Smith, Book of Mormon, p.450.
} 
Scholarly support for this theory began with an anonymous publication of a seventeenth century rabbi, Manasseh Ben Israel. He published an account in 1650, Origin de los Americanos, esto es esperanza de Israel. An unknown author from this tradition helped to rekindle the theory about the Ten Lost Tribes around 1800. After describing the Holy Land and the ten captivities of the Jews by foreign occupation forces. This unknown author focused on the Fourth Captivity, in which the Assyrian king carried off the Ten Tribes to destinations beyond the Euphrates River. They then supposedly migrated beyond the Caspian Sea and intermingled with "Tartaric" tribes in the area of ancient Scythia. ${ }^{17}$ The book echoed Manasseh Ben Israel's proclamations.

Because the dispersal of the tribes took place during the realms of several kings, the Ten Lost Tribes ended up in diverse areas from America, Tartary, China, Media, to the Sabbatical River and Ethiopia. ${ }^{18}$

The anonymous author of a Synopsis accounted for the Ten Tribes' further migration from "Tartary" via Greenland and the Strait of Darien (Bering Strait) into uninhabited areas of America, such as the future kingdoms of New Spain and Peru. The Tribes took possession of them. ${ }^{19}$ With these speculations the corresponding theory evolved into a complex entity which scholars from varied perspectives attempted to explain. The underlying premise of these variations hypothesized that the Lost Tribes reached Central and South America directly from the Old World: through Persia, across the Chinese frontiers, and across the Bering Strait. Because of the latter route, the theory coincided with other theories about a northeastern Asian origin for the American Indians.

\footnotetext{
${ }^{17}$ Anonymous, A Synopsis or Complete System of the Indian Nations, Proving Them Out of All Doubt in Belief, to be Originally Jews, Sent into Captivity by the Assyrian Kings. London: c. 1800. "Tartar" in Assyrian meant "remnants" or "remains."

${ }^{18}$ Anonymous, A Synopsis or Complete System of the Nations, pp. 16, 17.

${ }^{19}$ Anonymous, pp. 16, 17.
} 
Two American scholars patterned their discussions after the Scriptural approach to investigation about the Ten Lost Tribes with precepts emulating the Old Testament and the Book of Mormon. Elias Boudinot, a non-Jewish proponent of the Biblical proposition, published his analysis of Indian descent from the Ten Lost Tribes, A Star in the West, in $1816 .{ }^{20} \mathrm{He}$ served in various capacities with the US government until 1805, when he resigned from public service to focus on Biblical studies. He descended from a long line of French Huguenots who fled to America after Louis XIV revoked the Edict of Nantes. He also founded the American Bible Society and became its first president in 1816 . His interests extended to educating the Indians and bringing them into society. ${ }^{21}$

Boudinot discussed how the Tribes got lost, arrived in America, and comprised the ancestors of the Indians. Humboldt must have laid the groundwork for him, as Boudinot focused on the claim that the "Tartars" had descended from the Israelites and, in turn, became the Indians' ancestors. This brought it closer into line with the premise about a northeastern Asian "Tartaric" origin for the Indians. ${ }^{22}$ He explained that soon after the removal of the Ten Tribes to Assyria in $721 \mathrm{BC}$, the Medes conquered the Assyrian Empire, which comprised a large area of western Asia. The Scythians, who lived farther north, conquered the uppermost regions of the Median Empire, while the Persians established their reign over the remainder.

The Ten Tribes migrated into sparsely populated areas north and east of the areas familiar

\footnotetext{
20 Elias Boudinot, A Star in the West, or a Humble Attempt to Discover the Long Lost Ten tribes of Israel, preparatory to the Return to Their Beloved City, Jerusalem, Trenton, N.J.: D. Fento, S. Hutchinson, and J. Dunham, 1816.

${ }^{21}$ Allen Johnson, "Boudinot, Elias," Dictionary of American Biography, Vol. 1, pp. 477, 478. James Grant Wilson and John Fiske, Appleton's Cyclopaedia of American Biography, Vol.1, New York: D. Appleton and Company, 1888 , p. 327.

${ }^{22}$ Elias Boudinot, A Star in the West, or a Humble Attempt to Discover the Long Lost Ten Tribes of Israel, Preparatory to the Return to Their Beloved city, Jerusalem, Trenton, N.J.: D. Fento, S. Hutchinson, \& J. Dunham,
} 
to Boudinot and his contemporaries. Boudinot speculated that the captive Israelites increased in population before their migration northward and eastward. He assumed various peoples intermingled with the Jews on their way, until their original, individual identities disappeared. ${ }^{23}$ Boudinot reflected that the numerous and diverse "Tartaric" languages, like the Indian languages, continuously changed and evolved to the point where they separated into mutually incomprehensible dialects. He hypothesized that all of the fifty-odd, Indian dialects derived from one source, as did the "Tartaric" dialects. ${ }^{24}$

Boudinot largely conformed to the accounts of other "Lost Tribe" proponents, including Joseph Smith. Boudinot started his account from the Book of Esdras, listed as an apocryphal source excluded from the Bible. Like the Mormon account, the Book of Esdras portrayed Jesus's appearance to the Ten Tribes shortly after his resurrection. They had crossed over great waters to a land devoid of human habitation, so they might practice their religious beliefs without disturbance. After passing over the Straits of Kamchatka (Bering Strait), they populated northwestern America and spread farther southward and eastward. Boudinot believed the "Tartars" came over with them to seek their fortune. ${ }^{25}$ Premises of this theory closely paralleled those featuring a northeastern Asian origin theory for the Indians. His intentional or unintentional amalgamation of the two theories laid a speculative groundwork at about the same time as Humboldt's empirical origin theory.

Boudinot concluded that tracing a dialect to its mother tongue provided the most

\footnotetext{
1816, p.65.

${ }^{23}$ Elias Boudinot, A Star in the West, p. 63.

${ }^{24}$ Elias Boudinot, A Star in the West, p. 64.

${ }^{25}$ Elias Boudinot, A Star in the West, p. 74.
} 
reasonable way to establish a people's origin. In this sense he imitated the techniques used by Humboldt and the comparative linguistic investigators. If the Indian languages contained characteristics peculiar to those of Asian peoples, then the Indians must have come out of Asia. He cited similarities between Indian languages and Hebrew, as did other advocates of the theory about the Ten Lost Tribes, and compared customs, manners, and traditions. ${ }^{26}$

Mordecai M. Noah (1785-1851), an eminent American journalist of Jewish descent, followed Boudinot's attempt to establish the validity of the theory about the Ten Lost tribes. In Discourse on the Evidences of the American Indians Being the Descendants of the Ten Lost Tribes of Israel (1837), Noah presented a more orthodox assessment of the theory based on interpretation of the Torah. He may have been part of the Jewish Mordecai lineage in the US South. ${ }^{27}$ Noah boasted numerous career accomplishments as trader, lawyer, politician, and journalist. His personal goal focused on a revival of Jewish heritage, whereby he erected a monument on Grand Island in the Niagara River. He declared the site a City of Refuge for the Jews in 1825 . He amassed a collection of political and religious articles including the work cited above. $^{28}$

Noah summarized the dilemma of the "Lost Tribes":

... what has become of the missing or dispersed tribes - to what quarter of the world did they direct their footsteps, and what are the evidences of their existence at this day? . . ${ }^{29}$

\footnotetext{
${ }^{26}$ Elias Boudinot, $A$ Star in the West, pp. 74-80.

${ }^{27}$ Mervin Berman, The Last of the Jews, New York: 1998, pp. 1-45.

${ }^{28}$ James Grant Wilson and John Fiske, " Noah, Moses M," Appleton's Cyclopaedia of American Biography, Vol. 4, New York: D. Appleton and Company, 1888, pp. 30, 31.

${ }^{29}$ Mordecai M. Noah, Discourse on the Evidences of the American Indians Being the Descendants of the Ten Lost Tribes of Israel, delivered before the Mercantile Library Association, Clinton Hall, New York: James van Norden, 1837, pp. 3, 4.
} 
He assumed that foreign conquerors carried off nine and one- half of the tribes; two and one-half remained in the Judean vicinity. (As the combined figures equaled the total number of Israeli tribes - twelve - not the Ten Lost Tribes themselves, Noah either rejected the usual tribal count or somehow misinterpreted the figure.) He discredited the historical account of the Tribes' ultimate dispersion among the Median population, as erroneous and confused. So, he resorted to quoting the Book of Esdras to reinforce his hypotheses.

Whereas thou sawest another peaceful multitude, these are the ten tribes, which were carried away prisoners out of their own land in the time of Osea, whom Salmanazar, King of Assyria, led away captive, and he carried them over the waters, so they came unto another land. . . They would leave the multitude of the heathen and go into a further country wherein never mankind dwelt, that they might keep their statutes, which they never kept in their own land (Assyria) and there was a great way to go, namely a year and a half. ${ }^{30}$

Noah considered the Book of Esdras as an authentic historical source, although many authors, scholars, and theologians had discredited it as uninspired by God. He further explained its obscurity and lack of acceptance: Esdras wrote during the first century of the Christian era, and Church fathers, such as Tertulian, Ireneus, and Clemens Alexandrius, showed great confidence in his writings. Esdras converted to Christianity, despite his strong affinity for the old Jewish prophecies and traditions. Most Christian circles later failed to recognize him as an inspired writer or prophet. Noah emphasized the value of the book as an historical record because of its great antiquity. ${ }^{31}$

Based on Esdras, Noah speculated that Israelite emigration reached from Ethiopia to the Indies with 300,000 tribe members from Persia alone. In the subsequent migration to the northeastern Asian coast, numerous members of the tribes failed to continue the journey and

\footnotetext{
${ }^{30}$ Mordecai Noah, Discourse on the Evidences, p.4.

${ }^{31}$ Mordecai Noah, Discourse on the Evidences, pp. 4, 5.
} 
remained in "Tartary," while others entered China. ${ }^{32}$

Noah supposed that the tribes who made it to the coast crossed over the Bering Strait without difficulty, migrated down the northwestern coast of America, and spread themselves over a two thousand year period across both Americas to Cape Horn. The hardier tribes stayed in the north, whereas the more cultivated ones moved into Mexico, Central America, and Peru. ${ }^{33}$ His latter two suppositions echoed themes from Humboldt about American Indian migration and the development of Indian civilizations. Humboldt published his origin theory by 1814, so Noah could have read about it before publishing his "Lost Tribes" version. Noah most likely read and cited evidence from Boudinot, who published in 1816, as his arguments resembled Boudinot's. Noah listed different forms of "evidence," especially religious and ceremonial practices, to support his argument about the "Lost Tribes." ${ }^{34}$ He recognized that these comparisons could only be taken so far, and the Indians could have derived from sources other than the dispersed tribes:

On the discovery of America by Columbus, and the discoveries subsequent to his time, various tribes of Indians were found to inhabit this our continent, whose origin was unknown. $^{35}$

Noah broke down his list of religious and ceremonial practices into six distinct components for comparison purposes beginning with a similarity of belief in one God. The second and third components included the computation of time through their ceremonies of the new moon and the divisions of the year into four seasons. Festivals and religious holidays

\footnotetext{
${ }^{32}$ Mordecai Noah, Discourse on the Evidences, p.5.

${ }^{33}$ Mordecai Noah, Discourse on the Evidences, pp. 5, 6.

${ }^{34}$ Mordecai Noah, Discourses on the Evidences, pp. 8, 9.

${ }^{35}$ Mordecai Noah, Discourse on the Evidences, p. 7.
} 
resembled Jewish ones. The fourth component concerned the Indians' imitation of the Jews in erecting temples, altars, and an Ark of the Covenant. The division of the people into tribes with a chief or grand sachem at the head reflected a socio-political practice common to both. The last component focused on similarities in sacrificial laws, ablutions, marriages, war and peace ceremonies, dietary prohibitions, and other miscellaneous areas. ${ }^{36}$ Noah also relied on supplementary "evidence" based on testimony and observations from missionaries and travelers to justify his position that the Jews were the Indians' ancestors. He claimed that Adair, Heckewelder, Charlevoix, McKenzie, Bartram, Smith, and Penn, all supported his suppositions with emphasis on Adair's findings. ${ }^{37}$

Noah's investigations followed the patterns established by more empirically based investigators, including Humboldt. Noah analyzed comparative data from the Hebrew and Indian cultures to formulate his theory, from word similarities between the two groups of languages. His methodology departed from that of the Atlantean origin theorists. Noah created a more refined, consistent work than Boudinot. He probably knew about Humboldt's origin theory in Views and Monuments. He emulated aspects of Humboldt's investigative methods. He also broached the subject of a northeastern Asian origin for the Indians from a different perspective than Humboldt. Noah favored the emigration of the Ten Lost Tribes across the Strait. Humboldt allowed for possibility of other Asian emigrations across the Strait. Unlike Humboldt, he conducted his anthropological and archaeological investigations from archival sources, not in the field. Noah's theory permitted a predominantly Tartaric ancestry and a migration of one single integrated people (Jews intermingled with Tartaric peoples) down the northwestern part of America to Cape

\footnotetext{
${ }^{36}$ Mordecai Noah, Discourses on the Evidences, p. 8.

${ }^{37}$ Mordecai Noah, Discourse on the Evidences, pp. 9, 10.
} 
Horn. His reasoning about the development of Indian civilizations as they migrated southward, resembled Humboldt's own hypotheses: Tribal origins across the Strait preceded evolution of cultural differences among the Indians. Noah differed dramatically from Humboldt in two key aspects: First, Noah did not allow for a pre-historic crossing. Second, Noah remained mired within the context of the theory about the Ten Lost Tribes, whereas Humboldt started from a broader basis open to empirical investigation.

\section{Section 7}

\section{Links with Other Ancient Peoples}

One variation on the theory about the Ten Lost Tribes involved Jews and Phoenicians as ancestral to the American Indians. Ira Hill, a relatively unknown American scholar, summarized his variation in Antiquities of America Explained, (1831). He indicated the Phoenicians, or Tyrians, exhibited great naval capabilities. They sent merchant ships to distant parts of the known world to establish colonies, such as Carthage in North Africa. At the height of Israeli power during King Solomon's reign (1015-975 BC), Israel traded extensively overseas despite its landlocked capital of Jerusalem. Solomon preferred to hire seasoned, professional, Tyrian sailors, though Israel's own coastal inhabitants knew the sea. Jewish sailors served as deck hands on the Tyrian ships. Hill emphasized that wherever Phoenicians went, Jews followed. Phoenicians and Jews frequently interacted in Solomon's day so one would not undertake an enterprise without the other's approval. Hill also speculated that the Tartars originated from disgruntled Phoenicians who migrated eastward..$^{38}$

\footnotetext{
${ }^{38}$ Ira Hill, Antiquities of American Explained, Hagerstown, M.D.: William D. Bell, 1831, Chapter 3, pp. 27-30; Chapter 6, p. 40. On p. 39 Hill specified the interrelationship between Jews and Phoenicians and the Tartars derivation from Phoenician ancestors.
} 
Another author, the Reverend George Jones (1800-1870) published his variations on the theory about the Lost Tribes for popular consumption: An Original History of Ancient America Founded upon the Ruins of Antiquity: The Identity of the Aborigines with the People of Tyrus and Israel (1843). He also emphasized Indian derivation from the Tyrians (Phoenicians) and the Jews. Jones randomly speculated on diverse topics. He cited both concrete scientific and vague para-scientific forms of evidence to support his frequently disjointed suppositions. He relied directly and heavily on Humboldt's View and Monuments as an authoritative source to shore up his vague and often unrelated hypotheses. His multi-faceted approach led to fragmented hypotheses, unrelated observations, circular arguments, and no definitive conclusions.

Jones argued that in $332 \mathrm{BC}$ the Tyrians built temples, pyramids, and cities in Mexico. He used evidence from these ruins to demonstrate Mexican Indian origins from the Phoenicians. Jones doubted whether the fine arts provided sufficient evidence for accurate historical records. He selectively laid out his parameters to investigate and bolstered these with the "evidence" he uncovered. His newly discovered "facts" resulting from his investigations "completely destroyed the atheistic position on prophetic truths. ${ }^{39}$ Jones's evidence and statements revealed a multiplicity of goals and agendas that he attempted to resolve in his writings. It appeared as if he were intent on an evangelical crusade to promote theological dogma against established secular premises of unspecified origin, whether from science, philosophy, or other non-theologically oriented sources.

Jones followed up this discussion with a comparison of Egyptian and Mexican pyramids. He concluded that the American ones were unrelated to the Egyptian pyramids. He invoked

\footnotetext{
${ }^{39}$ George Jones, The Original History of Ancient America Founded upon the Ruins of Antiquity: The Identity of the Aborigines with the People of Tyrus and Israel; and the Introduction of Christianity by the Apostle St. Thomas, London: Longman, Brown, Green, and Longmans, 1843, pp. 28-31.
} 
Humboldt's impeccable authority with reference to Humboldt's illustrations of the Mitla Ruins. For Jones, these ruins eliminated the possibility of an Egyptian origin for the Mexican structures. $^{40}$

The essentials of Jones's writings stood on shaky grounds by mid-nineteenth century, because serious primary resource researchers had already made deep inroads into the speculations derived from inconclusive forms of evidence and purely speculative sources. Writers such as Jones failed to make the transition to more empirical methods, although they cited the authority of scientific investigators to support their allegations. Humboldt's authority was strong among scientific, para-scientific, and speculative researches alike. A variety of works reflected Humboldt's pervasive influence on the origins debate. Writers who did not theorize still cited Humboldt for coherence and cohesiveness of their stipulations. As one of these, Jones drew on evidence from Humboldt to bolster his claims. He upheld the validity of Humboldt's evidence, because Humboldt had proclaimed it as true. These theories from ancient sources continued to receive serious attention by scholars at mid-century, though findings of empirical investigators contradicted their premises. Also, they prevailed despite Humboldt's widely recognized authority in the origins debate, the empirical bases of his findings, and formulation of his Bering Strait origin theory from his use of the scientific method to accumulate evidence and hypothesize.

James Kennedy, in his address to the American Ethnological Society, Probable Origin of the American Indians with Particular Reference to that of the Caribs (1854), elaborated on the Jewish-Phoenician theme that featured Carthaginian colonization of America via the Strait of Gibraltar. He hypothesized that Carthaginians settled in America. Since the Phoenicians had built Carthage, he reasoned that they settled in America.

\footnotetext{
${ }^{40}$ George Jones, The Original History of America, p.117.
} 
Kennedy reflected in his address that sixteenth- and seventeenth-century writers claimed the Carthaginians knew about America from early times. Many of his contemporaries discredited this claim, while others supported it. Kennedy emphasized that these colonists included peoples such as the Egyptians, Greeks, Romans, and the Jews. He believed classical authors learned of America from Phoenician or Carthaginian sources.

Kennedy speculated that the Phoenicians established the pre-Columbian civilizations in the Yucatan and Central America. He reasoned that Jews and Egyptians had influenced the Phoenicians, so their civilization reflected both Jewish and Egyptian cultural traits. Investigations during Kennedy's life helped to support his supposition that the ruins found on the coasts of Yucatan and Central America reflected the influences of a foreign, maritime peoples, rather an indigenous one. He thought if the foreigners had been Carthaginians, they would have brought Africans with them. The religious rites of the Yucatan inhabitants differed from those of other native peoples, indicating different origins. Kennedy concluded that Carthaginian colonization, 1800 years before the Spanish conquest, gradually declined, until it disappeared. ${ }^{41}$

Other nineteenth century theorists supported Phoenician origins for the Indians. Johann Vater (1771-1826), a Prussian philologist who published under the pseudonym Christoph Adelung, maintained in 1810, that the first wave of Phoenicians arrived very early. An error by Solomon's Ophir fleet, possibly caused by a shift of the East-West trade winds, had driven the fleet to America. In German the effect literally translated as 'the fleet's having been 'thrown' to America." ${ }^{42}$

\footnotetext{
${ }^{41}$ James Kennedy, Probable Origin of the American Indians with Particular Reference to that of the Caribs, pp. 29, 31.

${ }^{42}$ Johann Severin Vater, Untersuchungen über Amerika's Bevölkerung aus dem alten Kontinents, Leipzig: 1810, p. 42. Antonio Rio, Descriptions of the Ruins of an Ancient City, p. 68. Rio clarified the general thought on the subject:
} 


\section{Section 8}

\section{Combination Theories}

John B. Newman's Origin of the Red Men (1843) represented a variation of the Lost Tribes theme that connected it with the Phoenician and Atlantean origin concepts. Newman first explained how the Jews became involved with the Tyrians (Phoenicians). The Tyrians followed the Israeli example and elected a king, Hiram, with whom King Solomon communicated. Solomon, the Israeli king, wanted Lebanon's cedar to build the new temple in Jerusalem. King Hiram eagerly provided the wood and lumberjacks. This established a strong commercial tie between the two countries, which co-operated on various projects. Newman emphasized the Tyrians' need to control the trade process with Israel. Newman expressed the opposite of Hill's statement in Antiquities of America Explained (1831), that King Solomon preferred to conduct overseas trade in Tyrian ships manned by Tyrian sailors with Jewish deck hands aboard:

The people of Tyre ... were jealous of allowing others to share their advantages ... although other nations were assisted in sea voyages and explorations, yet these must be performed in Tyrian ships, manned by Tyrian sailors and directed by Tyrian pilots ... ${ }^{43}$

The Tyrians dispersed to other areas around the Mediterranean after Alexander the Great destroyed Lebanon. The Sidonians, wartime allies with the Macedonians, abandoned ships which the Tyrians used to cross over to Atlantis. This showed how Newman integrated Atlantis with the

\footnotetext{
"This celebrated writer [Vater] recites the opinion of the most classic authors on the discovery of America, and the origin of its inhabitants, to which, however, he does not always assent, and among them produces that of Hornius, who supported by the authority of Strabo, affirms as certain that voyages from Africa and Spain into the Atlantic Ocean were both frequent and celebrated."

${ }^{43}$ John B. Newman, Origin of the Red Men; An Authentic History of the Peopling of America by the Atlanteans and Tyrians; The Origin of the Toltecs, the Description and History of Atlantis, An Island that Once Extended from near the Coast of Africa to the West Indies, New York: John C. Wells, 1849, p. 14 for quote. Newman reflected Hill's basic idea about Tyrian commerce, except Hill emphasized that King Solomon preferred this arrangement himself. Newman, who wrote eighteen years after Hill, must have either read Hill or both referred to the same sources on the subject.
} 
Phoenicians and Jews: Long before Tyre (Lebanon) fell, Hercules had ventured through the Strait of Gibraltar. Hercules and the Tyrian mariners related wondrous tales about Atlantis upon their return home. Newman trusted Plato's account about Atlantis as the most accurate one available. Newman focused on the Atlantean invasion of Europe and Asia. From Plato's work, Newman obtained his description of its technically advanced civilization and its subsequent disappearance beneath the ocean's surface. ${ }^{44}$

Understanding the relationships among the Israelites, Phoenicians, and Atlanteans proved intricate, confusing, vague, and contradictory. He believed that the first expedition to Atlantis lost its way and returned without locating Atlantis. Newman then cited numerous writers, other than Plato, to verify both the existence and consequent destruction of Atlantis and declared that Atlantis was actually America itself, though he had previously contradicted this statement with the tale of its destruction and disappearance.

To offset this contradiction, Newman speculated that a significant part of Atlantis's population survived, because many ancient traditions, especially the Peruvian, correlated with Atlantean traditions. He fabricated the idea that the Tyrians, upon their return from Atlantis, reported its destruction to keep the profitable commerce they developed a secret from Europeans. $^{45}$

\footnotetext{
${ }^{44}$ John B. Newman, Origin of the Red Men, p.14-26.

${ }^{45}$ John B. Newman, Origin of the Red Man, pp.26-29. See also footnote no. 45.
} 


\section{Section 9}

\section{Welsh and Scandinavian Origin Theories}

Newman included two other pre-Columbian discoveries that generated Indian origin theories - the legendary discovery of America by the medieval Welsh and the actual discovery by the Scandinavians. The Welsh chieftain, Gravan, supposedly discovered overseas lands in the West called the Greenlands of the Ocean. In 1170, after a bitter civil strife in Wales, Prince Madoc (Magog) led an entourage in search of the Atlantic and American territories. The legend sparked new interest when George Burder (1752-1832) put together a collection of letters, excerpts from history books, magazine articles, pamphlets, and his views on the subject into a volume which he published in 1797, The Welch Indians or a Collection of Papers, Respecting A People Whose Ancestors Emigrated from Wales to America, in the Year 1170, with Prince Madoc. ${ }^{46}$ With no formal seminary education, Burder entered the Congregationalist ministry in 1778. He became a traveling preacher in England and Wales, whereby he developed an interest in foreign missions. He presented a publication on the Welsh Indians to the London Missionary Society. In 1804, he helped to found the British and Foreign Bible Society. Burder published numerous works including sermons, poems, and evangelical works besides his collection of papers on the Legend of Prince Madoc. ${ }^{47}$

David Williams, a professor at the University of Wales, published a critique on the

\footnotetext{
${ }^{46}$ George Burder, The Welch Indians; or a Collection of Papers, Respecting A People Whose Ancestors Emigrated from Wales to America in the Year 1170, with Prince Madoc, (Three Hundred Years before the First Voyage of Columbus), And Who Are Said Now to Inhabit a Beautiful Country on the West Side of the Mississippi, London: Printed for T. Chapman, No. 151, Fleet Street, 1797; paper no. 1, p. 5.

${ }^{47}$ Stephen and Sydney Lee, "Burder, George," The Dictionary of National Biography Founded in 1882 by George Smith, From the Earliest Times to 1900, Vol. 3, London: Oxford University Press Since 1917, pp. $294,295$.
} 
Legend of Prince Madoc and the tale about the Welsh expatriate, John Evans, whose investigations concluded that no Welsh-speaking Indians existed in America.

The legend arose from obscure unsubstantiated sources such as chronicles, poems, and reports mistakenly attributed to the wrong authors. The historian David Williams repeats the legend's essentials published in Burder's work, then examines each aspect of the legend piecemeal to observe how it evolved. He argues that the legend achieved popularity during the reign of Queen Elizabeth II of England (1558-1603). It spread rapidly, because it suggested a British counterclaim to Spain's in the New World. The Spanish Conquistadors wanted to keep the immense wealth found in America for Spain. Britain proposed that Madoc, son of Owen Gwynedd of Wales, had discovered America over three hundred years before Columbus. The Legend of Madoc received a renewed impetus in mid-seventeenth century with the addition of a new twist to the tale. The exile of Puritan ministers to America after the restoration of King Charles II further enhanced the spread of the recreated version. One of the Puritan ministers, Morgan Jones, sent a written testimony about Welsh being spoken by Indians to Theophilus Evans, author of a history of Wales. Evans published the statement in 1740, because it bolstered Britain's claim to America. Various Christian denominations thought it important to send missionaries to supposed Welsh speaking Indian tribes. The revived legend had metamorphosed considerably from the original version: Madoc's descendants had lost their faith, but preserved a copy of the Bible (400 years before the Bible had been translated into Welsh). ${ }^{48}$

Both Williams's secondary source commentary and Burder's primary source collection emphasized the "white-skinned" Welsh- speaking Indians. Missionaries who worked among the

\footnotetext{
${ }^{48}$ David Williams, John Evans and the Legend of Madoc 1770-1799, Cardiff: University of Wales Press, 1963, pp. $13-25$.
} 
Indians in the eighteenth century reported their findings to a group of Welsh expatriates in London. Their stay in England had increased their Welsh patriotism and subsequent interest in Welsh heroes. Burder extracted accounts from missionaries who claimed to have heard Indians speak Welsh:

I have received no less than three several accounts, perfectly agreeing with one another, proving the existence of an extensive nation of white people, speaking the Welsh language; and we find them ... under the name of the White Padoucas ... The Madawgwys, or the people of Madawg ... are called indiscriminately the Padoucas and the White Indians . . ${ }^{49}$

The British, always eager to prove that Britons had discovered America first, welcomed the revival of the legend. They had long questioned whether Columbus had been the first to discover America in $1492 .{ }^{50}$ The London-based Welsh expatriates conspired to send two from their group to America, John Williams, know as "Iolo," and John Evans of Waunfawr. Brought up in a Methodist home with two preachers, his father and a brother, Evans wanted to preach the gospel to the Welsh Indians. Iolo backed out, but Evans set out for America in 1792. Evans had a single purpose for the expedition: to verify the existence of Welsh-speaking Indians. This represented a perfect example of the co-existence of the tradition based on ancient sources and legends with the newer empirical methods of investigation.

Burder tried to verify the legend through comparison of the Welsh language with American Indian dialects and reports brought back by missionaries. He heard about an entire settlement that spoke pure Welsh. These settlers claimed their ancestors hailed from a country

\footnotetext{
${ }^{49}$ Quote from George Burder, The Welch Indians, pp. 8, 9; David Williams, John Evans, and the Legend of Madoc, p. 27.

${ }^{50}$ David Williams, John Evans and the Legend of Prince Madoc, pp.23-25.
} 
"beyond the great waters" in the direction of the rising sun. ${ }^{51}$ John Evans intended to discover by first-hand observation and data collection, whether the white Padoucas on the Missouri River spoke Welsh and descended from Madoc's entourage. Mackay, a Scottish explorer hired by the Spaniards to explore the upper reaches of the Missouri, teamed up with Evans in his search for the "white" Mandans. Mackay directed Evans to keep a journal of how far he traveled, geographical data, and particulars about the Indians he encountered, such as their language, belief system, and lifestyle. In various aspects Evans resembled Humboldt's expedition, conducted under the auspices of an official assignment combined with a personal agenda to investigate Indian origins. Like Humboldt, Evans carefully charted the areas he crossed and recorded his observations. Evans finally discovered the "white" Mandans. He concluded that they were solely of Indian origin with no evidence of Welsh ancestry. He lived among the Mandans for six months while gathering data. They provided him with remarkably accurate information about the upper reaches of the Missouri River. He wrote that he found no evidence of Welsh spoken among the Indians. He decided that they simply did not exist based on his observations. He had set out to investigate a legend and, instead, established himself as an explorer in the best empirical tradition, whose maps and data guided the Lewis and Clarke expedition in $1804 .{ }^{52}$

The legend about Prince Madoc continued to draw supporters through the mid-nineteenth century, despite Evans's evidence and his conclusions. It inspired poets and artists, such as the English poet, Southey, who wrote a narrative poem in two volumes called "Madoc." The American artist, George Catlin, who himself lived among the Mandans, contradicted Evans's conclusions about the Mandans. Catlin believed that they did speak Welsh. Thomas Stephens, the

\footnotetext{
${ }^{51}$ George Burder, The Welch Indians, p. 5.

${ }^{52}$ David Williams, John Evans and the Legend of Prince Madoc, pp. 41-65.
} 
best Welsh scholar of his day, wrote a critical examination of the legend in 1858, which failed to dispel the mystery behind the Legend of Madoc. ${ }^{53}$

The second pre-Columbian encounter featured a stronger historical and archaeological basis than the Madoc legend. This legend was also a mixture of fact and fiction. Recent archaeological evidence has virtually confirmed Scandinavians or "Vikings" as the first Europeans to reach America in 1000 A.D., about 500 years before Columbus. ${ }^{54}$ Eric the Red, (? post 1000), exiled from the Viking settlement of Iceland, conducted the first Scandinavian incursion into the New World. In 986 A.D., he discovered a barren island off the North American coast, which he christened Greenland. From there his son, Leifur Eriksson (970-1020), ${ }^{55}$ sailed farther westward, and discovered the northeastern coast of America. He called this area where he landed Markland. Farther south Leif Eriksson founded a short-lived colony he named Vinland, because of numerous wild grapevines found in the vicinity. Reports of the discovery eventually reached Europe, but remained largely forgotten until Columbus's rediscovery in 1492. The origin theory developed largely from imaginative extrapolation of events of the discovery by authors, such as John B. Newman. He claimed Eriksson's Vikings reached Massachusetts after repeated landings and set up camp. They found good soil and abundant game. Newman related the tale about Tyrker, the German, and his prolonged absence from camp. Leif found Tyrker intoxicated, as he arrived in camp. To Erikkson's surprise, the German described the grapevines bearing fruit. When the party returned to Scandinavia, they referred to the new land as Vinland. Newman added key statements about Europeans acknowledgment of the discovery to support the related

\footnotetext{
${ }^{53}$ David Williams, John Evans and the Legend of Prince Madoc, pp.71-77.

${ }^{54}$ Eric Oxenstierna, The Norsemen, Edited by Karen Hutter, Greenwich Comp: New York graphic Society, 1965

${ }^{55}$ Richard F. Tomasson, Iceland, The First New Society, Minneapolis: University of Minnesota Press, p. 144; the
} 
origin theory:

The discovery of Vinland was not made in an obscure age. The discovery of Vinland was immediately known in Norway; and in the latter half of the eleventh century Adam of Bremen heard it from Swein, King of Denmark. This discovery, he emphatically remarks, is not a fable, but we know it from certain information of the Danes. ${ }^{56}$

The origin theory took hold after Columbus's discoveries. Georg de Hornn in 1699 already rejected the Scandinavian origin theory for the Indians based on observations that indicated no Scandinavian physical characteristics existed among the Indians. By mid-nineteenth century the majority of scholars disregarded the Scandinavian theory as valid. The theory failed to attract the attention of later scholars involved in the origins debate. Scholars may have discarded the origin theory based on the Vikings' discovery of America, but repeated historical and archaeological findings have verified the Viking discovery within the time dimensions set by the theory. At least three attempts to colonize the fertile region of Vinland proved unsuccessful. Evidence from the Flatey Book, a chronicle of the Vikings, indicated that they had established a settlement on American soil called "Leifsbodarna." Historians amalgamated various fragments from Icelandic documents into one coherent work. They pinpointed the settlement of Vinland to the coastal area between Boston and New York City. Helge Ingstad, Norwegian Arctic explorer and archaeologist, familiarized himself with the entire northeastern American coast. He searched for remains resembling the structures built in Greenland and Scandinavia a thousand years ago. Ingstad and an international team of archaeologists discovered remains of turf walls, postholes, pieces of slag, scraps of iron, and charcoal in 1961 on Newfoundland. The charcoal find proved

\footnotetext{
author uses the untranslated original name for Leif Ericsson and affirms him as "discoverer of America."

${ }^{56}$ John B. Newman, Origin of the Red Men, pp. 44, 45, Eric Oxenstierna, The Norsemen, p. 255, repeats Newman's account of Adam of Bremen, who told the story in his Hamonaburg History around 1070 A.D. The escapade of Tyrker's discovery of grapes, featured in the Greenland Saga, indicated that Tyrker had found abundant berries, not "grapes".
} 
especially significant, because carbon-14 dating indicated the remains correlated with the timing of the Viking expeditions to America. ${ }^{57}$ All evidence indicates that no Viking descendants survived from the short-lived settlements to resuscitate the Scandinavian origin theory.

\section{Section 10}

\section{Conclusion}

Origin theories from ancient sources and texts, mythology and legends (ancient and medieval) survived well into the nineteenth century despite the rise of newer systematic methods of inquiry. Proponents of these theories resorted to quasi-empirical methods of investigation to reinforce their beliefs. Often they cited established empirical investigators, such as Humboldt, to add credibility to their theories. This effort reflected a co-existence of a tradition passed on from accepted, but unverifiable sources with the newer, empirically established tradition based on concrete, verifiable forms of evidence. With this existing dualism, many of these theories experienced a revival despite efforts to discredit them, only to supplant them with origin theories derived from more concrete, visible forms of evidence.

These origin theories played a role in the development of origin theories by Humboldt and other empirical investigators. Their theories would have remained incomplete and made little sense, if these speculative theories were not taken into account. These mythical theories also played an important part in the origins debate during the nineteenth century, because they

\footnotetext{
${ }^{57}$ Eric Oxenstierna, The Norsemen, p. 259; Michael D. Lemonick and Andrea Dorfamn, "The Amazing Vikings", Time, 8 May 2000, pp. 68-80; confirms Dr. Helge Instad's discoveries of artifacts from Norse settlements especially L'Anse aux Meadows on Newfoundland. The supposed settlements on the New England Coast were doubtful, but extensive amounts of artifacts were found in the Arctic zone of eastern Canada and western Greenland.
} 
provided contrasting and alternative precursor ideas.

The next chapter examines the work of the philologists, who often started from the speculative tradition. They represented the first empirical investigators to assess Indian origins through linguistic comparisons of Indian languages with various Indian and Old World tongues. Some only collected data on languages for intrinsic knowledge and use by theoretical philologists. The succeeding chapter analyzes the impact of both on the nineteenth-century origins debate. 


\section{CHAPTER THREE}

\section{Philology Addresses Indian Origins}

\section{Section 1 \\ Philologists, the First of the Empirical Investigators}

The parallel existence of the ancient source tradition and the rising empirical one dominated the origins debate during the first half of the nineteenth century. The two interacted closely with each other, as proponents of the ancient source theories often used empirical methodology to substantiate their theories. Empirical investigators initiated their research of Indian origins with empirical methodology unlike these investigators who adhered to ancient sources of myths, legends, and texts. The empiricists refined their various techniques of investigation and approaches to the origins debate as the century progressed. The majority of them relied on their own or others' findings from empirical investigations. Humboldt's investigations of Indian origins analyzed in a previous chapter, reflected his usage of both.

The comparative linguists or philologists (the term used in the nineteenth century) pioneered empirical investigations for assessment of Indian origins. Philologists who theorized freely "borrowed" linguistic data from those who conducted researches for intrinsic purposes. Philologists Caspar Wistar, Pierre Du Ponceau, Johann Gottlieb Heckewelder, John Pickering, and David Zeisberger, expressed no explicit intentions to theorize. Their works pursued other agendas that competed with their research efforts. Their contributions appear in this chapter. Other philologists, including Benjamin Smith Barton, Thomas Jefferson, and Albert Gallatin drew from other types of empirical evidence, sometimes even from quasi-empirical sources. 
Their analyses and findings comprise the essence of this chapter.

Most of the philologists belonged to the American Philosophical Society in Philadelphia, where they exchanged ideas in a congenial atmosphere without intense rivalry or conflict. Other APS members represented different disciplines for which comparative linguistic investigation formed only a secondary pursuit. Natural scientists, including Humboldt, belonged to the Society. Often categories overlapped. A natural scientist or missionary's interests included language, so boundaries between the philologists' interests and those of other disciplines often merged. The philologists operated on the basis of a "modus vivendi" with members of other disciplines.

Their primary contribution to investigations on Indian origins lay in the use of available evidence provided by grammatical comparisons of Indian languages with one another and Old World languages. From these comparisons philologists hypothesized about Indian origins. Philology evolved during the first half of the nineteenth century from a rudimentary discipline focusing on vocabulary comparisons, to one that involved intricate means of investigating syntax, idioms, general grammatical structures, and dialects for comparative analyses. The philologists around mid-nineteenth century often dismissed the achievements of earlier linguistic pioneers, as Heckewelder, Vater, and Barton. Albert Gallatin spanned the period of early investigations with the later, more sophisticated ones. He founded the American Ethnological Society in 1842, which counted many of these newer philologists in its ranks. Gallatin also revised his comparative linguistic focus to more of an ethnological-anthropological emphasis, when he wrote his collection of essays on Indian origins for the Society from 1845-1848. Humboldt's position on comparative linguistics for assessing origins proved equivocal at best. Humboldt accepted philology as a useful tool for investigating origins, but viewed it as only one of many techniques available. Humboldt's Views and Monuments, reflected passages from Barton's New 
Views of the Origin of the Tribes and Nations of America (1797). ${ }^{1}$ Humboldt often downplayed the value of linguistic techniques in comparison with other techniques in analyzing origins. Theoretical philologists still cited Humboldt's authority on origins despite this allegation. APS manuscripts of the meetings held upon Humboldt's visit to America failed to disclose actual exchanges among philologists and Humboldt on comparative linguistics and Indian origins. Philologist John Pickering (1777-1846) best summarized the position of the majority of linguistic investigators concerning origins and the usefulness of linguistic techniques:

... For, if the origin of the population of the Continent is . . . a most interesting and important question; and if we can more successfully arrive at the solution of it, by tracing the progress of the various nations of men over different regions of the globe, through the medium of their languages, than in any other manner. . ; then it is undeniable, that a careful inquiry into the languages of a people [the American Indians], is a subject of great moment to the inhabitants of the old as well as the new world ...

Philologists, whether interested in Indian origins or not, agreed that empirical linguistic investigations held the key to uncovering Indian origins. Other types of evidence proved useful, but secondary.

\section{Section 2}

\section{Those Who Laid the Groundwork}

Various philologists provided the linguistic data for their more theoretically oriented counterparts through investigations in the field, primary and secondary source research, and critiques of the findings of origin theorists. Mention of these logically precedes discussion about

\footnotetext{
${ }^{1}$ Marie Pratt, Imperial Eyes, shortened version of Humboldt's original title translated into English.

2 John Pickering, An Essay on a Uniform Orthography for the Indian Languages of North America, Cambridge: Cambridge University Press-Hillard and Metcalf, 1820, pp. 7, 8.
} 
their theoretical counterparts.

Many of these theorists themselves conducted comparative studies, but relied heavily on these pioneering philologists. This relationship hearkened back to a similar occurrence during the early days of the Scientific Revolution. Johannes Kepler used data gathered by the Danish astronomer, Tycho Brahe, to test the heliocentric hypothesis derived from Copernicus. David Zeisberger (1721-1808) and John Gottlieb Heckewelder (1743-1823), two Moravian missionaries, gathered field data about the American Indians and their languages, while evangelizing among them. Heckewelder assisted Zeisberger in his duties, then remained to accumulate further data about the languages, customs, and mannerisms of the Lenni Lenape or Delaware Indians. Zeisberger himself had studied numerous Indian languages at the Indian School in Bethlehem, Pennsylvania and spoke several Indian tongues. He composed published and unpublished manuscripts, including a Lenni Lenape language grammar published posthumously in $1827 .^{3}$

Heckewelder joined the American Philosophical Society, where he shared his results in different areas, especially linguistics. He reported to philologist Caspar Wistar in 1816, that he had donated all of his manuscripts on Indian languages to Benjamin Smith Barton for Barton's investigations. The American Philosophical Society voiced interest in Heckewelder's manuscripts, none of which Heckewelder had kept. Heckewelder retained a copy of Zeisberger's Lenni Lenape grammar, and hesitated to send a copy of the grammar to the APS for perusal,

\footnotetext{
${ }^{3}$ James Grant Wilson and John Fiske, "Heckewelder, Johann Gottlieb Ernestus," Appleton's Cyclopaedia of American Biography, Vol. 3, New York: D. Appleton and Company, 1887, p. 157; Dumas Malone, "David Zeisberger," Dictionary of American Biography, Vol. 10, New York: Charles Scribner's Sons, 1964, pp. 645-647; Pierre Du Ponceau translated Zeisberger's work from the original German and published it with an editor's preface as the work, David Zeisberger, Grammar of the Language of the Lenni Lenape or Delaware Indians, Translated from the German Manuscript of the Author by Peter Stephen Du Ponceau with a Preface and Notes by the Translator, Philadelphia: James Kay,1827.
} 
because it was not translated. He eventually sent it to the Society for translation and publication, which changed the Society's focus from mannerisms, and customs to Indian languages. The Historical Society of Pennsylvania published Heckewelder's work examining the Indians' languages, history, mannerisms and customs posthumously in $1876 .{ }^{4}$

Caspar Wistar (1761-1818) and Pierre Du Ponceau (1760-1844), two of the "groundwork" philologists, successively served as presidents of the Society, which established a continual emphasis on linguistic investigations. These philologists who laid the groundwork occasionally touched on origins issues, but they often criticized those who focused on Indian origins. Du Ponceau emphasized that he had no interest in any other aspects about Indians, save language, and ridiculed philologists who did. ${ }^{5}$ Nevertheless, he did take a theoretical stand on origins. He revealed in a correspondence between himself and Heckewelder, that he and Heckewelder favored a northeastern Asian derivation for the Indians. Du Ponceau later criticized Barton for relying only on vocabulary similarities for origins investigations.

Du Ponceau reflected the transition occurring in philology as a discipline by recommending that investigators concentrate on grammar and structure, rather than vocabulary

\footnotetext{
${ }^{4}$ Peter S. Du Ponceau, "A Correspondence between the Rev. John Heckewelder of Bethlehem and Peter S. Du Ponceau, Esq., Corresponding secretary of the Historical and Literary Committee of the American Philosophical Society, Respecting the languages of the American Indians," Transactions of the Historical and Literary Committee of the American Philosophical society, Held at Philadelphia for Promoting Useful Knowledge, Vol. 1, Philadelphia: Abraham Small, 1819, pp. Zz, 361, and 362; See John Heckewelder, History, Manners, and Customs of the Indian Nations Who Once Inhabited Pennsylvania and the Neighbouring States, Philadelphia: Publication Fund of the Historical Society of Pennsylvania, 1876; Reprint: Arno Press and New York Times, 1971, "Introduction," pp. 351, 352; Rev. William C. Rachel of Bethlehem explained how Heckewelder's compiled published work featured correspondences with Du Ponceau and Wistar and the translation of Heckewelder's findings from the German.

${ }^{5}$ Peter S. Du Ponceau, "A Correspondence between the Rev. John Heckewelder of Bethlehem and Peter S. Du Ponceau ..," p. 358; Bernard Sheehan, "Origins," Chapter 2, Seeds of Extinction, Jefferson Philanthropy and the American Indian, Chapel Hill: University of North Carolina Press, 1973, p. 48; Du Ponceau advocated scientific investigation for its own sake, without the encumbrance of weighty hypotheses.
} 
comparisons. ${ }^{6}$ Philology's new approach paved the way for a growing (but not unanimous) acceptance of a northeastern Asian origin theory.

Du Ponceau continued his attacks on theoretical philologists, whom he believed, placed their theoretical agenda ahead of linguistic investigations for their own sake. In Zeisberger's Grammar (1827), he condemned Barton for his apparently selfish motives behind his theoretical work:

... But he [Barton] conceived that by comparing the American with Asian languages he could prove the origin of our Indians from the nations which inhabit the opposite coast of Asia; and thus he sacrificed the real advantage of science to the pursuit of a favorite theory ... ${ }^{7}$

From these statements Du Ponceau indicated that by 1827, philology had acquired the characteristics of exact empirical science with its increasingly sophisticated methods of inquiry. He emphasized the inherent value of investigations for the mutual benefit of all such empirical investigators, and condemnation of those linguistic investigators who employed their methodology to support a pet theory. This indicated that the discipline of philology acquired comparable status with competing scientific disciplines for validity in accumulation and assessment of empirical evidence.

\footnotetext{
${ }^{6}$ Peter S. Du Ponceau, "A Correspondence between the Rev. John Heckewelder of Bethlehem and Peter S. Du Ponceau," part ii, "Respecting the Language of the American Indians," p. 418.

${ }^{7}$ David Zeisberger, "Translator's Preface," Grammar of the Language of the Lenni Lenape or Delaware Indians, 1827.
} 


\section{Section 3}

\section{Benjamin Smith Barton}

Benjamin Smith Barton (1766-1815) pioneered comparative linguistic studies to investigate Indian origins. He studied literature, medicine, and the sciences at the College of Philadelphia. Barton's interest in Indian studies started when he encountered American Indians as an assistant in a geographical survey of Pennsylvania's western boundary. He had studied medicine at Edinburgh and London, obtaining his M.D. from the University of Göttingen in 1789. Barton returned to America to practice medicine and teach at the College of Philadelphia. His non-medical writings revealed his keen interest in the study of American languages. ${ }^{8}$

Barton's New Views of the Origin of the Tribes and Nations of America (1797) helped to shape the origins debate of the early nineteenth century. Much of Barton's work did not come from his research, as he had only visited and never lived among the Indians. Nor had he spoken their languages. He preferred to draw on knowledge of Indian languages gathered from linguists and missionaries in the field, especially David Zeisberger and John Heckewelder, to develop a comparative analysis of vocabularies, syntax, and grammar for evaluating Indian origins. Barton also borrowed ideas about origins from earlier theorists, including De Laet, Clavigero, Gibson, Adair, Brerewood, De Acosta, Grotius, and De Hornn. ${ }^{9}$ Barton, however, failed to expound on

\footnotetext{
${ }^{8}$ Allen Johnson, "Barton, Benjamin Smith," Dictionary of American Biography, Vol. 1. New York: Charles Scribner's Sons, 1927-1936, pp. 17, 18.

${ }^{9}$ Benjamin Smith Barton, New Views of the Origin of the Tribes and Nations of America, pp. ix, xii; John H. Powell, "Address of Dr. John Powell," On the Origin of the American Indians, Philadelphia: The Athenaeum of Philadelphia, 1946, p. 23; Powell emphatically proclaimed the significance of Barton's work, "With The New Views of the Origin of the Tribes and Nations of America, The Scientific Study of the Indian may be said to have come of age."
} 
the numerous theories already in existence, but referred readers to sources that summarized these past theories.

Barton divided these theories into two classes: 1) America's original inhabitants derived from Old World Sources or Atlantis, 2) Indians originated here in America. He supported the first conclusion, as his own work indicated a northeastern Asian origin for the Indians. These suppositions affected his philological investigations, as he compared vocabularies from New World languages with those of the Old to test various theories and support his theory. ${ }^{10}$ Barton emphasized that proponents of the first class of theories outnumbered those of the second class. Many clergy favored the first category. Enlightenment scholars, including Voltaire, supported the second type. Barton cited the views of proponents from both sides, but referred back to the early seventeenth-century hypotheses of Edward Brerewood, a professor of astronomy, whose avocation of linguistic analysis led him to an interest in Indian origins. He presented in English for the first time the hypothesis of northeastern Asian origin based on speculations made by Spanish scholars on the subject, especially José de Acosta. Barton based his own argument on Brerewood's original hypotheses, partly because of a similar means of assessing origins: comparative linguistic analysis. Brerewood theorized that a northeastern Asian, Tartaric origin appeared the most plausible, because Tartary lay closest to the American continent. Brerewood's hypotheses showed amazing insight for an era when the "Straits" region had not been mapped out. He also singled out a northeastern origin from remote possibilities of other peoples' having crossed over the Strait. Brerewood dismissed the theory about the Ten Lost Tribes as ancestors

\footnotetext{
${ }^{10}$ Benjamin Smith Barton, "Preliminary discourse," New Views of the Origin of the Tribes and Nations of America, pp. ii and iv.
} 
of the American Indians. ${ }^{11}$

Barton concluded that linguistic comparisons provided the most reliable means for assessing Indian origins. He created a collection of American vocabularies and grammars to collate with living and extinct Old World languages. He supposed that dialects retained enough similarities with their respective mother tongues to reveal the original structure of these languages. Barton believed other methods of investigation were less reliable than linguistic comparisons. $^{12}$ Barton used inductive reasoning to form his hypotheses about Indian origins: ... if these characteristical Marks are found in the American languages, we can not doubt of their truly being original; the People who speak them have passed over into that Hemisphere a short Time after, the First Dispersion of Mankind, especially if they are entirely unknown in our Continent. ${ }^{13}$

He also affirmed that permanent traces of a people's original customs, manners, religions, and traditions remained with their descendants, especially religious practices. These supplemented linguistic evidence in formulating hypotheses about origins, but did not supplant such evidence. ${ }^{14}$ Barton supplemented vocabulary comparisons in his work with additional statements about origins. He concluded that his comparative vocabularies verified that American Indians and various Asian peoples derived from a common source. He emphasized that the exact origin or origins of the Indians still remained unresolved. Barton remained undecided about this

\footnotetext{
${ }^{11}$ Benjamin Smith Barton, "Preliminary Discourse," New Views of the Origin of the Tribes and Nations of America, pp. iv, v, and vi; Lee Huddleston, Origin of the American Indians, pp. 114, 115.

${ }^{12}$ Benjamin Smith Barton, New Views of the Origin of the Tribes and Nations of America, "Preliminary Discourse," pp. viii, xi, xii. On p. xi, Barton metaphorically described the relation of dialects to their mother tongues, "from the Rivulets arising from the principal Springs, I mean the Dialects, we may ascend to the Mother Tongues themselves."

${ }^{13}$ Benjamin Smith Barton, New Views of the Origins of the Tribes and Nations of America, "Preliminary Discourse," pp. xi, xii.

${ }^{14}$ Benjamin Smith Barton, "Preliminary Discourse," New Views of the Origin of the Tribes and Nations of America, pp. xii-xv.
} 
subject, so he failed to support northeastern Asian derivation theories, such as Bering Strait Theory. ${ }^{15}$

Barton considered the inverse possibility that the Old World languages descended from the New World ones, more in line with Thomas Jefferson's views that Indian languages spawned Asian languages. Barton tried to resolve the dilemma by adding Indian traditions to establish origins. $^{16}$

He elaborated on a tradition about origins from the direction of the rising sun, which implied a European derivation. ${ }^{17}$ The traditions of the Toltecs and the Aztecs, however, pointed toward the setting sun as their direction of origin, supporting an Asiatic derivation. Barton stated that the Aztecs inhabited a country far to the north of the Gulf of California they called "Atzlan," a decade before Humboldt wrote this down in Views and Monuments. Europeans found the areas west of the Mississippi more thickly settled than areas east of it. This indicated to Barton that the Indians came from Asia. ${ }^{18}$ The prevalence of more "monuments" in America west of the Mississippi than east of it further reinforced Barton's proposition. ${ }^{19}$

Barton touched on the possibility of separate origins for North and South American Indians, suggested by the different orientations to the setting sun of the Indian tribal legends. Various writers proposed Polynesian or African peoples as the ancestors of South America's

\footnotetext{
${ }^{15}$ Benjamin Smith Barton, "Preliminary Discourse," New Views of the Origin of the Tribes and Nations of America, p. lxxxviii.

${ }^{16}$ Benjamin Smith Barton, "Preliminary Discourse," New Views of the Origin of the Tribes and Nations of America, pp. 1xxxviii, xc. William Peden, Notes on the State of Virginia by Thomas Jefferson, Chapel Hill: University of North Carolina Press, 1955, p. 102 Jefferson noted, " . . A greater number of those radical changes of language having taken place among the red men of America, proves them of greater antiquity than those of Asia...

${ }^{17}$ Benjamin Smith Barton, New Views of the Origin of the Tribes and Nations of America, pp. xci-xcii.

${ }^{18}$ Benjamin Smith Barton, New Views of the Tribes and Nations of America, pp. xc-xcv for quote.
} 
Indians versus northeastern Asian Tartars. Barton argued decisively against this possibility backed by his linguistic comparisons. He anticipated Humboldt's origin theory (the Bering Strait Theory) from northeastern Asia for all of America's Indians, but remained uncommitted. He favored a single origin for North and South American peoples, because of the similarities of their languages. ${ }^{20}$

Nevertheless, Barton admitted the possibility of migration from Asia and Africa to South America. A comparison of South American languages with Asian languages, especially Malayan (from which Polynesian dialects derived) demonstrated that South American Indians shared a common ancestry with southeastern Asians:

... I think [it] proper to deduce from such resemblances ... that the languages of the Americans in both continents, and the Malays, etc. retain some fragments of the language which they both have borrowed from the more northern Asiatics. ${ }^{21}$

Barton further believed that linguistic change in many American and Asian Indian languages took three to four thousand years to occur, well within the limits of the Biblical time frame. This represented a major difference between Barton and Humboldt. Humboldt designated the probability of a prehistoric migration, suggesting that language changes occurred over a longer period than the Biblical time frame allowed. Barton's work in other ways presaged Humboldt's work, Views and Monuments, with its systematic methods of inquiry, presentation of accumulated evidence, and discussion of uncertainties about the respective theories. Both investigators integrated material from other scholars' work. The similarity between Barton's arguments and those later presented by Humboldt in Views and Monuments seems to indicate

\footnotetext{
${ }^{19}$ Benjamin Smith Barton, New Views of the Origin of the Tribes and Nations of America, pp.xcv, xcvi.

${ }^{20}$ Benjamin Smith Barton, New Views and Origin of the Tribes and Nations of America, p. xcii.

${ }^{21}$ Benjamin Smith Barton, New Views of the Origin of the Tribes and Nations of America, pp. xcix-c.
} 
that Humboldt knew Barton's work in detail. No direct evidence of this exists in the correspondence or other manuscripts. Humboldt in his work on origins sometimes echoed Barton's statements on origins almost verbatim.

\section{Section 4}

\section{Johann Vater}

European philologists who researched Indian languages participated in a long-distance dialogue with American investigators. The most prominent of these, the Prussian philologist Johann Vater (1771-1826), published ideas on origins in Untersuchungen über Amerika's [sic] Bevölkerung (1810) in his name, and Mithridates (1816) under the pseudonym of Adelung. By the time Zeisberger's Grammar came out in 1827, Vater's work appeared dated, since philology had been changing dramatically. Du Ponceau eulogized Vater upon his death as "irreplaceable," but affirmed that so much progress had occurred in philology that Vater's work required a complete revision. $^{22}$

Vater stood out as one of the philologists who acknowledged Humboldt's work on American Indians, while reminding him that he had directly benefited from Vater's investigations. Vater and Humboldt had corresponded directly as indicated by Vater's belief that Humboldt had benefited from his philological investigations. He emphasized that no exact departure point for Indian migrations had been found, though he cited Brerewood's northeastern

\footnotetext{
${ }^{22}$ Peter S. Du Ponceau, "Translator's Preface," Grammar by David Zeisberger, 1827, p. 5; Du Ponceau diabolically eulogized Vater: "excellent as the Mithridates was at the time when it was published, such is the progress which the philological science has made since that period; that it would require to be written anew. But VATER is no more, and who will venture to assume his vacant place?" Christoph Adelung (1732-1808),Mithridates, Lüdke, Jenz, Tübingen, 1816.
} 
Asian origin hypothesis along with other ideas from Barton's New Views of the Origin of the Nations and Tribes of America (1797). ${ }^{23}$ Vater apparently favored this theory, though he tried to objectively discuss competing theories. Vater reiterated Brerewood's hypothesis in detail. He supported it with evidence that the American Indians' complexion closely resembled that of the Tartars. He drew this conclusion from first-hand observers in northeastern Asia. ${ }^{24}$

The Indians of Canada strongly resembled the Tungusi, a Tartaric people of northeastern Asia. The geographical distance between the Tungusi and the Canadian natives was less than previously thought. This led Vater to believe that the Tartars had once roamed North America. Vater failed to endorse any theory in the end. He refuted hypotheses about peoples, such as the Romans, Greeks, Danes, Celts, Swedes, and Hindus, having populated the New World. He pointed out problems with the available evidence he uncovered to discredit the respective origin theory or hypothesis. He used a systematic approach to form, contradict, and reaffirm hypotheses with concomitant skepticism. Vater reasserted the Northeastern Asian hypothesis and pointed out that the population coming across the Strait spread throughout North and South America comprised a mixture of these migrants with other newcomers. He argued for multiple points from which peoples migrated and intermingled versus a single northeastern Asian origin. ${ }^{25}$ Vater imitated Barton in many respects through his investigation of comparative vocabulary. Barton had collected the similarities among sounds of the Asian languages by reference to Russian Czarina Catherine's project carried out by German scholar Peter S. Pallas for

\footnotetext{
${ }^{23}$ Johann Severin Vater, Untersuchungen über Amerika's [sic] Bevölkerung, Leipzig: FCW Vogel, 1810; Benjamin Smith Barton, New Views of the Origin of the Nations and Tribes, p.5, featured Brerewood's discussion on northeastern Asian origins cited by Vater.

${ }^{24}$ Benjamin Smith Barton, New Views of the Origin of the Tribes and Nations of America, pp. 33-35.

${ }^{25}$ Johann Vater, Untersuchungen über Amerika's [sic] Bevölkerung, pp. 40-42.
} 
comparing languages from the Arctic Ocean to the Caucasus. Vater compared American Indian words with those of the Asian languages. He argued that the value of the comparison depended on the sum total of the words in the languages. ${ }^{26}$ Vater reflected his indifference about analyses of "mistakes" in grammatical structures of American Indian languages, as he summed up his position this way, "What also is the result of all this?"27

With this question Vater concluded that investigators too hastily established a relationship between Asian tribes and Indians from just a few word comparisons. Vater argued that one must base any premise about relations between Indians and Asians on a comparison of a significant portion of their languages. Comparisons based on too small a sample of words did not reliably indicate origins. Like Jefferson and Barton, he left open the possibility of indigenous origins, because of the unreliability of scanty word comparisons. Or American peoples may have lost connection with Old World peoples in the distant past, which permitted each American culture to develop its own inherent set of traits and language independently. ${ }^{28}$

Vater contributed to investigations on origins by educating Europeans about the complexities of American Indian languages in the two works he published. These publications reinforced efforts of European investigators to assess Indian origins. His investigations echoed back to American theorists, especially philologists, and represented their most significant consequence. His work reflected Humboldt's estimate of the value of linguistic comparisons in evaluating Indian origins. Vater helped to establish philology as a worldwide discipline and

\footnotetext{
${ }^{26}$ Johann Vater, Untersuchungen über Amerika's [sic] Bevölkerung, pp. 42-56; Vater wrote that these numbers of words should be comparatively greater than a "drop in the sea" of numbers of words which the volume or size of compared languages included or comprehended; translation by the author.

${ }^{27}$ Johann Vater, Untersuchungen über Amerika's [sic] Bevölkerung, pp. 57, 58; translation by the author.

${ }^{28}$ Johann Vater, Untersuchungen über Amerika's [sic] Bevölkerung, pp. 58-72.
} 
method of inquiry. He never drew any definite conclusions about different language groups, nor did he formulate an origin theory, despite the depth of knowledge he had acquired in linguistic studies and diverse origin hypotheses. ${ }^{29}$

\section{Section 5}

\section{Thomas Jefferson}

An examination of the scientific work and political ideology of Thomas Jefferson (17431826) precedes a discussion of adherents to his philosophy and methodology. Barton was not directly included in this group, as he operated in a parallel context to Jefferson scientifically, but from a different perspective politically. Albert Gallatin closely followed aspects of both his methods and ideology to claim the label, "Jeffersonian." Lewis Cass acquired the label, though his attitudes about Indians certainly differed.

Thomas Jefferson is best remembered for his prominent political role during the early years of the United States. His interest in American Indians, their languages, and origins, are not so well known. As an intellectual and president of the American Philosophical Society from 1797 to 1815 , he actively participated in debates on these issues with his understanding of whitenative relations and the futures of the two groups together. His ideas emerged through debate with members of the American Philosophical Society and consequently influenced theirs. This section and the next explore that interaction.

\footnotetext{
${ }^{29}$ Peter S. Du Ponceau, "Translator's Preface," Grammar of the Lenni Lenape or Delaware Indians by David Zeisberger, p. 5; Vater died on 16 March 1826.
} 
Jefferson pursued diverse careers as diplomat, statesman, author, lawyer, architect, and scientist. Dr. William Small at the College of William and Mary sparked his lifelong interest in science, which represents the primary concern here. He organized his memoranda about Virginia, including his scientific investigations, during his first break in public service, 17821783. Jefferson published these in a discourse, Notes on the State of Virginia, in 1785, and a later edition in 1797 that contained information on the American Indians and their origins. The same year the American Philosophical Society elected him president. He served in this capacity until 1815 , most of it during his time as president of the US. He pioneered in numerous branches of science including paleontology, ethnology, geography, botany, and philology. He studied Indian and European languages, ready to establish a reputation in philology, until he lost volumes of irreplaceable notes on Indian languages in 1809. He never again acquired even a semblance of his former collection. Jefferson demonstrated competency as a precise investigator in all fields, if not as an accurate evaluator, who proved himself no more credulous than many of his contemporaries. ${ }^{30}$

Jefferson created a philosophy about the future of America's Indians and their relationship to "white" European-American Society that juxtaposed public policy for treatment of the Indians with the "dilemma" of their origins. He combined idealism with reality, but his theory posed only a tangential contact with reality. Reality was the intense rivalry of EuropeanAmericans over land ownership and use. Most Americans, including Jefferson, envisioned a westward expansion to the Pacific. Indian settlement formed a major obstacle to this westward

\footnotetext{
${ }^{30}$ Edwin Smith, "Jefferson, Thomas," Concise Dictionary of American Biography, New York: Charles Scribner's Sons, 1964, pp. 492-496; Bernard W. Sheehan, "Origins," chapter 2; Seeds of Extinction, Jeffersonian Philanthropy and the American Indian, Chapel Hill: University of North Carolina Press, 1973, p. 55. Jefferson for years had feared losing his collection of linguistic data. A thief broke into his trunk during shipment of his household possessions to Monticello and dumped the entire priceless collection into the river.
} 
drive, so the problem of Indian removal occupied the minds of settlers and politicians alike. Jeffersonians proposed a "humane" displacement of Indians from their lands by integrating them into "civilized" society through education, ownership of property (including African-American slaves), and dress. The influence of the Enlightenment on Jefferson reflected itself through a "magnanimous" and "generous" gesture termed "philanthropy." Parallel to the financial generosity given by today's philanthropists, Jeffersonians thought they were offering the Indians a generous opportunity to assimilate into American Society. The alternative to the philanthropists' goals meant forced removal of the Indians from tribal lands accompanied by destruction of their settlements and execution of recalcitrants. Later Indian removal advocates, such as Andrew Jackson and the "last of the Jeffersonians," Lewis Cass, blatantly advocated forced removal and swift retribution for those who resisted. ${ }^{31}$

For Jefferson, discovery of the American Indians' origins helped to humanize them. Jeffersonian philosophy placed a high value on inclusiveness that prohibited denying Indians membership in the human family. Jefferson developed his philosophy on origins from the basic question, "From whence had these people come? .. " ${ }^{32}$ His reasoning on origins reflected inconsistencies and contradictions, which he proved unable to reconcile with each other. He fundamentally agreed that the American Indians and the northeastern Asian Tartars derived from the parental branch of the human family, but remained equivocal about which people produced the other. First, Jefferson proposed a truly indigenous origin for the Indians. He also tentatively

\footnotetext{
${ }^{31}$ Bernard Sheehan, "Origins," Seeds of Extinction, p. 45; Sheehan's comments paraphrased and supplemented by the author.

${ }^{32}$ Bernard Sheehan, Seeds of Extinction, pp. 45, 46; quote on p. 45.
} 
proposed an origin in America for the Asian population. ${ }^{33}$

Jefferson believed that comparative linguistic study presented the most valuable means to provide reliable evidence on Indian origins. He predicted that if investigators completed the vocabularies of the various American languages, this reflected potential for comparison with Old World languages. ${ }^{34}$ Jefferson, like Barton, agreed that American Indians and Tartars came from one parental source based in linguistic findings, though Jefferson refused to acknowledge whether linguistic investigations would inevitably affirm a northeastern Asian origin for the Indians. Language similarity established that contact had occurred between the two peoples, but linguistic study failed to identify which people parented the other. ${ }^{35}$

Jefferson ultimately concluded that the Indians originated in the Americas, forming the ancestral stock of the northeastern Asian Tartars. Greater diversity of dialects in America than in Asia convinced Jefferson that the American languages were older:

A greater number of those radical changes of languages have taken place among the red men of America, proves them of greater antiquity than those of Asia . . ."36

Jefferson had formulated his origin theory from a composite blend of his long study of Indian languages, philanthropic philosophies, and Enlightenment thought. A sense of disorganization and confusion characterized his investigations and conclusions. He received numerous and severe criticisms for a theory which he himself had never fully accepted. ${ }^{37}$

\footnotetext{
${ }^{33}$ Thomas Jefferson, Notes on the State of Virginia, p. 102; Bernard Sheehan, pp. 54-56.

${ }^{34}$ Thomas Jefferson, Notes on the State of Virginia, p. 101.

${ }^{35}$ Bernard Sheehan, Seeds of Extinction, pp. 54, 55.

${ }^{36}$ Thomas Jefferson, Notes on the State of Virginia, p. 102; Julian Boyd P., Papers of Thomas Jefferson, Vol. 2, 22 June to 31 Dec. 1786, Princeton, N.J.: Princeton University Press, 1954, p. 316.

${ }^{37}$ Bernard Sheehan, Seeds of Extinction, pp. 56, 66, 67.
} 


\section{Section 6}

\section{Albert Gallatin}

Philologists such as Albert Gallatin (1761-1849) spanned the gap between the earlier, less systematic comparative linguistic investigations and those of the more sophisticated science that later evolved. Born in Switzerland, he came to America at age nineteen. He served briefly with the Continental Army during the Revolutionary War, after which he first returned to Boston, then settled in western Pennsylvania. His selection as Secretary of the Treasury under Jefferson highlighted a forty-year public service career. ${ }^{38}$

Gallatin's linguistic work began when he entered the American Philosophical Society and culminated as founder-president of the American Ethnological Society in 1842. Gallatin started his ethnological studies in 1820. A true Jeffersonian, he believed that Indians should be assimilated into the mainstream of American society, but favored westward expansion. This Jeffersonian policy assumed voluntary or forced removal of Indians from coveted western lands. ${ }^{39}$

His choice of philology as a tool for investigation coincided well with his Enlightenment background. Enlightenment principles motivated its adherents to study Indian languages, since investigation of peoples' languages ultimately revealed the early history of the human race, and for European-Americans, the origin and history of the Indians. ${ }^{40}$ His initial efforts were general,

\footnotetext{
${ }^{38}$ Allen Johnson and Dumas Malone, "Gallatin, Albert Alphonse," Dictionary of American Biography, Vol. 4, New York: Charles Scribner and sons, 1931, 1932, pp. 103-108; Gallatin's Enlightenment-based philosophy included his sanction of Rousseau's "back to nature" movement.

${ }^{39}$ Henry Adams, The Writings of Albert Gallatin, Vol. 1, Philadelphia and London: J.B. Lippincott and Company, 1879 , pp. 227, 233, 638, and 640; Gallatin thought it necessary to thoroughly learn about the Indians themselves and their territorial claims before development of a policy on removal of the Indians from their lands.

${ }^{40}$ Robert E. Bieder, Science Encounters the Indian, 1820-1880, The Early Years of Ethnology, Norman and London:
} 
until Humboldt requested that he organize his findings into a precisely defined framework, a Synopsis of Indian Tribes. Humboldt had offered to include the Synopsis in Humboldt's 1823 work, but it never materialized. It appeared partially in published form in 1826 and entirely in manuscript form in $1836 .^{41}$ Humboldt's request demonstrated a direct interaction of Humboldt with other investigators on origins.

Gallatin submitted his original Synopsis with subsequent additions to the American Antiquarian Society in Massachusetts. In it Gallatin specified that all Indian languages spoken from the Arctic to Cape Horn possessed certain common characteristics. This important step went far to establish a common origin for all of America's Indians, regardless of tribe or nation. Shortly after Humboldt failed to incorporate his Synopsis, Gallatin published A Table of Indian Languages of the United States, East of the Stony Mountains, Arranged According to Languages and Dialects in 1826. Gallatin expanded this around 1836, butit remained an unpublished manuscript. $^{42}$

In his work with the Otomi language, Gallatin illustrated the systematic thoroughness of his investigations. He noticed the Otomi language differed remarkably from all other Indian

University of Oklahoma Press, 1986, p. 24.

${ }^{41}$ John Austin Stevens, Albert Gallatin, American Statesman, Boston and New York: Houghton Mifflin, Cambridge: The Riverside Press, 1883, p. 374; Humboldt sent Gallatin's Synopsis on to an Italian geographer, Adrian Balbi, who later published it as part of his own work.

42 John Austin Stevens, Albert Gallatin, American Statesman, pp.377, 378; Albert Gallatin, A Synopsis of the Indian Tribes within the United States East of the Rocky Mountains, and in the British and Russian Possessions in North America (1836), remains an unpublished manuscript of Indian grammars never entirely completed. It is available on microfilm in the West Virginia Albert Gallatin Collection. The originals are at the New York Historical Society in New York City. Robert E. Bieder, Science Encounters the Indian 1820-1880, p. 31, refers to the work that heralded Gallatin's Synopsis with a similar title that he published in 1826. James Grant Wilson and John Fiske, Appleton's Cyclopaedia of American Biography, Vol. 2, p. 579, states that his scientific publications included Synopsis of the Indian Tribes, Cambridge: Cambridge University Press, 1836. This disputes it as an unpublished manuscript. This dissertation relies on the unpublished manuscript form written around 1836, which featured "Rocky" Mountains versus "Stony" Mountains in the shorter published edition of 1826. 
tongues, yet still retained some common characteristics. Gallatin assumed that the source of his information may have contained faulty methodology and conclusions, but the facts were correct. $^{43}$ Gallatin used grammars from tribal groups as varied as the Huatesca, the Poconchi of Guatemala, and the Mayans. He found similarities between the Mayan and Huatescan languages in Mithridates (1816). ${ }^{44}$ Gallatin also included an astrological-astronomical chronology of the Mexican peoples borrowed directly from Humboldt's Views and Monuments, which Humboldt had termed "cosmogonies." The blend of the observations precisely calculated in astronomy with the mythological expressions afforded by astrology combined to produce a calendar for the Mexicans and other peoples. This revealed another example of Gallatin's involvement with Humboldt. Humboldt definitely influenced Gallatin.

Gallatin did not theorize in his Synopsis about Indian origins, as Humboldt did in Views and Monuments. He began hypothesizing in the 1840's as president of the American Ethnological Society. He developed his conclusions about origins, as he closely interacted with investigators of various disciplines. He and his colleagues published Transactions of the American Ethnological Society in two volumes in the late 1840's. In the first volume, Gallatin wrote down his thoughts in "Essay on the Semi-Civilized Nations of Mexico and Central America through Their Languages, Numeration, Calendars, History, Chronology, and Probable Origin of Their Civilization." 45 He included a section on origins, "Conjectures on the Origin of the American Civilization," in which he stated:

\footnotetext{
${ }^{43}$ Albert Gallatin, Synopsis of the American Indian Languages, pp. 63, 64.

${ }^{44}$ Albert Gallatin, Synopsis of the American Indian Languages, p.34. Mithridates and other works figured into the composition of the Synopsis.

45 John Austin Stevens, Albert Gallatin, American Statesman, pp.379, 380; Because of the diversified membership of the Ethnological Society, many of their publications represented a conglomerate of diverse influences with no specific relation to the general scientific community. Their Transactions were generally respected.
} 
It is not intended to discuss at large the question, whence the first inhabitants of America originally came, farther than to observe that all probabilities point out Asia . . ${ }^{46}$

\section{Reminiscent of Barton's New Views and Origin of the Tribes and Nations of America,}

Gallatin emphasized linguistic comparisons, but included analyses of customs, manners, and

history. Gallatin appeared to tentatively support a northeastern Asian origin for the Indians from his conjectures. He believed, as Barton did, that philology held the key to the origins riddle. He echoed Barton's hypothesis for an ancient crossing from Asia, but for him the Biblical time frame eliminated a prehistoric crossing advocated by Humboldt and other theorists:

... I cannot see any possible reason that should have prevented those who after the dispersion of mankind toward the east and northeast, from having reached the extremities of Asia, and passed over to America, within five hundred years after the flood [the Deluge] ...

Gallatin focused on the "civilized" agricultural peoples of the Tropics, whose traits resembled those of European civilization. ${ }^{48}$ Like Humboldt, Gallatin questioned whether these advanced cultures developed domestically, or derived from a source different than that of the other American Indian tribes. If the Aztecs and the Incas shared ancestors with other Indians, did their advanced civilizations acquire their knowledge from outside or develop it themselves? The debate focused on two important issues 1) the presumed inferiority of the red (Indian) race versus the white, and 2) whether "savage" tribes were able through their own efforts and without outside

\footnotetext{
${ }^{46}$ Albert Gallatin, "Notes on the Semi-Civilized Nations of Mexico, Yucatan, and Central America," Transactions of the American Ethnological Society, Article 1, New York: Bartlett and Welford, London: Wiley and Putnam, 1845; Milwood, New York: Kraut Reprint Co., 1976, p. 174. Gallatin's statement revealed his vague attempts to formulate an origin theory resembling Humboldt's. John Austin Stevens, Albert Gallatin, American Statesman, p.380. In his "Essay" Gallatin introduced little new information on the subjects of discussions, especially origins. Unlike Humboldt, he failed to formulate his own theory and build support for his conclusions.

${ }^{47}$ Albert Gallatin, "Notes on the Semi-Civilized Nations of Mexico, Yucatan, and Central America," pp. 176, 177, and 179. On p. 176 in his footnote, Gallatin declared no positive proof existed for his hypothesis, quote on p. 179.

${ }^{48}$ Albert Gallatin, "Notes on the Semi-Civilized Nations . . . .," p. 180.
} 
assistance, to emerge from the "rudest" and "lowest" social state, gradually attaining the "highest degree of civilization."49 Gallatin concluded about the Mexicans, that whatever advancements the first emigrants brought with them were later lost. If the civilizations did not develop independently, newcomers of other origins may have introduced these advancements to them. Perhaps the Indians directly imported them from foreign quarters prior to the Conquest. ${ }^{50}$ Gallatin asked whether agriculture (considered an essential element for civilization's development) derived from a foreign source or developed domestically. He specifically surmised that American agriculture developed domestically, because Old World grains were unknown to the American Indians, while maize, native to America, formed the core of American agriculture. Gallatin cited evidence from Humboldt "as indubitable that maize is exclusively a plant of American origin." ${ }^{51}$ This illustrated another instance of Humboldt's authority and influence. Gallatin dismissed recent pre-Conquest Asian or European migrations as responsible for creating the American Indian civilizations, because of insufficient evidence. He denied the validity of prevalent hypotheses, such as Viking settlements and consequent spread of Viking cultural influences. $^{52}$

Barton, Vater, and Gallatin pioneered scientific investigations on origins from data they compiled from the fieldwork of other philologists. Barton and Vater were among the first to use linguistics as a tool to assess origins. Both used vocabulary comparisons to explore origin

\footnotetext{
${ }^{49}$ Albert Gallatin, "Notes on the Semi-Civilized Nations," p. 181.

${ }^{50}$ Albert Gallatin, "Notes on the Semi-Civilized Nations," pp. 181, 182.

${ }^{51}$ Albert Gallatin, "Notes on the Semi-Civilized Nations," p. 196.

52 Albert Gallatin, "Notes on the Semi-Civilized Nations," p. 198. Gallatin discounted the Vikings' settlements, but not their discovery of America. His statements about the Vikings' settlements may have also applied to other preConquest origin theories about the Welsh, Mongolian, and Malayan sources for civilization in America.
} 
possibilities. Vater spread his knowledge to Europeans. Neither specified a northeastern Asian origin for the Indian, as did Humboldt. Gallatin symbolized the maturing of origins investigators, particularly philologists. His approach to origins and philological investigations represented a more comprehensive perspective, gleaning evidence and insights from various new disciplines. Gallatin even sponsored an umbrella organization of investigators from diverse disciplines. All benefited from Gallatin's broad knowledge of philology, which spanned the years of the discipline's evolution from singular vocabulary comparisons to complex comparative analysis of grammatical structures, idioms, and dialects.

This section reflects the continuous effects of Humboldt's research. Humboldt's results profoundly influenced Gallatin's mature work published in Transactions of the American Ethnological Society, though Gallatin disagreed with several of Humboldt's conclusions. Through Gallatin and "gentlemen" avocational researchers discussed in the following chapter, Humboldt remained a part of the origins debate into the mid-nineteenth century. Gallatin demonstrated a prime example of this through his investigations of the American civilizations in Transactions. He differed with Humboldt on the development of the Mexican calendar. Humboldt had concluded that the Mexican calendar developed domestically, whereas Gallatin admitted the possibility of imported astronomical knowledge on the calendar's formation. $\mathrm{He}$ conceded the peculiarities found in the Mexican calendar preceded the introduction of astronomical knowledge.

Gallatin cited Humboldt for support on the possibility of imported astronomical knowledge:

... Baron Humboldt has . . collected and pointed out the various facts and analogies which may be adduced in favor of the opinion that the astronomical knowledge of the 
Mexicans was communicated to them by foreign, probably Asiatic nations ... ${ }^{53}$

He also borrowed descriptions of the Muyscan and Peruvian calendars from Humboldt's work. And like Humboldt, he supposed that these calendars originated independently of the Mexican one, which had not derived from imported astronomical knowledge. ${ }^{54}$ Gallatin agreed with Humboldt that American agriculture developed domestically. ${ }^{55}$ In summary, Albert Gallatin drew from Humboldt's work for arguments on Indian languages, calendars, and agriculture. He added new information and a distinctive method for promoting Indian origins as the highest priority of his investigations. He may not have been the most original investigator, but he crystallized the results of a generation of researchers.

\section{Section 7}

\section{Lewis Cass}

Analysis of the philologists' role in formulating origin theories requires reference to frontier philologist and statesman, Lewis Cass (1782-1868), known as the "last Jeffersonian," because of his basic adherence to Jefferson's tenets on westward expansion, Indian removal, and origins. He emphasized a "humane" policy for organizing newly acquired Indian territory, but differed from other Jeffersonians on assimilation of Indians into American society. As a member of the Ohio legislature, he drew up resolutions of loyalty to Jefferson, and identified himself with

\footnotetext{
53 Albert Gallatin, "Notes on the Semi-Civilized Nations," p. 183.

${ }^{54}$ Albert Gallatin, "Notes on Semi-Civilized Nations," p. 184.

55 Albert Gallatin, "Notes on the Semi-Civilized Nations," p. 196.
} 
the cause of union. ${ }^{56}$

Cass was a frontier philologist who advocated the use of philology as a tool for researching Indian origins. Indian origins proved important to Cass as a determinant for extermination or forceful removal of Indians, if their derivations indicated subhuman status and inferior mentality to European-Americans. He believed, like other philologists, that the study of Indian languages proved the best means for resolution of the nineteenth-century origins debate. ${ }^{57}$

Cass criticized eastern philologists, especially Du Ponceau. He claimed they borrowed their Indian grammar and vocabulary lists from travel accounts. These philologists did not interact directly with the Indians, as he had. They failed to understand the Indians as well as their frontier counterparts, so he rejected their evidence as invalid. ${ }^{58}$

Cass possessed the advantage of direct contact and first-hand experience in analyzing their languages, so his criticism of eastern philologists was a fair one. Many eastern philologists had acquired their knowledge about Indian languages from others' works, so they operated from a more abstract position than Cass. His worldview played a significant role in his assessment of their languages, civilization, and origins. Cass thought that Indians possessed no capacity for reasoning. This perspective affected his findings and conclusions. He affirmed that Indian languages did not contain the sophisticated characteristics attributed to them by eastern philologists. Cass maintained:

\footnotetext{
${ }^{56}$ Frank B. Woodford, Lewis Cass, the Last Jeffersonian, New Brunswick, N.J.: Rutgers University Press, 1950. The title and the contents of the work reveal how Cass earned this designation. Allen Johnson and Dumas Malone, "Cass, Lewis," Dictionary of American Biography, Vol. 2, p. 562, 563. For his loyalty Jefferson appointed him marshal of Ohio.

${ }^{57}$ Robert E. Bieder, Science Encounters the Indian, 1820-1880, Norman and London: University of Oklahoma Press, 1986, pp. 26-29.

${ }^{58}$ Robert E. Bieder, Science Encounters the Indian 1820-1880, pp. 26-29.
} 
... The range of thought of our Indian neighbors is extremely limited . . . and we ought not to expect to find the complicated refinements of polished tongues among those of our Indians. . . 59

Du Ponceau professed that Indians joined words together to form one large inflected complex with prefixes and suffixes attached to make the word's meaning more precise. He labeled this construction, "polysynthetic." Humboldt had previously acknowledged this construction, which resembled German word complexes, as "agglutination" (English translation for Humboldt's German terminology). Cass vehemently disagreed with this assessment of Indian languages, because of his low estimate of Indian intelligence. Jefferson and other Jeffersonians believed Indians were capable of reasoning and mental development. The feud brought other investigators, especially Gallatin, into the dispute. The argument questioned the essential worth of philology as a tool to trace Indian origins. Cass agreed that philology proved to be useful means to investigate origins, but downplayed its potential. He showed no direct concern with the origins issue himself. Cass specified no places of origin or times of migration. His main goals focused on Indian removal, treaties with the Indians for their lands, and westward expansion. ${ }^{60}$

\footnotetext{
${ }^{59}$ [Lewis Cass] Review, "Manners and Customs of Several Indian tribes [and] Historical notes Respecting the Indians of North America," North American Review, Vol. 22 (January 1826), Boston: Frederick T. Gray, 1826.

${ }^{60}$ Robert E. Bieder, Science Encounters the Indian 1820=1880, pp. 26-29. See footnote on p. 28.
} 


\section{Section 8}

\section{Conclusion}

The philologists as a group of systematic investigators had acquired a sophistication and refinement of research methodology, despite setbacks from frontier philologists, as Cass, who almost brought about the demise of philology as an investigative tool to determine origins. He did not succeed and comparative linguistic studies remained an important format for assessing Indian origins at mid-nineteenth century. Combined with the efforts of newer types of empirical investigations, philology helped to complete the scientific attempts to assess origins.

Philology had evolved from a simplistic discipline of sporadic vocabulary comparisons at the turn of the century into a detailed and organized science of examining grammatical structures, syntax, polysynthetic word combinations, and idiomatic structures of the complex, American-Indian languages. The philologists pioneered systematic empirical investigations both in Europe and America. Humboldt himself admitted the pragmatic value of comparative linguistics along with other methods of assessing origins. Philologists divided themselves into two basic groups: Those who studied Indian languages in the field for their intrinsic value or for use by other investigators, and those who chose to theorize from the evidence. Many belonged during the earlier period to the American Philosophical Society, where they could freely exchange ideas and information. The later ones affiliated themselves with the newly formed American Ethnological Society founded by Albert Gallatin, himself a life-long philologist who spanned the years of the discipline's development. The philological investigations on origins reflected the continuing role and influence of Humboldt on their research and the entire origins debate in which they played a significant part. 


\section{CHAPTER FOUR}

\section{Gentlemen Scholars and Theorists}

\section{Section 1}

\section{Basic Themes}

- During the first half of the nineteenth century, systematic researchers investigated Indian origins. Many of them carried on their research activities as an avocation, while engaged in a full time profession, such as medicine. These new researchers constructed their discussions of the origin of American Indians from reports filed by Humboldt and others. They paid particular attention to reports on cultural characteristics. Although they ignored historical sources in favor of these contemporary "ethnological" accounts, they were just as nebulous as writers from the speculative tradition. The investigations formed an integral part of the origins debate and comprise the essence of this chapter. They contributed significantly to the shape and outcome of the debate. These researchers' hypotheses often contradicted the Bering Strait Theory, but their accumulated evidence supported it and contributed to its increased acceptance. This helped to initiate a paradigm shift in its favor.

The second argument in this chapter demonstrates how Humboldt's work pioneered as a model for content, structure, method, and source material for these primary-source investigators. Researchers from previously unmentioned fields cited Humboldt as an authoritative source on origins. They came from the disciplines of geography, medicine, ethnology, archaeology, history, and phrenology to take part in the origins debate. Several focused only on Indian origins, and others on the Mound Builders. These professional fields, particularly medicine, afforded a 
diverse liberal arts educational background and numerous opportunities to pursue avocations as amateur historians, writers, and bona fide scientific researchers. Medicine evolved into an exacting scientific discipline during the nineteenth century. This empirical structure based on analysis, diagnosis, and prognosis proved useful in the organization and systematic analysis of research material and hypotheses. A physician also possessed the finances to carry on as a "gentleman" researcher of independent means. As a group they patterned their research after the methodology and structure of empirical investigators, such as Humboldt and the philologists.

A few of these researchers reinforced hypotheses about northeastern Asian origins for the American Indians and migrations across the Strait, as supported by Humboldt's evidence and analysis. The second category remained ambivalent and skeptical about the Bering Strait Theory. Most of these adhered to a pattern that allowed for the possibility of a northeastern Asian origin for part of the Indians, and another source for the rest of the Indians. This pattern evolved into a new model for the 1840s with a northeastern Asian origin for North American Indians, and a Malayan-Polynesian origin for South American Indians. These often differed on other grounds, such as domestically developed civilizations versus "imported" civilizations for the Indians. This diversity in opinion complicated resolution of the origins debate. Many appeared to express initial support for the Bering Strait Theory, questioned evidence in support of it, and ended up ambivalent about its validity. Others questioned its validity and totally renounced the theory. 


\section{Section 2}

\section{Physician-Climatologists: \\ Williamson and Murray}

Hugh Williamson (1735-1819) was the earliest of these researchers and belonged to the American Philosophical Society. His Observations on the Climate in Different Parts of America . . (1811) included suppositions about Indian origins. ${ }^{1}$ He pursued a medical career and graduated the University of Utrecht. Williamson expressed keen interest in Indian origins during the period of his medical practice in Philadelphia. Williamson published papers on observations and experiments from different fields of science, including Observations on the Climate in Different Parts of America . ..(1811). ${ }^{2}$

The observations he made in the Carolina swamps influenced his work on climate and Indians. He verified his researches from first-hand evidence he gathered in the manner of the field investigators, one of the few gentlemen investigators to do so. Williamson believed that the American Indians came from northeastern Asia during a very early period:

We discover nothing that deemed certain, except that they came, the greater part of them, from Asia, and that the time of their arrival is very distant ...

Williamson pointed out speculations on origins of American peoples developed at a time when scholars and explorers still thought that a wide ocean separated America from Asia. He realized that explorations, such as those of Captain James Cook (1728-1779) in 1778, revealed the closest proximity of Asia to America in the far north. Peoples who wandered over from Asia lived on

\footnotetext{
${ }^{1}$ Hugh Williamson, Observations on the Climate in Different parts of America, Compared with the Climate in Corresponding Other Parts of the Other Continent, New York: T. and J. Swords, 1811.

${ }^{2}$ Dumas Malone, “Williamson, Hugh, “ Dictionary of American Biography, Vol. 10, New York: Charles Scribner and Sons, 1936, pp. 278-300.

${ }^{3}$ Hugh Williamson, Observations on the Climate in Different Parts of America, p. 102.
} 
islands between northeastern Asia and northern America. He concluded that the descent of the majority of North America's Indians from Asiatic "Tartars" stood as a foregone conclusion. He failed in his analysis to differentiate Indian from Inuit peoples. ${ }^{4}$

Williamson withheld support for derivation of the various Mexican peoples, especially the Toltecs, from northeastern Asia and the migration route across the Strait. He affirmed that cotton and maize failed to thrive in high latitudes, so the Mexicans could not have brought the seeds of these plants from the northeast of Asia. With this departure from the Bering Strait Theory, Williamson increasingly expressed ambivalence about the theory's validity. He proposed an alternative route for migration across a continuous island chain from Japan to America:

... I deem it highly probable that the first emigrations were made from Asia by these islands ... 5

Williamson denied another premise through his claim of different origins for the Peruvian or Inca civilizations. He concluded the various Mexican civilizations arose from "Tartaric" groups from northeastern Asia. His conclusion that Peruvians derived from India proved more tenuous than those that other researchers later proposed. ${ }^{6}$ This conclusion contradicted Humboldt's for a unified people from northern North America to Cape Horn. He reasoned that the American Indians had reverted to a more backward state. They had no chance to recover their

\footnotetext{
${ }^{4}$ Hugh Williamson, Observations on the Climate in Different Parts of America, pp. 102, 104: In stating that the aborigines of North America are chiefly descended from Tartars, I am supported by common tradition among these people, as the obvious facility of the passage ...".

${ }^{5}$ Hugh Williamson, Observations on the Climate in Different Parts of America, p. 116.

${ }^{6}$ Hugh Williamson, Observations on the Climate in Different Parts of America, p. 128: “The Peruvians may have migrated from the southern parts of Asia . . they came from India ...”
} 
loss, as did colonists in the Old World. ${ }^{7}$ Williamson did not believe that America's soil or climate negatively affected the Americans' mental capacities in any way. No references to Humboldt appeared in his work, though both published in the same period. ${ }^{8}$

Hugh Murray (1779-1846) in his work, Historical Account of Discoveries and Travels of North America . . (1829), ${ }^{9}$ attempted to resolve the origins debate through his research. He assisted Sir John Leslie, renowned Scottish explorer, who wrote Narrative of Discovery and Adventure in the Polar Seas and Regions in 1829. Murray wrote about Africa, India, China, and the US. ${ }^{10}$ He began his Historical Account with a statement about a single origin for the human race:

How or whence America has been peopled is connected with some of the deepest problems reflecting the origin and nature of the human species ... 11

Scientific investigators may have rejected the Bering Strait Theory altogether, if multiple origin theories had gained wide acceptance. A single origin encompassed the question of Indian origins, although one could propose a single origin human origin followed by complex, intertwined, multiple migrations. Murray focused on the problem of color as a secondary

\footnotetext{
${ }^{7}$ Hugh Williamson, Observations on the Climate in Different Parts of America, p. 122.

${ }^{8}$ Hugh Williamson, Observations on the Climate in Different Parts of America, pp. 132-139. On p. 135, Williamson mentioned that he cited information on Hindu chronologies from a dissertation by Sir William Jones.

${ }^{9}$ Hugh Murray, Historical Account of Discoveries and Travels in North America, including the United States, Canada, the Shores of the Polar Sea, and the Voyages in Search of a Northwest Passage; with Observations on Emigration, Vols. 1 and 2, London: Longman, Rees, Orme, Brown, and Green; Edinburgh: Oliver and Boyd, 1829, Vol. 1, Chapter 2, 1829.

${ }^{10}$ Stephen Leslie and Sydney Lee, "Murray, Hugh," The Dictionary of National Biography Founded in 1882 by George Smith, From the Earliest Times to 1900, Vol. 13, Oxford: Oxford University Press, 1917.

${ }^{11}$ Hugh Murray, Historical Account of Discoveries and Travels in North America, Including the United States, Canada, the Shores of the Polar Sea, and the Voyages in Search of a Northwest Passage; with Observations on Emigration, p. 37.
} 
determinant of Indian derivations. He believed color separated one race from another. $\mathrm{He}$ recognized the sun's effects on skin color, but denied this effect solely determined color. Environmental determinists claimed climate as the crucial element in determining color. Murray cited American Indians as a prime example for refuting climate as a major color determinant: ... But it is said the Americans themselves ... offer the strongest argument against this supposed power of climate in forming the peculiarities of race. One tint, one form, is said to prevail over the whole continent from the equator to the pole ... ${ }^{12}$

Through this statement Murray supported the main conclusion of Humboldt's theory, that the Indians represented one unified people throughout the Americas. Murray deferred to Humboldt's authority in this matter. He challenged, however, other positions of Humboldt's. Murray, for example, focused on one of Humboldt's inconsistencies about climate and skin color:

But it is the color of the American nations, which has been especially urged as subverting the theory of a unity of race. Even Humboldt himself conceives that climate forms the color of the old world, but does not act upon it in America. ${ }^{13}$

Murray further followed in Humboldt's footsteps with his observations about a variety of shades of color, but simultaneously contrasted Humboldt's observations. He specified that a relationship existed between the absence of black-skinned Americans and climate. Special conditions prevailed in America, which lowered temperatures relative to those in similar latitudes of the Old World. Murray succinctly cited Humboldt in this matter:

... there are admitted to be great varieties in the depth of the brown complexion; but M. Humboldt contends that these cannot ... be referred to the greater or lesser degree of heat .. $^{14}$

\footnotetext{
${ }^{12}$ Hugh Murray, Historical Account of Discoveries and Travels in North America . . ., pp. 44, 45: “ . . Humboldt remarks, that 'after living longer among the indigenous Americans, we discover that celebrated travelers, who could only observe a few individuals ... have singularly exaggerated the analogy of form among the Americans' ..."

${ }^{13}$ Hugh Murray, Historical Account of Discoveries and Travels in North America . . . pp. 44, 45: “ . . Humboldt remarks, that 'after living longer among the indigenous Americans, we discover that celebrated travelers, who could only observe a few individuals ... have singularly exaggerated the analogy of form among the Americans' ..."
} 
Murray's reliance on Humboldt demonstrated one more example of how Humboldt influenced individual investigators and the origins debate directly and indirectly.

Murray then presented arguments supporting a northeastern Asian origin for the Indians. He observed that the general phenotype resembled the Mongolian race with variations of the face and cranium. The general type formed because of situational and lifestyle influences, so modifications emerged when these two aspects changed. Thus, Murray accounted for a single northeastern Asian origin and the subsequent differences in physical features existent among the Indians, comparable to those differences between the parental Asian peoples and the Indians. ${ }^{15}$ Murray concluded from these arguments:

... The north-east of Asia is the quarter from which it is probable, and indeed almost certain, that the great mass of the Americans were derived ... ${ }^{16}$

With corollary arguments in support of migration across the Strait, he appeared to have sealed the case for upholding Bering Strait Theory, while simultaneously discrediting other origin theories. He noted how relatively well populated the northwestern areas of America were compared to other regions of the continent. He also promoted the Mexican traditions that they came from the Northwest. ${ }^{17}$ He emphasized Humboldt's conclusions about the derivation of the various Mexican civilizations:

\footnotetext{
${ }^{14}$ Hugh Murray, Historical Account of discoveries and Travels in North America . . ., p. 47.

${ }^{15}$ Hugh Murray, Historical Account of Discoveries and Travels in North America, pp. 45-50. On p. 50, Murray cited Humboldt's argument for diversity within unity.

${ }^{16}$ Hugh Murray, Historical Account of Discoveries and Travels in North America, p. 45.

${ }^{17}$ Hugh Murray, Historical Account of Discoveries and Travels in North America, p. 54, 55.
} 
This conclusion is not at all shaken by the fact quoted by Humboldt, that the Toultec [sic] conquerors, who came from the new barbarous regions in the northwest, were the framers of the most remarkable of the Mexican monuments ... ${ }^{18}$

Third, he related Chinese and Hindu monuments built by "Tartaric" monarchs to "Tartaric" responsibility for Toltec construction.

Murray reversed his support for the Bering Strait Theory and its supposition of a unified people with his inconclusive views about philological investigations conducted by Vater, Barton, and Pallas. Murray proposed that the Asiatic countries most remote from America contributed as much to linguistic similarities between Asian and American Indian languages, as those countries in closest proximity to America. ${ }^{19}$

Although Murray supported Bering Strait Theory generally, he recognized the possibility of separate origins for South American Indians. In this he contradicted Humboldt:

But it may be said, that although people by this channel [Bering Strait] undoubtedly passed over from the Old World to America, this does not exclude other colonies from finding their way across the Atlantic or Pacific ... ${ }^{20}$

In this statement Murray echoed a trend shared by all of the gentlemen scholars and theorists to assign separate origins for North and South American Indians. This trend persisted into the 1840s, and could have established an alternative to the Bering Strait Theory, if not for field investigators such as Ephraim H. Squier and Edwin Hamilton Davis. This alternative encompassed all of the aspects of the Bering Strait Theory, with the only difference being the

\footnotetext{
${ }^{18}$ Hugh Murray, Historical Account of Discoveries and Travels in North America, p. 57. Murray quoted from Humboldt's Political Essay on the Kingdom of New Spain.

${ }^{19}$ Hugh Murray, Historical Account of Discoveries and Travels in North America, pp. 57, 58. On p. 57, Murray credited philologists' efforts as valid in assessing origins: “. . . Several learned and diligent efforts have recently been made to fix on a more precise basis the origin of the American nations. Attempts have been made to find in their languages such a similarity with those of the old continent as might indicate the one as derivative from the other ...".

${ }^{20}$ Hugh Murray, Historical Account of Discoveries and Travels in North America, p. 55.
} 
distinction between North American and South American Indians. Humboldt's evidence indicated that North and South American Indians emanated from one source across the Strait. With very little first-hand evidence to support their case, they and others were unable to formulate a North American versus South American origin theory. Murray evaded the entire issue. He proclaimed that the debate about Indian origins presented foregone conclusions with no need for further investigation:

European writers ... busied themselves to an extraordinary degree in conjecturing whence and by whom this vast continent had been peopled ... the mysteries which once hung over the subject have been in a great measure dispelled . . ${ }^{21}$

In this regard Murray echoed the suppositions of fellow gentlemen researchers, especially of Hugh Williamson.

\section{Section 3}

\section{Scholars Who Kept Humboldt's Ideas in the Debate}

\section{J. H. McCulloh and B. H. Coates}

The same year Murray published his work (1829), James Haines McCulloh, a Baltimore physician, published Researches, Philosophical and Antiquarian Concerning the Aboriginal History of America, in which he examined hypotheses about Indian origins. He published an earlier version, Researches in America, Being an Attempt to Settle Some Points Relative to the Aborigines of America in $1816 .{ }^{22}$ McCulloh was another gentleman physician scholar whose reference kept Humboldt in the origins debate into the 1830s. He sprinkled his work with

\footnotetext{
${ }^{21}$ Hugh Murray, Historical Account of Discoveries and Travels in North America, p. 50.

22 J. H. McCulloh, Researches, Philosophical and Antiquarian, Concerning the Aboriginal History of America, Baltimore: Fielding Lucas, Jr., 1829.
} 
references from Humboldt, demonstrating his recognition of Humboldt's authority on the subject and continuing influence on the debate, albeit a more indirect one. [Humboldt during this period had turned his attention directly to matters of physical science, which he would later publish in his most renowned work Kosmos.] McCulloh intended to enumerate various theories, but not to theorize himself:

As we cannot perceive any advantage of the reader in the introduction of exploded or insufficient theories, we forebear to enumerate; ... we have not philosophical principles. It certainly must be within the influence of some solution . . . 23

McCulloh emphasized his main purpose was to discover the truth for its intrinsic value. This foreshadowed the intent of Ephraim George Squier and Edwin Hamilton Davis to research mound structures without preconceived notions or other agendas. Through this method of investigation, he would reach viable conclusions. His methodology first required assessment of the condition of America prior to the arrival of Columbus. After he had acquired correct information on the subject, he intended to examine difficulties in assessing origin of humans and animals. Through such methodology, he believed that he would obtain results capable of being generalized into consistent and satisfactory conclusions. ${ }^{24}$ With this philosophy it was unavoidable that McCulloh ultimately became entangled in the theoretical aspects of the origins debate.

McCulloh first assessed physical characteristics of the Indians, especially skin color. He considered the description of Indians as copper-colored to be mistaken. Peoples around the world

\footnotetext{
${ }^{23}$ J. H. McCulloh, Researches, Philosophical and Antiquarian, Concerning the Aboriginal History of America, p. x.

${ }^{24}$ J.H. McCulloh, Researches, Philosophical and Antiquarian, p. x.
} 
shared this characteristic. ${ }^{25}$ He borrowed the information about the Indians' resemblance with other "brown" peoples from Humboldt's first-hand observations. ${ }^{26}$ Humboldt did not affirm these resemblances accurately identified race according to McCulloh. ${ }^{27}$ McCulloh conducted no first-hand investigations, but compiled his researches from others' work. He proposed no new hypotheses, but endorsed the northeastern Asian origin theory. ${ }^{28}$ Reminiscent of Humboldt, he acknowledged skin color variances among the Indians:

... Baron Humboldt remarks, ' if the uniform tint of the skin may be more coppery and redder toward the north, . . . the denomination of copper coloured men (rouges cuivrés) could never have originated in equi-noctial America to designate the natives' . . ${ }^{29}$

McCulloh also cited Humboldt to deny that climate affected skin color. ${ }^{30}$ Also, McCulloh rejected philologists' efforts to determine Indian origins through vocabulary studies of Old and New World languages. ${ }^{31}$ He particularly dismissed Vater's comparative studies and undercut Barton's findings as useless, bringing his diatribe against philology to a head. ${ }^{32}$

\footnotetext{
${ }^{25}$ J.H. McCulloh, Researches, Philosophical and Antiquarian, p. 16. McCulloh added, “..... By this circumstance we shall be able to unite the American Indians. . . from whom they have been inconsiderably separated by this fanciful distinction."

${ }^{26}$ J.H. McCulloh, Researches, Philosophical and Antiquarian, the analogy between the Mongol and American races is particularly evident in the colour of the skin and hair, ". . . high cheek bones, and the direction of the eyes. We cannot refuse to admit, that the human species does not contain races resembling one another more than the Malays, Mongols, Mantcheaux, and Americans ...".

27 J.H. McCulloh, Researches, Philosophical and Antiquarian, p. 18. Humboldt's qualification stated, “. . . these features of resemblance do not constitute an identity of race ...”.

${ }^{28}$ J.H. McCulloh, Researches, Philosophical and Antiquarian, p.18.

${ }^{29}$ J.H. McCulloh, Researches, Philosophical and Antiquarian, pp. 18, 19. On p. 23 appears an applicable reference from Humboldt's Political Essay, "The other localities of white nations, are in South America; and are thus noticed by Baron Humboldt . . . Yet these tribes have never mingled with Europeans and are surrounded with other tribes of a dark brown hue." .

${ }^{30}$ J.H. McCulloh, Researches, Philosophical and Antiquarian, pp. 31, 32: “ . . Humboldt remarks, that notwithstanding the variety of climates and elevations inhabited by the different races of men, nature never deviates from the models of which she made selection thousands of years ago."

${ }^{31}$ J.H. McCulloh, Researches, Philosophical and Antiquarian, p. 38, McCulloh found, "The question most interesting . . . is, whether any connexion exists between them [American Indian languages] and those of any other people of the earth ... the comparisons of them has been attended with any thing but satisfactory conclusion ...".
} 
Other scholars also found the early philologists' efforts insufficient to determine origins. McCulloh thereby eliminated consideration of a northeastern Asian origin for the Indians based on vocabulary studies. He conceded that grammatical structural studies possibly provided a tool for determining origins. He relied on Humboldt's remarks for this concession:

... Baron Humboldt observes, .. . ' I am well aware that languages are much more strongly characterized by their structure and grammatical forms, than by analogy of their sounds of their roots .... 33

Humboldt's pervasive authority and influence on later investigators, including McCulloh, rescued philology from oblivion as a useful means to assess origins. Strengthened Humboldt's authority among later investigators. Humboldt had already developed a reputation in natural science and expertise in diverse and often opposed scientific disciplines. ${ }^{34}$ McCulloh accepted Humboldt's assessment of Indian origins based on linguistic data, because Humboldt accepted the validity of comparative linguistics to assess origins. ${ }^{35}$

McCulloh cited Humboldt's field observations about Indian customs and practices throughout his researches. ${ }^{36}$ His investigative pattern of hypothesis and affirmation followed Humboldt's format in Views and Monuments. ${ }^{37}$ Through burial customs and time divisions, he

\footnotetext{
${ }^{32}$ J.H. McCulloh, Researches, pp. 39, 40. On p. 39 find his comments about Vater: "Those comparisons amount to nothing ...". His criticisms of Barton's work are found on pp. 39, 40: “The late Dr. Barton was many years employed in a similar research, and with about the same success ... no general resemblance has been detected between the words of the American languages, and those of the eastern continent. ..”.

${ }^{33}$ J.H. McCulloh, Researches, p. 40, from Humboldt's Personal Narrative.

${ }^{34}$ J.H. McCulloh, Researches, Philosophical and Antiquarian, p. 40.

${ }^{35}$ J.H. McCulloh, Researches, pp. 58, 59.

${ }^{36}$ J.H. McCulloh, Researches, pp. 61-115.

${ }^{37}$ Marie Pratt, Imperial Eyes, Travel Writing and Transculturation, p. 131. Shortened title form composed by author and used in this dissertation.
} 
compared northeastern Asians with American Indians from Humboldt's evidence. ${ }^{38}$ Yet,

McCulloh doubted the possibility of migration across the oceans to America, migration across the Bering Strait, and the ability of humans to pass over the ice in winter or in the summer by boats. $^{39}$

McCulloh seriously questioned the Bering Strait Theory, then doubted its validity supported by evidence gathered from explorers and other systematic investigators. He oscillated between support and total rejection of its premises. Throughout his analysis, he relied extensively on Humboldt's first-hand evidence, so he recognized Humboldt's part in the origins debate. McCulloh's suppositions more closely resembled those from the speculative tradition that ran parallel to empirical thought during the first half of the nineteenth century. He switched from systematic empirical investigations to endorsement of speculative origin theories in the final analysis. This diminished his credibility as a systematic scientific researcher. Like Murray, his researches culminated in open-ended, noncommittal conjectures about Indian origins. ${ }^{40}$

B.H. Coates, a systematic gentleman-physician followed in the footsteps of McCulloh. He also seriously questioned the Bering Strait Theory and proclaimed his conclusions about it during his 1834 address, Annual Discourse Delivered before the Historical Society of Pennsylvania. He openly challenged Humboldt and his theory with a proposed reversal of the migration pattern from northeastern Asia:

\footnotetext{
${ }^{38}$ J.H. McCulloh, Researches, Philosophical and Antiquarian, pp. 116-118 for selections about various practices. On p. 118, McCulloh stated: "Baron Humboldt says we must imagine that some connexion anciently existed between these people [of Nootka Sound] and the Toltecks [sic] ..."

${ }^{39}$ J.H. McCulloh, Researches, Philosophical and Antiquarian, pp. 127, 428. On p. 428, McCulloh emphasized: “... Facts ... do not even countenance of men by Behring Straits, if we are to judge either by languages, or the appearance of the different people on either side ...”. McCulloh cited James Cook's observations about apparent differences on p. 428.

${ }^{40}$ J.H. McCulloh, Researches, Philosophical and Antiquarian, pp. 454-456. On p. 455 McCulloh stated that "the speculations of Ray, Whitehurst, Buffon, Kirwan, and Pennant, upon the subject of Atlantis are all in favour of its
} 
... not only is the evidence wanting that America was peopled through these regions from the Asiatic continent, but there is the strongest reason to believe that emigration took place in the other direction, and that the northeastern extremity of the older world was actually colonized from the new! ${ }^{41}$

Coate's hypothesis resembled Jefferson's indigenous origin theory and reverse migration into

Asia. He also thought scant linguistic evidence existed to validate a northeastern Asian

derivation for the Indians. Coates at first favored a separate creation for the Indians, and found

himself in the same dilemma as Jefferson did. ${ }^{42}$ He turned to navigation as an alternative solution to the problem of America's colonization, since a separate creation proved incompatible with tenets from Scripture and natural history. ${ }^{43}$

Coates targeted the core of the Bering Strait Theory, as McCulloh had done. He retained one key aspect, the prehistoric period for migration. These migrations must have occurred prehistorically, because the Indians brought no remnants of civilization with them, especially domesticated animals. ${ }^{44}$ Coates echoed Humboldt's stipulation that the Mexican and Peruvian civilizations exhibited the strongest evidence for having developed "homegrown" civilizations. He directly borrowed Humboldt's dates for the migrations of the Toltecs and Aztecs. ${ }^{45}$ Coates

former existence, . . . if to their considerations our few proofs may be added, it may not be presumptuous to think the tradition almost well established."

${ }^{41}$ B.H. Coates, Annual Discourse Delivered before the Historical Society of Pennsylvania, on the $28^{\text {th }}$ day of April, 1834, on the Origin of the Indian Population of America, Philadelphia: Printed for McCarty \& Davis, 1834, p. 6.

${ }^{42}$ B.H. Coates, Annual Discourse Delivered before the Historical Society of Pennsylvania, pp. 9, 10.

${ }^{43}$ B.H. Coates, Annual Discourse Delivered before the Historical Society of Pennsylvania, p. 11: . . The proximity of land is evidently sufficient throughout the whole round of the Arctic circle to permit a people so nautical in their habits to colonize, in that latitude, the whole circumference of the globe . . Not only does there exist the facility ... of navigating from Asia to America, or in the opposite direction, by crossing Behring's Straits, ... together with the more southerly route of communication . . . roads assigned by so many writers as those by which the progenitors of our Indians reached this continent; but in the direction of Europe the difficulties are by no means insuperable ...".

${ }^{44}$ B.H. Coates, Annual Discourse Delivered before the Historical Society of Pennsylvania, pp., 12, 13. This premise Coates held in common with Humboldt.

${ }^{45}$ B.H. Coates, Annual Discourse Delivered before the Historical Society of Pennsylvania, p. 32. These dates were 544 AD for the Toltecs, and 1178 AD for the Aztecs. 
qualified his statements with questions about the validity of using Indian tradition to determine

Indian origins. He contested the origins of the entire native population of the Americas:

I am willing to grant . . . that these reflections render it highly probable that descendants of the Mongolians exist among the Indian tribes, but is not the evidence defective towards such a conclusion as that which would draw the whole population of our continent from this source [from beyond Behring's Straits] . . ? To suppose the colonies of Mongolian descent have contributed to fill the amount of the American population, is a $\underset{46}{v e r y}$ different position from that which refers to this explanation the origin of the whole . . 46

Coates thought other peoples had colonized America, among them the Oceanic or Malayan peoples of the South Sea Islands, who originated from southeastern Asia. ${ }^{47}$ He perceived no major differences between the Malayans and the American Indians. Both belonged to the Mongolian race. Coates emphasized that differences that prevailed among American Indians proved greater than the Indians' differences with the Malayans. He again relied on Humboldt's evidence for citing differences in support of his Malayan hypothesis; that Malayan descendants had populated South America. ${ }^{48}$

Coates's methodology produced positive results despite his contradictory arguments. He tried to discredit the Bering Strait Theory, but instead reinforced it through increased attention to its details and the arguments against it. He also dismissed other origin hypotheses, especially speculations of Indian derivations from various ancient and medieval Old World peoples. This

\footnotetext{
${ }^{46}$ B.H. Coates, Annual Discourse Delivered before the Historical Society of Pennsylvania, pp. 17, 18, 32, 33. Quote on pp. 32 and 33.

${ }^{47}$ B.H. Coates, Annual Discourse Delivered before the Historical Society of Pennsylvania, p. 38. Coates declared: “ ... America, like other sections of the world was peopled from several sources: .....

${ }^{48}$ B.H. Coates, Annual Discourse Delivered before the Historical Society of Pennsylvania, pp 38-44. Coates quoted Humboldt's observed differences, such as the "fair Cherokee, the black Brazilian, the gigantic Carib, and the stunted Chayma." Coates continued on p. 45: “. . . that the Malay features . . . never appeared to us to have a well characterized distinction from the Indians sufficient to constitute a section of mankind; and that the craniums of the two races ... are nearly identical ... We see nothing, therefore, in the features of the Indians which forbids their descent from Malay colonists ....".
} 
permitted more intensive analysis of the Bering Strait Theory itself. His numerous references to Humboldt reinforced Humboldt's continuing role in the on-going origins debate. Coates, like McCulloh and Murray, kept Humboldt's ideas in the debate well into the 1830s.

\section{Section 4}

\section{Other Inconclusive Investigators C. S. Rafinesque}

Constantine Samuel Rafinesque (1783-1840) provided still another example of a scholar who frequently cited Humboldt as an authoritative source in his work, The American Nations: or Outlines of a National History of the Ancient and Modern Nations of North and South America (1836) in two volumes. ${ }^{49}$ He chose a career as a naturalist, not as a physician, in distinction from researchers previously discussed. He never acquired the organized methodology and attitude of the precise empirical investigator.

Rafinesque moved to Philadelphia in 1802 from his birthplace near Constantinople in 1802. He introduced himself to members of the city's entire scientific community, including Thomas Jefferson and physician Benjamin Rush. He also developed a vocabulary of the Osage Indian language. After a stay in Europe from 1805 to 1815 , he returned to the United States for the remainder of his life. The natural sciences comprised his chief preoccupation. He wrote on a

\footnotetext{
${ }^{49}$ C.S. Rafinesque, The American Nations; or Outlines of a National History of the Ancient and Modern Nations of North and South America, Vol. 1 \& 2, Philadelphia: C. S. Rafinesque, 1836. Paris: Meilhac and Baillere, 1836, p. 7. The "Preface" of the first volume featured citations from the "Introduction" to Humboldt's Views and Monuments. The title page from Vol. 1 features a direct quote from Humboldt.
} 
variety of specialties, especially botany and ichthyology. His investigations reflected historical, linguistic, and natural scientific influences. ${ }^{50}$

In the first volume of his work, Rafinesque concentrated on writers whom he believed had forgotten what had been written about American history. He thought such writers, as philosophers and impartial critics, should have also learned about the various sciences. He curiously exempted Humboldt from these criticisms. Rafinesque proposed a plethora of unrelated hypotheses about Old World peoples who had reached America in the distant past. ${ }^{51}$ Rafinesque rejected a northeastern Asian origin for all of America's Indians, ${ }^{52}$ although he cited emigration via Bering Strait as likely for North America Indians. Meanwhile he proposed another "more direct" route for the rest of America's Indians:

It has appeared probable to me that most of the ancient colonies to America must have come by the nearest and direct way; ... . while nearly all those of North America appeared to have reached America by the opposite direction of eastern Asia, through Alaska or the Streight of Bering ... 53

Rafinesque set up an epochal scheme to trace the origins of the various American peoples. His claim to thoroughness included all possible means of investigation and sources scattered from numerous writers. He cited Humboldt for his expertise on American astronomy. He viewed

\footnotetext{
${ }^{50}$ Dumas Malone, "Rafinesque Constantine," Dictionary of American Biography, Vol. 8, New York: Charles Scribner and Sons, 1935, pp. 322, 324.

${ }^{51}$ C.S. Rafinesque, The American Nations, or Outlines of Their History, Ancient and Modern: Including the Whole History of the Earth and Mankind in the Western Hemisphere; The Philosophy of American History; The Annals, Traditions, Civilization, Languages \& c. of All the American Nations, tribes, Empires, and States, Vols. 1 \& 2, Philadelphia: C.S. Rafinesque, 1836, p. 23. Rafinesque declared: "Meantime I state as highly probable, ... that all the nearest nations in the Eastern Hemisphere have either visited or colonized the Americas ... We shall throughout these historical outlines find ample proofs of this fact, exploding the erroneous belief that a single nation could have populated the whole of the Western Hemisphere.

${ }^{52}$ C.S. Rafinesque, The American Nations, or Outlines of Their History, pp. 27, 28: “. . . all the ancient American tribes have numerous affinities between each other...".

${ }^{53}$ C.S. Rafinesque, The American Nations, or Outlines of Their History, pp. $28,29$.
} 
comparative linguistic study as a valuable tool for investigating origins. ${ }^{54}$ His scheme failed to yield a definite origin theory. The conglomeration of unrelated data and speculations neither supported nor invalidated the Bering Strait Theory, but sustained a variety of other theories.

\section{Section 5}

\section{Separate Origin Theorists}

\section{Alexander Bradford}

If Rafinesque contributed little to the debate about origins, his contemporary, attorney Alexander Bradford (1815-1867), tried to follow the organized pattern of the gentlemenphysician scholars. Bradford turned his energy to ethnological research, but said little about the Bering Strait Theory, despite numerous references to Humboldt. His publication, American Antiquities and Researches into the Origin and History of the Red Race (1843), was a pioneer effort in Indian ethnological studies. He vowed that no preconceived notions influenced his work, as McCulloh had stated. The conclusions he reached, however, totally undermined the Bering Strait Theory. ${ }^{55}$

Bradford's first premise established that all of American Indians came from one stock, although he questioned whether the "civilized" and uncivilized tribes came from the same place. The degree of "civilization" attained by the Indians posed a dilemma. Did the stage at which the immigrants found themselves represent the beginning of an evolution to a "civilized" state, or the

\footnotetext{
${ }^{54}$ C.S. Rafinesque, The American Nations, or Outlines of Their History, Ancient and Modern, pp. 35-61.

55 Alexander Bradford, American Antiquities and Researches into the Origin and History of the Red Race, New York: Wiley and Putnam, 1843. On p. 6 of the "Preface," he stated: “. . . biased at the onset strongly towards the theory of migration by Behring's Straits ... I was forced to abandon it."
} 
decline from a prior "civilized" state? Bradford decided to assess whether or not they both came from the same place. ${ }^{56} \mathrm{He}$ argued for a unified Indian people directly from Humboldt's origin theory. Based on others' first-hand observations, Bradford proposed that no part of the world's inhabitants demonstrated such uniformity as America's peoples. ${ }^{57}$

Bradford affirmed this uniformity, though he acknowledged the differences that Humboldt had observed on his trip. ${ }^{58}$ Bradford also drew from philologists' investigations to reinforce his belief that the languages of the inhabitants from the Arctic Ocean to Cape Horn had preserved distinctive characteristics common to all, a general structural unity and a positive similarity of grammatical forms. He affirmed:

It was an old common error to consider the residents of every Indian village as a distinct tribe ... this mistake was confirmed by the impression that many languages, now ascertained to be nearly related, were wholly dissimilar. . . 59

Bradford researched seven different areas that supported Indian unity. He asserted that all Indian groups shared common religious practices. Also, he noted that hieroglyphic painting was widespread among the Indians. Humboldt concluded that the Peruvians had not yet perfected picture writing or hieroglyphics. Bradford affirmed the opposite:

... The curious and complicated system of picture writing possessed by the Mexicans was not only known to many nations in their vicinity, but also to at least one of the South

\footnotetext{
${ }^{56}$ Alexander Bradford, American Antiquities and Researches into the Origin and History of the Red Race, p. 179: “. .. it becomes proper to examine whether there are any substantial grounds of distinction, indicating a difference of origin, between the two great divisions of American aborigines, - the barbarous, and the civilized."

${ }^{57}$ Alexander Bradford, American Antiquities and Researches, pp. 179, 180, paraphrased quote. North American Review, Vol. 54, pp. 297, 298: "The term 'Red Race' . . reveals at once the leading idea of the theory. He deems the entire race of red hungers who cover the continent to be a homogeneous and primitive stock of the human family, not derivable, or derived, from any one existing nation or people, now known by name to Europe, Asia, or Africa ....".

${ }^{58}$ Alexander Bradford, American Antiquities and Researches, p. 245, quote from Humboldt: "All the Americans are generally distinguished by the same prominent peculiarities. In a country stretching from the Arctic regions to the fifty-fifth degree of south latitude, this uniformity is exceedingly remarkable ...”.

${ }^{59}$ Alexander Bradford, American Antiquities and Researches, pp. 280, 281.
} 
American tribes, while it is conceived that traces of its ancient use may be observed among others ... ${ }^{60}$

Bradford emphasized the uniformity of mythological traditions from the major Indian civilizations and the less developed Indian cultures. These dated back to a very ancient time period. He finally cited a general population movement from west to east, which indicated a migration from the west across the Bering Strait. ${ }^{61}$

Bradford reinforced evidence for a northeastern Asian derivation for the Indians by his confirmation of migratory routes and greater population in western America. He referred to Humboldt's Views and Monuments about this, other Indian traditions, and legends about Mexico and Peru. To further reinforce the concept of Indian unity, Bradford explained that Indians throughout the United States, Mexico and Peru practiced similar burial customs, because of the universal "superstitious" reverence for the dead. Maize cultivation was nearly a universal agriculture practice, even in the higher latitudes, where maize did not normally grow. Bradford concluded his assessment with the enumeration of miscellaneous customs that all Indians supposedly shared. ${ }^{62}$

Bradford established a unity and common origin for the Indians. He argued about migration routes as indicators for civilizations arriving in the southern part of the continent from across the Strait:

In the examination of the ruins in North America, the traditions connected with them . . . those in the southern part of the continent present claims to the highest antiquity ... the first abode of the civilized nations . . . through the immense regions of the north . . ${ }^{63}$

\footnotetext{
${ }^{60}$ Alexander Bradford, American Antiquities and Researches pp. 182-183. Quote is found on p. 182.

${ }^{61}$ Alexander Bradford, American Antiquities and Researches pp. 181-191. On p. 190 is found a paraphrased quote.

${ }^{62}$ Alexander Bradford, American Antiquities and Researches, pp. 182-194, 203. Legends quoted from Humboldt's Views and Monuments. On pp. 194-198, Bradford mentioned many of the miscellaneous customs.

${ }^{63}$ Alexander Bradford, American Antiquities and Researches, p. 199.
} 
Bradford added that migrations of the Toltecs and related peoples southward after crossing the Strait reinforced the validity of the Bering Strait concept. The Toltecs and related peoples (the Chichimecs, Nahuatlecs, and Aztecs) successively pushed into the Valley of Mexico. They encountered the Chiapanese, Miztecs, Zapotecs, and others who had developed aspects of civilization similar to them. Remnants of the southward migrating tribes diffused throughout the northern regions and into eastern America.

Bradford believed that the Bering Strait did not impede communication between Asia and America, based on seventeenth century wanderings of the Chukchis of northeastern Siberia and the ease with which the Aleutian tribes sailed westward to Kamchatka. He concluded, however, that only "uncivilized" tribes crossed over the Bering Strait. He thought it unlikely that "civilized" peoples would have found their way from Asia to South America by this route. Bradford further concluded that peoples came to America by other means in addition to the Bering Strait. $^{64}$

Bradford, like McCulloh, turned from empirical themes towards the mythological ones, supporting Atlantean Theory. It is surprising that systematic investigators, such as Bradford and McCulloh, endorsed theories with the least evidence in their favor after voicing skepticism about established empirical hypotheses. ${ }^{65}$

Bradford enumerated peoples who could have settled America from these speculative sources. His explanations did not emphasize any of these peoples as the Indians' direct ancestors. His hypothesis included all peoples of the ancient world as possible ancestors. Only then could a

\footnotetext{
${ }^{64}$ Alexander Bradford, American Antiquities and Researches. pp. 215, 216.

${ }^{65}$ Alexander Bradford, American Antiquities and Researches, pp. 216-232. Bradford supported the supposed existence of "Mu," the "lost continent" in the Pacific Ocean.
} 
scholar have decided among different theories according to degrees of probability. ${ }^{66}$ Bradford invoked many authoritative sources in forming his conclusions, but Humboldt was by far the most prominent. Bradford still considered the possibility of an ancient Indian origin and the derivation of northeastern Asian peoples, such as the Chukchis, from America:

... we find the Tchutski [sic] . . . may be clearly identified with the American family, as well by their languages as by their manners, customs, and appearance, and it is thought they are of American origin ... the resemblance in their customs to those of the Americans ... is common to many others of Siberia, and no argument can be drawn from that circumstance ... ${ }^{67}$

Most significantly the meaning of "Tartar" or "Tartaric" had changed dramatically by midnineteenth century. From a vague, comprehensive generic term for the vast majority of Asian peoples, including Chinese and Japanese, it developed into a precise terminology limited to Caucasoid peoples of western Asia. Whereas Scythians represented an amorphous group of people who ranged from southwestern Asia deep into Siberia, they became more geographically defined according to the revised terminology. Earlier scholars, including Humboldt, used the terms, "Tartaric" and "Mongolian" interchangeably to classify all the peoples of northeastern Asia. Humboldt had based his theory about the American Indians' derivation on the comprehensive generic "Tartaric" designation:

'The American race, ... has a striking resemblance to the Mongol nations, which include those formerly called Huns, Kulans, and Kahmucks' ... ${ }^{68}$

\footnotetext{
${ }^{66}$ Alexander Bradford, American Antiquities and Researches, pp. 239, 241. On p. 239, Bradford delineated these peoples: “. . . they are the Atlantides, the Phenicians [sic], and the Cartaginians, the Hebrews, Egyptians, Hindus, Chinese, Tartars, Malays, Polynesians, the Northmen and the Welsh; whilst some ... considered America as the most ancient of the continents, and the Indians as the real aborigines of the soil ...".

${ }^{67}$ Alexander Bradford, American Antiquities and Researches, pp. 281, 282.

${ }^{68}$ Alexander Bradford, American Antiquities and Researches, pp. 281.
} 
Bradford's revision restricted the term "Tartar" to Caucasoid peoples of western and central Asia. This separated them from the eastern and northeastern Asian peoples, whom he classified as Mongoloid. Bradford stated his rationale:

... in the utter commixture of the northern tribes, to use Tartar as a generic name would lead but to further confusion. The Tartars, as the term is now understood, belong to the Caucasian family ... The Mongolian physiognomy is widely different and is nearly allied to the American . . . there are some tribes in Siberia of a regular copper color . . ${ }^{69}$

His attempt to amalgamate many diverse peoples into a single race diluted the concept of American Indians as the "red race" derived from copper colored "red" northeastern Asian peoples. This distorted any theorizing, because Bradford remained undecided about peoples included in the definition of Mongolian. Scythians all derived from a Mongolian ancestry, yet his revised classification indicated a split of the Scythian peoples and territory between Mongolian and "Tartaric." His terminology precluded the possibility of Indian derivation from ancient Caucasian peoples featured in the speculative tradition. It provided impetus for Indian origin theories based on derivations from peoples included under the Mongolian classification, especially Malayans and Polynesians. ${ }^{70}$

The remainder of Bradford's work summarized his ideas. He relied heavily on outside sources, especially Humboldt, for comparisons of the Mexican, Muyscan, and Peruvian calendars with various Asian chronological systems. ${ }^{71}$ With assorted forms of evidence, Bradford compared artifacts, customs, and institutions of the American Indians with those of

\footnotetext{
${ }^{69}$ Alexander Bradford, American Antiquities and Researches, pp. 281.

${ }^{70}$ Alexander Bradford, American Antiquities and Researches, pp. 292, 293.

${ }^{71}$ Alexander Bradford, American Antiquities and Researches, pp. 324, 326 presented extracts from Humboldt's Views and Monuments. Bradford commented, "The illustrious Humboldt instituted a comparison between the Mexican symbols of the days, and the zodiacal [sic] signs employed in the astronomical systems of Eastern Asia . . . Bradford greatly detailed the comparisons of the astronomical origins.
} 
several Old World peoples. He drew heavily on Humboldt's Views and Monuments for these comparisons. $^{72}$

Bradford introduced a logistical twist on the Indians' derivation from the Mongols. He assumed that several Mongolian peoples had been civilized longer than the northeastern Asians of his day. His evidence indicated that the Siberian tribes had also once been more civilized. Earthworks and mural remains like the ones found in America existed in Siberia. The central Mongolian belief of Shamanism that prevailed in northeastern Asia closely resembled the beliefs of the American Indians. Bradford concluded from this that both had descended from the same previous "more civilized" people. ${ }^{73}$

Bradford contrasted and compared the Chinese with the American Indians from this context. Both had symbolic paintings and ancient writings. He then contrasted Malayans and Polynesians to find a connection with the American Indians. Malayans and Polynesians resembled each other closely in language, appearance and their institutions, and their supposed Mongolian ancestors. The Malayans who shared so many customs and practices with the American Indians populated the Pacific Islands. Bradford built a case for the feasibility of an eastward Malayan-Polynesian migration, because of the prevailing westerly winds in the Pacific Ocean at certain times during the year. Various Pacific Islands populated by Malayans lie close to the Americas. ${ }^{74}$

\footnotetext{
${ }^{72}$ Alexander Bradford, American Antiquities and Researches, pp. 365-378.

${ }^{73}$ Alexander Bradford, American Antiquities and Researches, pp. 397, 398: "It is said that the Tartar and the Mongol writings extant are of a date long subsequent to the time of Mohammed ... Be this as it may, in many parts of Siberia, there are characters and figures engraven or painted on stones and rocks ... Some of these remind us of the ancient inscriptions in America."

${ }^{74}$ Alexander Bradford, American Antiquities and Researches, pp. 410, 419. A comment about distance between the South Sea Islands and the South American coast finds the Easter islands only 1800 miles away.
} 
Bradford argued that the Mexicans and Peruvians resembled the peoples of the "cultivated" nations of East Asia, such as China and Japan, more than they did the nomadic Siberian tribes. He surmised that all belonged to the same race, but a cultural decline had occurred in both northeastern Asia and America. ${ }^{75}$ He denied the Indians' inherent unity in customs, appearance, and traditions as evidence of how they had diverged from their parent cultures. ${ }^{76} \mathrm{He}$ proposed that various tribes came from northeastern Asia:

... It is not to be denied that there are some tribes in North America which may have proceeded in modern times from Siberia ... ${ }^{77}$

Bradford claimed most of the Indian groups derived from the Malayans and their Polynesian descendants. He concluded that no perfect solution to the "problem" of Indian origins existed. ${ }^{78}$

Bradford's conclusions followed a trend that began during the period in which he wrote. He and several of his contemporaries supported the idea of a South Sea Island origin for South American Indians. Investigators continued to scrutinize a northeastern Asian derivation and migration across the Strait for North American Indians. Their detailed analyses did not support a single migration across the Strait. The Bering Strait Theory received increased exposure and analysis because of this. This guaranteed a secure niche for it in the scientific community among other origin theories. Bradford's researches also extensively used evidence from Humboldt, reinforcing Humboldt's continued role in the debate.

\footnotetext{
${ }^{75}$ Alexander Bradford, American Antiquities and Researches, pp. 431, 434. Paraphrased quote from pp. 431, 432.

${ }^{76}$ Alexander Bradford, American Antiquities and Researches, pp. 431-433.

${ }^{77}$ Alexander Bradford, American Antiquities and Researches, p. 432.

${ }^{78}$ Alexander Bradford, American Antiquities and Researches, pp. 433, 434: "When and by whom was America peopled? This interesting question, if it shall be ever solved, of course can only be answered in a general manner."
} 


\section{John McIntosh}

John McIntosh followed the trend set by Bradford and others, which supported separate origins for North and South American Indians. He published one of his works in the same year (1843) that Bradford published his American Antiquities and Researches. McIntosh published his other works in 1836 and 1859; the 1836 work under the surname of "Mackintosh." In The Origin of the North American Indians; with a Faithful Description of Their Manners and Customs, Both Civil and Military, Their Religions, Languages, Dress, and Ornaments (1843), McIntosh started with a Biblical account of creation. ${ }^{79} \mathrm{He}$ relied on eyewitness accounts from missionaries and travelers to provide the necessary information, because the Indians lacked a recorded history. McIntosh also drew from the accounts of ancient travelers. He believed that manners and customs authentically reflected the original relationship of two peoples. So, McIntosh provided a listing of similarities to support his hypotheses:

... we may fairly conclude that the Aborigines of this country must have derived their origin from these Asiatic tribes to whom they bear the greatest resemblance in language, religion, manners, habits and customs. 80

McIntosh theorized about Indian origins from Scriptural tenet that the Scythians, Tartars, and Mongolians all derived from Noah's descendant, Magog. Magog colonized all of the northern countries of Asia, from which America derived many of its inhabitants. ${ }^{81}$ Magog's descendants, the Scythians, populated Kamchatka and northern Siberia, which provided the closest access to America. McIntosh proposed that the North American Indians descended from the Scythians. ${ }^{82}$

\footnotetext{
${ }^{79}$ John McIntosh, The Origin of the North American Indians; with a Faithful Description of Their Manners and Customs, Both Civil and Military, Their Religions, Languages, Dress, and Ornaments, New York: Nafis and Cornish, 1843, pp. xxvii-xxxiii.

${ }^{80}$ John McIntosh, The Origin of the North American Indians, p. xi.

${ }^{81}$ John McIntosh, The Origin of the North American Indians, p. xxxiii: “ . . . it would appear that Tartary and Siberia were originally colonized or peopled by the Scythians, the posterity of Magog...”.
} 
McIntosh's theory raised questions about the origins of South American Indians, whom he believed had lived in North America before the arrival of migrants from northeastern Asia. McIntosh anticipated dilemmas about separate origin possibilities:

... But whether the South American Indians, and other tribes who must have had possession of North America, prior to the arrival of the present race, in as much as they were certainly more civilized, came from Tartary and Siberia in the north, is a question which we may, hereafter, have occasion to examine . . .83

He hypothesized that a comparison between the American Indians' characteristics and those of various Asiatic tribes would reveal the Indians' origins. ${ }^{84}$ McIntosh pointed out that several historians had introduced misconceptions about the Indians' religious rites, languages, and customs, which led to misrepresentation of their relationship to other peoples. He discredited theories the speculative tradition. He emphasized that the American Indians did not descend from the "Lost Tribes" of Israel, because the linguistic similarities between the Hebrews and the American Indians did not exist. ${ }^{85}$

McIntosh believed that linguistic comparisons supported an eastern Asian origin:

... were we even to allow for the affinity of languages in its fullest extent, the only legitimate inference would be that the languages of America are of Oriental origin, and consequently that America was peopled from Asia ...

\footnotetext{
${ }^{82}$ John McIntosh, The Origin of the North American Indians, p. xxxiii.

${ }^{83}$ John McIntosh, The Origin of the North American Indians, p. xxxiii.

${ }^{84}$ John McIntosh, The Origin of the North American Indians, p. xxxiii.

85 John McIntosh, The Origin of the North American Indians, pp. 76, 78: “. . . Some authors have contended that the lost tribes of Israel are the red men of North America . . . The distant relationship between these primitive languages of America is enough to overthrow this argument ...".

${ }^{86}$ John McIntosh, The Origin of the North American Indians, p. 78.
} 
He resorted to earlier writers, such as Barton. He found that the progenitors of all the American Indians from Cape Horn to Labrador, who shared similarities in complexion, language, and customs had migrated from the northeastern regions of Asia. ${ }^{87}$ He cited Brerewood on northeastern Asian origins for the Indians to reinforce his own suppositions on origins. ${ }^{88}$ McIntosh quoted Jefferson and James Cook in his assessment of a northeastern Asian origin for the North American Indians:

... the continents of Asia and America are separated by a streight [sic] only eighteen miles away, ... This short distance should account for the peopling of America from the northeast parts of Asia ... we may fairly conclude that America was peopled from the northeast parts of Asia . . .89

McIntosh supported this alternative theory, illustrating the controversy among investigators of the 1840s about separate origins for North and South American Indians, and the origins of the Mound Builders. He opposed Humboldt on domestic development of civilization in America: All of the American Indians derived from specific sources and arrived at a very early period. He claimed that different races had populated the Americas from the Old World with "more civilized" tribes preceding Indians' arrival in America. The Tartars, Siberians, and Kamschadales most resembled the American Indians. (McIntosh employed the previous classification scheme for Tartaric peoples.) McIntosh intertwined the existence of a "superior civilized" people with a northeastern Asian ancestry for the American Indians, eliciting a highly speculative conclusion: ... While the present Indians can be identified as the descendants of the Tartars or Siberians, and when it can be proved beyond a doubt that America was inhabited by a

\footnotetext{
${ }^{87}$ John McIntosh, The Origin of the North American Indians, p. 83.

${ }^{88}$ John McIntosh, The Origin of the North American Indians, p. 84, features quote from Brerewood on the northeastern Asian ancestry of the Indians.

${ }^{89}$ John McIntosh, The Origin of the North American Indians, p. 85 for quote. For Jefferson's theory see Thomas Jefferson's Notes on the State of Virginia, p. 101, cited in John McIntosh's Origin of the North American Indians, 1859 edition.
} 
more civilized race than the present, it may be fairly conjectured that the original and more civilized inhabitants were exterminated . . . by a Tartar invasion . . ${ }^{90}$

McIntosh referred to Du Ponceau's authority for linguistic comparisons. With these comparisons, McIntosh expressed his particular methodology by declaring a great disparity existed among the languages of the northeastern Asians who came. He thought nothing unusual that three seemingly unrelated "primitive" Indian languages came from northeastern Asia. ${ }^{91} \mathrm{He}$ also created a table of Asiatic and American languages. He then turned to religious beliefs and practices. McIntosh emphasized similarities in beliefs among the Tungusi, Coriaks, Kamschadales, and the North American Indians. He elaborated on ornaments, dress, customs, and warfare among the Siberians and the North American Indians. ${ }^{92}$

McIntosh's assessments on Indian origins and the arrival of "civilized" peoples before the Indians form a transition to the succeeding chapter in this dissertation on the Mound Builders. In summary, these conclusions apply to McIntosh's speculations: First, he reinforced key elements of the Bering Strait Theory, while contradicting others. Next, his focus on a northeastern Asian derivation for North American Indians fractionated the idea of one unified American Indian people. Third, his hypothesis about migration of a separate "civilized" people before the Indians obliterated a unified concept for North American Indians as one people. Fourth, he affirmed that the Indians' ancestors migrated during a prehistoric period. He added that the Americas had formed at the same time as did the other continents, which contradicted the suppositions of the

\footnotetext{
${ }^{90}$ John McIntosh, The Origin of the North American Indians, pp. 89, 90 of the 1859 edition.

${ }^{91}$ John McIntosh, The Origin of the North American Indians, p. 95. Quote from Humboldt paraphrased.

92 John McIntosh, The Origin of the North American Indians, pp. 90-147. Conversely, he cited an absence of proof to verify cannibalism among them. McIntosh composed his table of languages from the earlier works, such as Barton's.
} 
"degeneracy" advocates. Fifth, McIntosh relied on Humboldt as an authoritative reference for his diverse hypotheses, in the pattern of other researchers from this period (1830s-1840s).

Throughout his analyses McIntosh discredited theories from the speculative tradition as unscientific and without foundation. He especially attacked the Indians' derivation from the "Lost Tribes" of Israel. Like Bradford, he reduced the number of theories for scientific investigation. This opened up the field of scientific inquiry, so empirical theories could evolve and gain acceptance by the scientific community. He reiterated others as "proofs" of the Bering Strait Theory. McIntosh adjusted his conclusions to reduce the severity of his arguments against it. ${ }^{93}$ He left the debate about the previously existing "civilized" peoples for other types of researchers to solve.

McIntosh turned his attention to endorsing a separate derivation for South American Indians. He proposed transoceanic crossings, then revised his position and allowed for a single derivation for both North and South American Indians. He turned to British historian Dr. William Robertson (1740-1803) for source material and hypotheses to support this revision. Robertson's work had evoked sharp criticism and controversy for its omissions and inaccuracies, but McIntosh cited him anyway. Robertson's pronouncements were of dubious value for McIntosh. ${ }^{94}$ With endorsement from Robertson, McIntosh more clearly patterned his premises after Humboldt's: that American Indian civilizations developed domestically, instead of being affected by outside influences, as other investigators had earlier surmised.

\footnotetext{
${ }^{93}$ John McIntosh, The Origin of the North American Indians, pp. 305, 306. McIntosh observed the plethora of origin theories prevalent in his day: “. . Amid this uncertainty and obscurity which hang over the early history of the American Indians, . . . Almost all of the nations of the earth have been ransacked to account for the peopling of the new world ...".

${ }^{94}$ Leslie Stephen and Sidney Lee, "Robertson, William," The Dictionary of National Biography Founded in 1882 by George Smith, Vol. 16, Oxford: Oxford University Press, pp. 1311-1316. Also see John McIntosh, The Origin of the North American Indians, pp. 309, 310.
} 


\section{Section 6}

\section{Summary and Conclusion}

Resistance to Bering Strait Theory increased among researchers toward the mid-nineteenth century. Mere exposure of the theory and repeated attacks on it and elimination of various speculative theories inadvertently strengthened its position in the scientific community. This chapter concentrated on serious investigators, medical doctors or lawyers, who drew on others' field research. They examined other theorists' hypotheses and conclusions, then constructed their own theories. Influenced by the new research fields, they offered counter proposals to Humboldt's ideas. A few dismissed Humboldt's Bering Strait Theory altogether, whereas others proposed multiple migrations. They affirmed North American Indians' origins from northeastern Asian peoples, while proposing a variety of derivations for South American Indians. This appeared as a strong, growing trend among researchers throughout the 1840's.

In these studies, these researchers offered proposals and counterproposals, based on the works of earlier and contemporary authorities. This was the way in which Humboldt continued his presence in the origins debate. Throughout this chapter Humboldt represents a key authoritative reference for these researchers' works. His observations and ideas form the continuous thread that connected otherwise seemingly unrelated. Authors cited him for evidence, hypotheses, and conclusions. Their agreement or lack of it was not the decisive factor for his predominant influence and his roles in the origins debate. Humboldt's role increasingly became indirect, but these researchers kept Humboldt in the debate into the 1830s and 1840s through their constant references to him.

Humboldt's Views and Monuments had secured a niche for at least the northeastern-Asian origin hypothesis, which undoubtedly added to the increased tension and controversy 
surrounding other issues of the debate. References to Humboldt by philologists, theorists of the speculative tradition, and "gentlemen" scholar researchers have all demonstrated the scope of Humboldt's expertise and knowledge in a wide variety of disciplines. This chapter reiterates the underlying theme of the dissertation: Humboldt played a vital role in the origins debate during the first half of the nineteenth- century through influences manifested in multiple ways. This affected the very outcome of the debate itself. 


\section{CHAPTER FIVE}

\section{Mound Builders and the Origins Debate}

\section{Section 1}

\section{Differentiation in Research}

Several investigators combined research on origins for American Indians and for Mound Builders. With today's more inclusive terminology and assessments, the controversy might have taken on less of an emphasis. Present terminology refers to "indigenous Americans," "First Americans," or "Native Americans," ("First Nations" in Canada), which would have applied to the Mound Builders and American Indians, no matter which one came first.

The theorists discussed in this chapter directed focus away from Indian origins and Bering Strait Theory to hypotheses about the Mound Builders. A new group of researchers emphasized the Mound Builders as a separate people from the Indians. Research efforts fractionated about the priority of topic for investigation. The controversy about the Mound Builders had been developing along with the origins debate since the latter part of the eighteenth century. It provoked several positive results: First, it brought the whole origins issue to a climax by midcentury. Second, it drew new disciplines into the investigations, which furthered the development of the new disciplines, especially archaeology and ethnology (later anthropology), while bolstering older disciplines, such as philology. Third, the investigations and resultant theories about the Mound Builders kept Bering Strait Theory in the forefront of scientific interest. Fourth, all of the preceding points indicated an impending paradigm shift which guaranteed a predominant place for Bering Strait Theory and the firm establishment of the sciences 
researching origins.

Facets of the Controversy about the Mound Builders' origins surfaced before 1800, with the discovery of earthworks or "tumuli" (burial mounds), fortifications, and artifacts in eastern America. These finds aroused the curiosity of speculators and investigators alike. Jefferson helped to sow the seeds of the "Mound Controversy" with his investigation of burial mounds near his estate. He inquired how the Indians buried their dead. In Notes on the State of Virginia (1797), he described and speculated about what he had found. He later regretted his imaginative and tentative conclusions. ${ }^{1}$ The remains further sparked his interest in Indians and their origins. ${ }^{2}$ Jefferson related the remains to Indian origins, whereas other investigators denied any connection between the Indians and the Mound Builders. Those investigators hypothesized that a more extensive and "civilized" people had built the mounds before the Indians' arrival in the Americas. $^{3}$

Commentators often favored positions antagonistic to one another. Caleb Atwater (discussed later) claimed that the Mound Builders represented an intermediary stage of "civilization" between that of the First Americans and the European-Americans of his day. Others argued about the occurrence of a cultural decline among the American Indians, with the

\footnotetext{
${ }^{1}$ Thomas Jefferson, Notes on the State of Virginia, published for the Institute Of Early American History and Culture at Williamsburg; Chapel Hill, N.C.: University of North Carolina Press, 1955, pp. 98-100. Stuart J. Fiedel, Prehistory of the Americas, Cambridge: Cambridge University Press, 1973, p. 48: Jefferson's mound excavations marked the first scientific archaeological research project in the Americas.

${ }^{2}$ Thomas Jefferson, Notes on the State of Virginia, Chapel Hill, N.C. University of North Carolina Press, 1955 , pp. 90-100, 281.

${ }^{3}$ Bernard W. Sheehan, Seeds of Extinction, pp. 49, 50: Jefferson cautioned investigators of the native remains to record precise descriptions of them, and that a person adopting a theory tended to see only the evidence which enhanced it. Jeremy Belknap (1744-1798) denied any relationship between American Indians and Mound Builders: "The Form and materials of these works seem to indicate the existence of a race of men in a stage of improvement superior to those natives of whom we or our fathers have had any knowledge ...".
} 
Mound Builders as the ancestors of the Indians. ${ }^{4}$ Several earlier scholars had thought along similar lines. Barton, New Views of the Origin of the Tribes and Nations of America (1797), declared that Indian tribal life showed signs of past greatness, which deteriorated as the Indians broke up into various tribal units. He speculated that the American Indians of his time related to the Aztecs. The Aztecs, he thought, had built the various earthworks in eastern America on their southward migration to Mexico. Authors Hugh Williamson and Benjamin Rush endorsed this position, but Jefferson found scanty evidence in its favor.

\section{Section 2}

\section{Organized Investigations}

William Bartram (1739-1823), traveler and naturalist, began his explorations in 17651766 with his father, botanist John Bartram, on an expedition up the St. John's River. Botanist John Fothergill financed William's expeditions during the years 1773-1777 in the southeastern United States. William Bartram joined the American Philosophical Society in 1786. In 1791 Bartram published his monumental work, Travels through North and South Carolina, Georgia, East and West Florida, the Cherokee Country, the Extensive Territories of the Musculges, or Creek Confederacy, and the Country of the Choctaws. Various authors exploited this book and translated into several European languages. Bartram provided the drawings for Barton's Elements of Botany (1803). ${ }^{5}$ In Travels through North and South Carolina, Georgia, East and West

\footnotetext{
${ }^{4}$ Bernard Sheehan, Seeds of Extinction, pp. 49, 50.

5 James Grant Wilson and John Fiske, "Bartram, William," Appleton's Cyclopaedia of American Biography Vol. 1, New York: D. Appleton and Company, 1888, p. 189.
} 
Florida (Philadelphia, 1791; London, 1792), Bartram wrote about his first-hand experiences in the Southeast, as he studied Indian languages and customs. His observations about the Indians in that region popularized the mystery surrounding the mounds there. ${ }^{6}$ He believed that a separate race of Mound Builders who preceded the American Indians had built the structures he observed. ${ }^{7}$ Bartram's speculating about the mound structures sparked the controversy about the origins and nature of the builders, that later influenced the shape and course of the origins debate. A consolidated edition of Bartram's writings provided information about ancient fields above the lowlands of the Oakmulge River, where visible traces of an ancient town with artificial mounts, terraces, and squares remained. ${ }^{8}$ Bartram conditionally credited the Creek Indians with settling this town after their emigration from beyond the Mississippi. He surmised that various tribes attacked the Creeks during their trek eastward, so they built the fortification to survive. ${ }^{9}$ He described one mound in detail, attributing it to Indian derivation rather than to that of a prior "superior" civilization. ${ }^{10}$ Bartram described another mound on an island which had Indian artifacts spread around it. ${ }^{11}$ This provided further evidence for American Indian construction of

\footnotetext{
${ }^{6}$ N. Bryllion Fagin, William Bartram, Interpreter of the American Landscape, Baltimore: The John Hopkins Press; London: Humphrey Milford oxford University Press, 1933, pp. 56, 57, 58.

${ }^{7}$ N. Bryllion Fagin, William Bartram, Interpreter of the American Landscape, p. 58: Bartram supposedly was the first to conceive the theory about a "superior" race of Mound Builders.

${ }^{8}$ William Bartram, Travels and Other Writings, Travels through North and South Carolina, Georgia, East and West Florida, Miscellaneous Writings, part 1, chap. 5, New York: Library of America, p. 67.

${ }^{9}$ William Bartram, Travels and Other Writings, p. 67.

${ }^{10}$ William Bartram, Travels and Other Writings, part 2, chap. 4, p. 100: "At about fifty yards from the landing place, stands a magnificent Indian mount ... But what greatly contributed towards completing the magnificence of the scene was a noble Indian highway, which led from the great mound ...".

${ }^{11}$ William Bartram's Travels and Other Writings part 2, chap. 4, p. 103: " . . This island appears to have been well inhabited, as is very evident, from the quantities of fragments of Indian earthenware, bones of animals, and other remains ... all over the island ...".
} 
the various mounds and artifacts Bartram observed on his journey. Bartram finally developed a still stronger case for this conclusion:

.. near the path was a large artificial mound of earth . . . supposed to be the work of the ancient Floridians, or Yamasees; with other traces of an Indian town . . ${ }^{12}$

In his Miscellaneous Writings, Bartram reversed his position that a separate race of Mound Builders who preceded the native Americans existed. Not surprisingly this sparked a controversy about the mounds' origins with oscillation between two opposite viewpoints by an early investigator, such as Bartram. This reversal on origins deviated from discussion of Indian migrations from the west by the Cherokees, Natchez, Chickasaws, Choctaws, and Creeks, because Bartram dismissed the possibility of a Cherokee origin for those mounds and artifacts. He confirmed the two previous points, saying:

. . it is certain they [Cherokees] were not the people who constructed them, as they own themselves, nor were they built by people from whom they took possession of the country . $^{13}$

A more recent investigator, John Reed Swanton (1783-1958), claimed that the theory about a separate race of Mound Builders originated with Bartram. Swanton explained the paradox of Bartram's contradictory positions resulted from failure to distinguish between the dual persona of Bartram, the serious, meticulous scientific explorer, and the sentimental eighteenth century amateur philosopher. Bartram's theory continued to flourish, while his most important evidence contradicting it was ignored. ${ }^{14}$

Thomas Jefferson commissioned one of the pioneer investigators of moundsites, Henry

\footnotetext{
${ }^{12}$ William Bartram, Travels and other Writings, part 2, chap. 6, p. 165.

${ }^{13}$ William Bartram, "Observations on the Creek and Cherokee Indians," Travels and Other Writings, pp. 529, 530.

${ }^{14}$ N. Bryllion Fagin, William Bartram, Interpreter of the American Landscape, pp. 58, 59 for Swanton's observations.
} 
Marie Brackenridge (1786-1871). Brackenridge conveyed the results of his investigations and conjectures about the mounds' possible origins to Jefferson. His biography does not indicate why Jefferson chose him for this particular assignment. Perhaps Jefferson selected Brackenridge to further his own research. He entertained a variety of interests, loved frontier life, and proclaimed a liberal political philosophy, similar to Jefferson and his associates. Between 1810 and 1814, Brackenridge investigated earthworks and artifacts in Louisiana and Missouri. ${ }^{15}$

In his work, "On the Population and Tumuli of the Aborigines of North America" (1813), Brackenridge updated Jefferson about his investigations. ${ }^{16}$ Brackenridge favored an "advanced" culture, race, and set of origins for the Mound Builders distinct from those of the American Indians. ${ }^{17}$ Brackenridge hedged about the possibility the Indians might have constructed the mounds:

The first and more ancient period is marked by these extraordinary tumuli or mounds. I have reason to believe their antiquity is very great. The oldest Indians have no traditions as to their authors, or the purposes for which they were originally intended ... ${ }^{18}$

Brackenridge supported a hypothesis that stated a "superior" agriculturally based civilization had existed in the Mississippi Valley; one as advanced as the Mexican civilizations. ${ }^{19}$ He relied on Humboldt's evidence to support his hypotheses. This reflected Humboldt's influence on

\footnotetext{
${ }^{15}$ Dumas Malone, "Brackenridge, Henry Marie," Dictionary of American Biography, Vol. 2, New York: Scribner's Sons, 1929, 1930, p. 543.

${ }^{16}$ Henry Marie Brackenridge, "On the Population and Tumuli of the Aborigines of America," Transactions of the American Philosophical Society, Vol. 1, Philadelphia: American Philosophical Society, 1818, p. 151: " . . Since the year $1810 \ldots$. I have visited almost everything of this kind worthy of note on the Ohio and Mississippi; ... something like hypothesis, has taken place of the vague wanderings of fancy ...".

${ }^{17}$ Henry Marie Brackenridge, "On the Population and Tumuli of the Aborigines of North America," p. 153: "In the valley of the Mississippi, there are discovered traces of two distinct races of people, ... one more ancient than the other. The traces of the last are the most numerous, but mark a population less advanced in civilization."

${ }^{18}$ Henry Marie Brackenridge, "On the Population and Tumuli of the Aborigines of America," p. 154.

${ }^{19}$ Henry Marie Brackenridge, "On the Population and Tumuli of the Aborigines of America," p. 152.
} 
earthworks investigators. Brackenridge speculated that a great civilization had thrived wherever earthworks, including mounds, existed:

... The most numerous ... of these remains are found precisely in the part of the country where the traces of a numerous population might be ...

This reflected the manner in which Humboldt influenced two separate, but parallel lines of investigation in the origins debate. Humboldt thus played a secondary role in the debate apart from his primary one in the development and acceptance of Bering Strait Theory.

Brackenridge verified his supposition about primary existing civilizations by comparisons with earthworks in Mexico. He once again cited Humboldt regarding the pyramids constructed by the Mexicans. ${ }^{21}$ Thereby, Brackenridge concluded that a "highly advanced" civilization of Mound Builders developed in the Mississippi Valley. ${ }^{22} \mathrm{He}$ attributed the mounds' construction to the Toltecs or the Olmecs, whom he thought inhabited the Mississippi Valley. ${ }^{23}$ Finally, Brackenridge speculated about the obscurity surrounding the origins and fate of America's inhabitants:

Who will pretend to speak with certainty as to the antiquity of America - the races of men who have flourished and disappeared - of the thousand revolutions which like other parts of the globe, it has undergone? ... ${ }^{24}$

\footnotetext{
${ }^{20}$ Henry Marie Brackenridge, "On the Population and Tumuli of the Aborigines of America," p. 154: Brackenridge indicated these locations as extending from the mouth of the Ohio to the Illinois River and the western side from the St. Frances to the Missouri River.

${ }^{21}$ Henry Marie Brackenridge, "On the Population and Tumuli of the Aborigines of America," p. 156: " . . .they [the tumuli] resemble the teocalli [Mexican pyramidal structures] . . . It is doubted by Humboldt, whether advantage had not been taken of some natural rise, in the formation of the pyramid of Cholula; with respect to the mound of Chohokia, there can be no doubt, ...".

${ }^{22}$ Henry Marie Brackenridge, "On the Population and Tumuli of the Aborigines of America," p. 158.

${ }^{23}$ Henry Marie Brackenridge, "On the Population and Tumuli of the Aborigines of America," p. 158.

${ }^{24}$ Henry Marie Brackenridge, "On the Population and Tumuli of the Aborigines of America," p. 158.
} 
Brackenridge deferred to Jefferson's expertise downplaying his own scientific significance. ${ }^{25}$ Brackenridge proved himself as a serious empirical investigator who made a valuable contribution to science, though a few of his suppositions reflected imaginative speculation.

Caleb Atwater (1778-1867) pursued archaeological investigations after moving west to Circleville, Ohio to practice law. He wrote a treatise similar to Brackenridge's in 1820 for the American Antiquarian Society, "Descriptions of the Antiquities Discovered in the State of Ohio and Other Western States ...". In 1829 Andrew Jackson assigned him to negotiate treaties with the Winnebago and other Indian tribes near Prairie du Chien, Wisconsin. Atwater published an account of the venture under the title, Remarks Made on a Tour to Prairie du Chien: Thence to Washington City, in 1829 (1831). He combined the two treatises into a composite volume, The Writings of Caleb Atwater (1833). Atwater also published the first history of Ohio in $1838 .{ }^{26}$

Atwater limited his 1820 work to suppositions about specific mounds located in the Ohio region. For his origin theory about earthworks and their builders, he dismissed Old World resources as responsible for construction of these structures:

Our antiquities have been noticed by a great number of travellers, few of whom have ever seen one ... They have frequently given to the world such crude and indigested [sic] statements, ... They find, too, articles scattered about and blended together, which belonged not only to different nations, but to different areas of time remote from each other - they are lost in a labyrinth of doubt. ... ${ }^{27}$

Atwater established the premises of his theory by creating three categories of remains: 1) those of

\footnotetext{
${ }^{25}$ Henry Marie Brackenridge, "On the Population and Tumuli of the Aborigines of America," p. 159: Brackenridge did not believe his theories influenced scientists as much as did Jefferson's.

${ }^{26}$ Allen Johnson, "Atwater, Caleb," Dictionary of American Biography, Vol. 1, New York: Charles Scribner's Sons, 1927-1936, pp. 415, 416.

${ }^{27}$ Caleb Atwater, "Descriptions of the Antiquities Discovered in the State of Ohio and Other Western States, Communicated to the President of the American Antiquarian Society," American Antiquarian Society, Transactions and Collections, Circleville, Ohio: American Antiquarian Society of Ohio, 1820, pp. 109, 110.
} 
the Indians, 2) remains from European descendants, and 3) unidentified remnants of a people who had built America's forts and tumuli (mound structures). ${ }^{28}$ He assessed the remains of the North American Indians as "rudimentary," which shaped his speculations about their origins. He reasoned that if the Indians had crossed Bering Strait, they would have migrated down the chain of Northwestern American lakes with their sea outlets. He believed this explained the higher Indian population density of the northern versus the southern regions of the United States and the eastern as opposed to the western. ${ }^{29}$

Atwater concluded that only European artifacts exhibited alphabetical inscriptions and did not date back before the arrival of Columbus. ${ }^{30}$ With the third class of artifacts, Atwater speculated more precisely about the Mound Builders' origins:

... [The] people who erected our ancient forts and tumuli ... which owe their origin to a people more civilized than our Indians, but far less so than Europeans . . . Coming from Asia, were they driven back by the ancestors of the Indians? . .

Atwater considered the possibility of a northeastern Asian origin for the Mound Builders, as he cited world-wide examples of earthworks resembling those in America. ${ }^{32}$

He elaborated further on earthworks in Ohio reflecting back on the puzzle about the Mound Builders' fate, "What finally became of this people? and, Where are their Descendants now?" ${ }^{33}$ Atwater answered these questions with theories concerning the origins of the Mexican

\footnotetext{
${ }^{28}$ Caleb Atwater, "Descriptions of the Antiquities discovered in the State of Ohio and Other Western States," pp. 111-121.

${ }^{29}$ Caleb Atwater, "Description of the Antiquities Discovered in the State of Ohio and Other Western States," p. 113. Rudimentary items meant stone knives, axes, pestles, and arrowheads.

${ }^{30}$ Caleb Atwater, "Descriptions of the Antiquities Discovered in the State of Ohio and Other Western States," pp. 114-120.

${ }^{31}$ Caleb Atwater, "Descriptions of the Antiquities Discovered in the State of Ohio and Other Western States," pp. 120-122.

${ }^{32}$ Caleb Atwater, "Descriptions of the Antiquities Discovered in the State of Ohio and Other Western States," pp. 121, 122: "These ancient works . . . are spread over an immense extent of the country, in Europe and the northern parts of Asia ... In Tartary they abound in all of the steppes ...".

${ }^{33}$ Caleb Atwater, "Descriptions of the Antiquities Discovered in the State of Ohio and Other Western States," p. 244.
} 
and Peruvian civilizations. He believed that the Mound Builders may have actually been the Mexicans who later migrated southward into Mexico. This belief came from the similarities he perceived between Mexican and North American earthworks. Atwater referred to Humboldt's expertise in this area, which indicated Humboldt's part in the Controversy. ${ }^{34} \mathrm{He}$ drew his comparison of the respective earthworks from Mexico and North America from Humboldt's Views and Monuments. ${ }^{35}$

\section{Section 3}

\section{McCulloh and Priest on Mound Builders' Origins}

In this section the focus turns briefly to perspectives of avocational scholars, James $\mathrm{H}$.

McCulloh and Josiah Priest. Both struggled with the issues of North American earthworks.

McCulloh's conflicting views about Indian origins versus the Mound Builders' appeared in the appendix of his 1829 work, Researches, Philosophical and Antiquarian, Concerning the

Aboriginal History of America. Though Atwater had published the first collective account about earthworks, his investigations had not extended beyond Ohio. ${ }^{36}$

McCulloh described and compared earthworks in other states than Ohio in detail. His evidence supported prevailing hypotheses about the Mound Builders' derivation, several of which had developed over two or three decades. McCulloh fell short of formulating theories about the

\footnotetext{
${ }^{34}$ Caleb Atwater, "Descriptions of Antiquities Discovered in the State of Ohio and Other Western States," pp. 244, 245: "Our ancient works continue all the way into Mexico, ... preserving the same forms, and appear to have been put to the same uses ... These sacred places in Mexico were called 'Teocalli'. The 'Teocalli' are attributed by the Mexican, to the Aztecks [sic] . . Teocalli, Humboldt says, is derived from the name of one of the gods, to which they were dedicated."

${ }^{35}$ Caleb Atwater, "Descriptions of Antiquities Discovered in the State of Ohio and Other Western States," p. 257: ". . . the correspondence which exists between the Teocalli, of the Mexicans, and the tumuli of the North Americans. The resemblance ... is supposed to furnish evidence they are the work of the same race of people ... and their increased population as they progressed from the north to the south, ..." Excerpts from Humboldt's Views and Monuments formed the remainder of the appendix beginning with pp. 251-265 and beyond.

${ }^{36}$ James H. McCulloh, Researches, Philosophical and Antiquarian, Concerning the Aboriginal History of America, Baltimore: Fielding Lucas, Jr. 1829, p. 502.
} 
Mound Builders. He began his appendix on the earthworks and artifacts with declarations derived from his worldview. He stated that a concentrated population of members from a "superior" race preceding the American Indians lived in the areas where the "rude monuments" were found. He reiterated the widely held opinion that the Indians had not built these magnificent works. The general consensus held that diverse peoples of Asiatic or European descent settled in the respective sections of the United States where investigators had discovered the earthworks and artifacts.

McCulloh introduced his perspective, but also claimed that few people were qualified to formulate a hypothesis on the subject. He maintained that others had created imprecise theories based on one or two earth works. ${ }^{37}$ He upheld his position about a separate race of Mound Builders:

. . consider us as opposed to this general theory, and to understand the observations we shall make to be directed against such an opinion. ..". ${ }^{38}$

McCulloh extrapolated from the accounts about fortifications and their uses to reinforce his argument against a separate race of Mound Builders:

...the savages of America almost universally protected these villages by a strong palisade ... The execution of the work ... is only indicative of rude society . . no one can ascribe these structures of a people possessing any knowledge of arts, or an economy anywise superior to the general instructions of the American Indians . . .".39

The second investigator, Josiah Priest (1790-1850), known for his separate origin theories for

\footnotetext{
${ }^{37}$ James H. McCulloh, Researches, Philosophical and Antiquarian Concerning the Aboriginal History of America, p. 511 "... We shall not take the trouble to disprove the more extravagant theories of some writers on these antiquities..."

${ }^{38}$ James H. McCulloh, Researches, Philosophical and Antiquarian Concerning the Aboriginal History of America, p. 511.

${ }^{39}$ James H. McCulloh, Researches, Philosophical and Antiquarian, Concerning the Aboriginal History of America, pp. 511, 512.
} 
North and South American Indians, unabashedly proclaimed his theory about a separate race of Mound Builders preceding the American Indians in American Antiquities, and Discoveries in the West ... (1833). ${ }^{40}$ The work indicated that Priest had explored alternative origin possibilities for various earthworks in America and abroad with different derivations for each. He included suppositions for construction of American earthworks by peoples, as diverse as the Egyptians, Romans, and Hindus. Priest proceeded with his speculations about a separate origin for the Mound Builders in an unorthodox manner. He argued first for a separate derivation for one Indian tribe, the Osages, because they also built mounds:

But, although the Osage Indians have so recently thrown up one such mound, yet this does not prove them to be of American Indian origin . . 41

The Osages had constructed one of the largest mounds in the United States in honor of a deceased chief. This reinforced the original purpose for the mounds as burial places or memorials to the dead. It helped to refute the proposal that a "more civilized" people, other than the American Indians, had built the mounds. Priest proposed a connection that linked the Osages with a prior "civilized" race:

...the Osage tribe originally descended from more ancient progenitors, prior to the intrusions of the late Indians from Asia ...

Priest expounded on his "other origin" theory for the Osage Indians. He believed that the American inhabitants prior to the Indians arrived directly from China across the Pacific, using the

\footnotetext{
${ }^{40}$ James Grant Wilson and John Fiske, "Priest, Josiah," Cyclopaedia of American Biography, Vol. 4, New York: D. Appleton and Company, 1888, p. 20: Priest was a harness maker by trade. He had little formal education, but published several books including American Antiquities.

${ }^{41}$ Josiah Priest, American Antiquities, and Discoveries in the West: Being an Exhibition of the Evidence that an Ancient Population of Partially Civilized Nations, Differing Entirely from Those of the Present Indians, Peopled America, many Centuries before Its Discovery by Columbus, Albany: Hoffman and White, 1833, p. 51.

${ }^{42}$ Josiah Priest, American Antiquities, and Discoveries in the West, p. 51: By this statement Priest weakened the previous promise about the existence of a separate "more civilized" people.
} 
Pacific Islands as stepping stones to cross instead of Bering Strait. His estimate surmised that emigrants came to South America immediately after the Deluge when the continents still remained connected. ${ }^{43}$ Subsequently, the Mound builders emigrated from Europe, China, and Africa after the continents had separated. ${ }^{44}$ Priest acknowledged that Mound Builders might have come from northeastern Asia after all. For his evidence he drew support from primary sources, particularly travel accounts. ${ }^{45}$ Priest concluded that the Indians' origins differed from those of the Mound Builders. The northeastern Asian Tartars and the North American Indians resembled one another, but neither shared any similarities with the South American Indians. ${ }^{46}$

Priest strayed far afield to build a case for Indian derivation from peoples other than the Scythians, especially from the Ten Lost Tribes of Israel. He provided renewed impetus for beliefs that other investigators had already disregarded, such as Atlantis origin theory. Priest primarily wanted to provide evidence for a people who supposedly had existed before the Indians:

We shall now attend more particularly to the evidences of an ancient population in this country, anterior to that of the present race of Indians, afforded in the discovery of Forts, Mounds, Tumuli, and their contents ... ${ }^{47}$

Priest provided descriptions of earthworks found in this country and abroad. He

\footnotetext{
${ }^{43}$ Josiah Priest, American Antiquities, and Discoveries in the West, p. 50.

${ }^{44}$ Josiah Priest, American Antiquities and Discoveries in the West, p. 53.

45 Josiah Priest, American Antiquities, and Discoveries in the West, p. 50: From Travels of George Clarke (16761769) it appears, ancient works existed to this day, in some parts of Asia, similar to those of North America ... so nearly alike, that there can be no hesitation in ascribing them to the same races, in Europe, Asia, Africa, and America ...".

${ }^{46}$ Josiah Priest, American Antiquities and Discoveries in the West, p. 55 " . . . there are others [reasons] for believing our aborigines of North America were descended from the ancient Scythians, and came to this country from the eastern part of Asia ..."

${ }^{47}$ Josiah Priest, American Antiquities and Discoveries in the West, pp. 83, 84.
} 
exaggerated population estimates for these sites along with sophisticated implements and structures of this hypothetical superior civilization. He cited Brackenridge when he speculated about comparison of population density with that of ancient civilizations in Egypt and Mesopotamia. $^{48}$

Priest relied on Humboldt's support in comparison of the Mound Builders' sophistication with that of Peruvian and Mexican civilizations. He cited Humboldt's estimates about the level of Inca civilization measured against European standards:

.. . Baron Humboldt informs us, in his Researches in South America that when he viewed the enormous masses of stone ... employed in constructing the ancient high road of the Incas, that he began to doubt whether the Peruvians were not acquainted with other tools than hatchets made of flint and stone ... such as it is known the early nations of Asia made use of ... ${ }^{49}$

He used Humboldt as an authoritative source, but radically departed from the view point Humboldt had established. Priest's hypotheses on Indian origins versus that of the Mound Builders left room for speculation with concrete supporting evidence. It proved Humboldt's findings and suppositions carried considerable weight, even with investigators such as Priest. Priest relied heavily on information from Humboldt about the migration from points north to support his own ideas about their migrations. ${ }^{50}$ He nearly plagiarized from Humboldt's writing in the way he borrowed almost verbatim the entire account their journeys from the two volumes of Views and Monuments. ${ }^{51}$ Priest related the account of the Aztec migration from Atzlan to show

\footnotetext{
${ }^{48}$ Josiah Priest, American Antiquities, and Discoveries in the West, pp. 184, 185. Brackenridge quoted earlier in the chapter.

${ }^{49}$ Josiah Priest, American Antiquities, and Discoveries in the West, p. 185.

${ }^{50}$ Josiah Priest, American Antiquities and Discoveries in the West, p. 189.

${ }^{51}$ Marie Pratt, Imperial Eyes and Transculturation in America, provided the abbreviated combined title for Humboldt's two volume work.
} 
that the country, provinces, or districts cited in their journals, must have referred to the countryside of Ohio, Illinois, and Mississippi. These lay near $42^{\circ}$ north latitude cited by Humboldt for Atzlan.

Priest finally examined various possibilities from Old World derivations. He rejected European naturalists' presumptions that humans in western America significantly differed from humankind in eastern Asia. He continually referred to Humboldt throughout this analysis. This enabled Humboldt to play a major role in Priest's researches and speculations, keeping Humboldt as a key player in the debate into the 1830's and beyond. Priest culminated his efforts with citations from other sources for his remaining accounts, about European colonists who had supposedly settled in America before the arrival of Columbus. ${ }^{52}$

\section{Section 4}

\section{The Phrenologists Samuel Morton}

Of those who investigated Mound Builder origins, phrenologists comprised a new group of investigators with innovative techniques. Mound sites provided an almost endless supply of human skulls for examination. Phrenologists performed comparative analyses of these skulls to assess the degree of racial evolution of the skulls' owners. These examinations frequently resulted in skewed data that established far-reaching racial implications for the Indians. ${ }^{53}$ Phrenologists played a crucial role in assessing the origins of the Mound Builders European

\footnotetext{
52 Josiah Priest, American Antiquities, and Discoveries in the West, pp. 192-337.

${ }^{53}$ Robert E. Bieder, Science Encounters the Indian, 1820-1880. The Early Years of American Ethnology, Norman and London: University of Oklahoma Press, 1986, p. 59: Bieder states phrenologists believed the brain contained the mind, so every race manifested its cultural characteristics because of the cranium's shape. A "typical" or "national" cranium represented each race.
} 
origin peoples. $^{54}$

Samuel George Morton (1799-1851) did not begin his career as a phrenologist, but later achieved the greatest fame among them. His mother's physicians introduced him to a medical career after completion of his formal Quaker education. Morton apprenticed with Dr. Joseph Parrish of Philadelphia, graduating at the University of Pennsylvania in 1820, joining the Philadelphia Academy of Natural Sciences. Morton studied in Europe, where he obtained his M.D. in $1823 .{ }^{55}$ At Edinburgh University he became acquainted with phrenologists, and later met Franz Joseph Gall, phrenology's founder in Paris. Morton's interest in phrenology at first did not influence his desire to collect skulls for comparative studies. Skull collecting introduced him to the study of ethnology and embellished him with the sobriquet, "father of American physical anthropology." 56

Morton's papers reflected his varied interests in medicine, geology, vertebral paleontology, and zoology. He earned a reputable position with the scientific community through his publications during the years 1829 through 1836, especially his work, Human Anatomy. His primary research interest focused on comparative studies of human skulls. Careful examination of his collection led to publication of two technical works, Crania Americana (1839) and Crania Aegyptica. His studies in anthropology enabled him to endorse a multiple origin theory for humankind. ${ }^{57}$ The newly formed discipline of phrenology needed respectability, and Morton's

\footnotetext{
${ }^{54}$ Robert E. Bieder, Science Encounters the Indian, 1820-1880, pp. 59-69.

${ }^{55}$ James Grant Wilson and John Fiske, "Morton, Samuel George," Appleton's Cyclopaedia of American Biography, Vol. 4, New York: D. Appleton and Company, 1888, p. 28.

${ }^{56}$ Robert E. Bieder, Science Encounters the Indian, 1820-1880, p. 60.

${ }^{57}$ Dumas Malone, "Morton Samuel George," Dictionary of American Biography, Vol. 7, New York: Charles Scribner's Sons, 1934, pp. 265, 266.
} 
reputation helped to achieve it. Medical journals published phrenological findings, which further enhanced its respectability. ${ }^{58}$

Morton first tried to embellish his phrenology investigations with an aura of scientific authenticity. He joined the American Ethnology Society, founded by Gallatin. He eventually succumbed to phrenologists' methodologies after repeatedly attending their meetings. He skewed data from American Indian skulls he examined, to affirm Americans Indians' supposed inferior racial status. Other phrenologists ventured beyond Morton's efforts to establish the races of humanity as separate, unequal species, not varieties of the single species of Homo Sapiens:

... But it is necessary to explain what is meant here by the word race. I do not use it to imply that all its divisions are derived from a single pair; .. . I believe that they have originated from several, perhaps even from many pairs, which were adapted, from the beginning, to the varied localities they were designed to occupy; . . 59

Morton and other phrenologists infiltrated the ranks of ethnologists, bringing their methodologies and theories with them. Phrenologists considered earlier empirical investigators, such as Gallatin, as outdated with their Enlightenment ideals of equality. The new American science of ethnology acquired a phrenological slant that sharply differentiated races. ${ }^{60}$ Morton did not establish a career in craniology solely because of his affiliation with phrenology. He primarily concerned himself with the question of whether humanity comprised one species or several. If

Scribner's Sons, 1934, pp. 265, 266.

${ }^{58}$ Robert E. Bieder, Science Encounters the Indian, 1820-1880, p. 59.

${ }^{59}$ Samuel George Morton, "Account of a Cranial Collection; with remarks of the Classification of Some Families of the Human Race," Transactions of the American Ethnological Society, Vol. 2, New York: New York Historical Society, 1848, p. 219.

${ }^{60}$ Robert E. Bieder, Science Encounters the Indian, 1820-1880, pp. 54, 55. 
the races formed a single species, how did the separate races develop $?^{61}$

If Morton played a significant role in the debate about human species, it followed that his thinking influenced the origins debate. Craniological examinations represented the key to the connection between Morton's queries and existence of the Mound Builders as a separate race apart from the American Indians. It provided the vital data to establish the distinctions. Proposals and skewed evidence by phrenologists for a separate human species further enhanced the case for a separate race of Mound Builders.

Morton's method compared brain size to cranial capacity. The cranial interior reflected brain size, so he believed that he could objectively determine cranial capacity. He postulated that cranial capacity differed among the various races. Brain size correlated directly with intelligence, so the rank of one determined the rank of the other. To support his theory, he also drew on material from philology and "moral" phrenology's investigations. ${ }^{62}$ In his 1842 address to the Boston Society of Natural History, he announced his findings:

. . It is chiefly my intention to produce a few of the more strikingly characteristic traits of these peoples to sustain the position that all the American nations, excepting the Eskimaux [sic] are of one race, and this race is peculiar, and distinct from all others. ${ }^{63}$

He assessed the Indians' physical characteristics from examining 400 Indian skulls excavated from recent burial grounds, donated to him by collectors, or those of freshly decapitated American Indians brought to him. He acquired skulls from mound sites, but they crumbled upon handling. From his analyses, Morton concluded that the skulls found in Peruvian, Mexican, and

\footnotetext{
${ }^{61}$ Robert E. Bieder, Science Encounters the Indian, 1820-1880, p. 60: Bieder defines the dilemma precisely: " . . The debate settled on races: were different races actually various species of men, or if, all were the same species, then how did the separate races evolve? ...". It was in this debate that Morton would play a major role.

${ }^{62}$ Robert E. Bieder, Science Encounters the Indian, 1820-1880, p. 64.

${ }^{63}$ Samuel George Morton, "An Inquiry into the Distinctive Characteristics of the Aboriginal Race of America," North American Review, 1842. p. 192.
} 
North American earthworks all represented a single type of cranium found among supposedly "unadvanced" tribes. He reasoned that one skull's origin confirmed the derivation of other skulls. ${ }^{64}$ All American Indians, whether prehistoric or contemporary Indians, "barbarous" North and South American Indians, or the "demi-civilized" peoples of the Mexicans, Incas, or Mound Builders, represented the same race and derivation according to Morton. ${ }^{65}$

Morton effectively leveled differences among American Indians. He denied the existence of a "superior" race of Mound Builders apart from the American Indians. He inadvertently supported a key premise of Bering Strait Theory, by postulating a single origin for American Indians. This indicated a single unified people. Morton's philosophical framework contradicted Humboldt's Enlightenment based beliefs by leveling differences among American Indians allowed by Humboldt, and classifying them as a permanent subspecies and subculture, incapable of further progress or evolution. Like researchers from various disciplines, he relied on the strength of Humboldt's findings whenever he cited observations different from his own. Morton integrated Humboldt's findings with his newly concocted evidence and hypotheses to insure respectability for his conclusions:

The observations of . . . Humboldt are sometimes quoted in disproof of this pervading uniformity of physical characters; . . . Humboldt adds the American race contains nations whose features differ as essentially from one another as those of the Circassians, Moors, and Persians. But, all those people are of one and the same race . . . thus it is that the American Indian, from the southern extremity of the continent to the northern limit of this range, is the same exterior man ...66

Morton found it difficult to reconcile differences between "civilized" and "uncivilized" American

\footnotetext{
${ }^{64}$ Samuel George Morton, ,"An Inquiry into the Distinctive Characteristics of the Aboriginal Race of America," $\mathrm{p}$. 193.

${ }^{65}$ Robert E. Bieder, Science Encounters the Indian, 1820-1880, p. 69.

${ }^{66}$ Samuel George Morton, "An Inquiry into the Distinctive Characteristics of the Aboriginal Race of America," pp. 193-195.
} 
Indians. ${ }^{67}$ He resolved this difficulty by dividing the Indians into principal families: the Toltecan (from Mexico and Peru) and the "less advanced American." ${ }^{68}$ He introduced evidence that supposedly demonstrated a connection between the Mound Builders and the "demi-civilized" peoples, the Mexicans and the Peruvians. He affirmed that Mound Builders belonged to the Toltecan family. The Review of "Crania Americana," aptly summarized his proposals: ... the American race differs essentially from all others . . nor do the feeble analogies . . . denote anything beyond casual or colonial communication with the Asiatic nations; and even these may be accounted for, as Humboldt has suggested, ... the American nations . . . are of one race and one species, but of two great families ... the cranial remains discovered in the mounds . . . belong to the same race, . . ${ }^{69}$

Notice the manner in which Morton intertwined Humboldt's findings to support those propositions.

In 1846, Morton addressed the American Ethnological Society and argued for a separate indigenous race of American Indians with no links to the Old World. ${ }^{70}$ The ramifications of his statements resounded throughout the scientific world, so the origins debate peaked by midnineteenth century with uncertainties, unresolved dilemmas, and unanswered questions. ${ }^{71}$ The long-term effect Morton had on the scientific world came from the statement "Morton's Crania

\footnotetext{
${ }^{67}$ Samuel George Morton, "An Inquiry into the Distinctive Characteristics of the Aboriginal Race of America," p. 202.

${ }^{68}$ [Review of] "Crania Americana; or a Comparative View of the Skulls of Various Aboriginal Nations of North and South America, ...", The North American Review, Vol. 51, Boston: Ferdinand Andrews, 1840, p. 185: Samuel George Morton, "An Inquiry into the Distinctive Characteristics of the Aboriginal Race of America," p. 201.

${ }^{69}$ Samuel George Morton, "An Inquiry into the Distinctive Characteristics of the Aboriginal Race of America," pp. 203-207; Review of "Crania Americana," pp. 184, 185.

${ }^{70}$ Samuel George Morton, "Account of a Craniological Collection ...", Transactions of the American Ethnological Society, pp. 218, 219: " . . Both Europeans and Asiatics may . . . have visited this continent by accident or design. That the Northmen did so, is a matter of history ... where are now these intrusive strangers ... I regard the American nations as the true autochthones [indigenous peoples], the primeval inhabitants of this continent...".

${ }^{71}$ Robert E. Bieder, Science Encounters the Indian, 1820-1880, pp. 80-82.
} 
Americana provided for a polygenetic racial history of man," which went beyond the limits of the origins debate and the Controversy about the Mound Builders. ${ }^{72}$ With this climactical statement came the breakup of the science of ethnology into a monogenetic versus polygenetic polarization. The deaths of Morton and Gallatin at the mid-point of the nineteenth century removed the cement that held the diverse factions of the American Ethnology Society together. ${ }^{73}$

Phrenology never represented a precise empirical discipline, because its investigators failed to organize and present their data systematically. Many of their investigations demonstrated random, disorganized methods, often accompanied by foregone conclusions. Morton's experiments with skull measurements may have adhered to a genuine, scientific format. He departed from that framework with his speculative arguments about the interrelationship between skull capacity and intelligence. The greatest irony came from the reliance of an investigator like Morton on empirical natural scientists, such as Humboldt, with whom he radically disagreed in methodology and theory.

\section{Section 5}

\section{Advent of Sophisticated Archaeology Squier and Davis}

Two archaeologists of the new mode, Ephraim George Squier (1821-1888) and Edwin Hamilton Davis (1811-1888), entered the controversy further confused by the phrenologists' skewed investigations. This new organized type of archaeologist replaced earlier, less organized

\footnotetext{
${ }^{72}$ Robert E. Bieder, Science Encounters the Indian 1820-1880, pp. 82, 83.

${ }^{73}$ Robert E. Bieder, Science Encounters the Indian, 1820-1880, pp. 139-141.
} 
"amateurish" researchers who conducted random, piecemeal investigations of the mounds and accompanying artifacts. Often these earlier investigators received no formal education, but developed and honed their skills through experience and self-taught methods. Armed with evidence from their systematic investigations, they delved directly into the core issues of the controversy about the Mound Builders.

Squier and Davis attempted to resolve the loose ends left by prior investigators, which brought the origins debate to a climax in the 1840s. They met with considerable success, but left questions unanswered, problems unresolved, and the issue of the Mound Builders' origins unresolved by their efforts. Squier and Davis published the results from their investigations in a controversial work, Ancient Monuments of the Mississippi Valley (1848). This publication constituted a turning point in the "Mound Controversy," and established itself as an American archaeological classic. $^{74}$

Ephraim George Squier achieved prominence in science. He pursued numerous careers in journalism, diplomacy, and finally archaeology. With little formal education beyond elementary school, he developed his skills through self-taught methods. In 1845 Squier moved to Chillicothe, Ohio, a major site of earthworks. He established an independent newspaper, the Scioto Gazette, and obtained a clerical position in the Ohio House of Representatives. There he collaborated with Davis to study the Mound Builders, earthworks, and artifacts. The Smithsonian Institution published the results under the title, Ancient Monuments of the Mississippi Valley. Squier later investigated earthworks and artifacts in New York, publishing the results in Aboriginal Monuments of the State of New York (1857). His accurate descriptions became

\footnotetext{
${ }^{74}$ Robert E. Bieder, Science Encounters the Indian 1820-1880, p. 108. Contemporaries of Squier and Davis judged their work a turning point in the study of the mounds.
} 
authoritative sources in their field. Squier also earned a reputation as an expert on Central America through his publications on archaeological investigations and general observations in the region. He later wrote more works on archaeology and ethnology. ${ }^{75}$

Edwin Hamilton Davis joined Squier in his investigations of the mounds in the Mississippi Valley. Davis developed a keen interest in them early in life, because the area where he grew up (Hillsboro, Ohio) featured many earthworks. Archaeology was not a paying profession at this time, so he attended Kenyon College to obtain his baccalaureate degree. He graduated in 1833. His commencement address on the mounds drew the attention of Daniel Webster, who encouraged Davis to continue his research on mounds. Davis graduated from Cincinnati College with his M.D. and set up practice in Chillicothe, Ohio. He funded the research of one hundred mounds. In 1854 Davis presented a lecture series on his findings to the Lowell Institute in Boston and various societies in New York City. ${ }^{76}$ Squier's motivation for investigating the mounds remained a mystery, whereas Davis's motives were clear. Perhaps the romantic aura of mounds located in dark, gloomy forests provided the impetus. Authors of romantic literature reinforced this image. ${ }^{77}$

The work of the two archaeologists, Ancient Monuments of the Mississippi Valley (1848) represented a surprisingly objective study for the period, though they still operated from previously established premises. Squier, for example, had read extensively from the works of Humboldt, McCulloh, Rafinesque, and Henry Rowe Schoolcraft (1793-1864) before setting out

\footnotetext{
${ }^{75}$ Dumas Malone, "Squier, Ephraim George," Dictionary of American Biography, Vol. 9.,New York: Charles Scribner's Sons, 1935, 1936, pp. 488, 489.

${ }^{76}$ Allen Johnson and Dumas Malone, "Davis, Edwin Hamilton," Dictionary of American Biography, Vol. 3, 1930, 1931, p. 113.

${ }^{77}$ Robert E. Bieder, Science Encounters the Indian, 1820-1880, pp. 105, 106.
} 
on his investigations. ${ }^{78}$

Squier and Davis vowed to investigate from an unbiased position and avoid speculation.

Physicist Joseph Henry (1797-1878) of the newly formed Smithsonian Institution, demanded that they forsake all speculative theorizing and restrict themselves to facts and transcription of their findings. Henry believed that too much nonsense had already been perpetrated in the name of science about the mounds and their origins. Squier and Davis agreed with him in principle, and submitted to Henry's demands:

...With no hypothesis to combat or sustain, ... a desire only to arrive at truth, ... everything like mere speculation has been avoided . . ${ }^{79}$

Squier and Davis never succeeded in removing biases from their investigations. Assumptions

formed an integral part of their archaeology, just as researchers borrowed from their

predecessors. Their research formed a detailed and comprehensive work, which represented a significant departure from past fragmented accounts. ${ }^{80}$ Squier and Davis presented a well organized, systematic and detailed description of the mounds. The biases in this work did not readily stand out or radically alter the results of their research. ${ }^{81}$ They refrained from formulating

\footnotetext{
${ }^{78}$ Terry Allen Barnhart, "Of Mounds and Men: The Early Anthropological Career of Ephraim George Squier," A PhD Dissertation, Oxford, Ohio: Miami University, unpublished, 1989, p. 104. Barnhart maintains that their synthesis of what was then known about the prehistoric earthworks of eastern America, Ancient Monuments of the Mississippi Valley (1848), was a conservative, judicious study with generalizations and deductions, mostly confined to what could have been legitimately inferred from the results of their investigations. Robert E. Bieder, Science Encounters the Indian, 1820-1880, p. 131.

${ }^{79}$ E.G. Squier and E.H. Davis, "Preface," Ancient Monuments of the Mississippi Valley, New York: Bartlett and Welford; Cincinnati: J.A. and V.P. James, 1848, pp. xxxviii and xxxiv: " . . if these monuments were capable of reflecting light upon the primitive history of the American continent, the origins, migration, and early state of the American race, that they should be more carefully and minutely, and above all, more systematically investigated . . .". Quote on p. xxxviii; Robert E. Bieder, Science Encounters the Indian, 1820-1880, p. 116. Bieder mentions Joseph Henry's demands and sentiments about the mound investigations.

${ }^{80}$ Terry Allen Barnhart, "Of Mounds and Men," p. 105.

${ }^{81}$ Terry Allen Barnhart, "Of Mounds and Men," p. 106. Barnhart believes their research represented a detailed attempt to classify mounds through the use of antiquated methods. Robert E. Bieder, Science Encounters the Indian, 1820-1880, p. 117. Bieder claims the work was a rather "dry" and "detailed" description of the mounds and contents.
} 
overt hypotheses on the Mound Builders' origins, but concluded with their observations about the Mound Builders:

...the facts thus far collected point to a connection ... between the race of mound builders and the semi-civilized nations which formerly had their seats among the sierras, upon the plains of Central America and Peru ... ${ }^{82}$

They finally argued that the Mound Builders formed an extinct subdivision of American Indians, who had advanced farther than the American Indians of their day. ${ }^{83}$ They cited evidence from phrenologists to conclude that the Mound Builders' skulls resembled those Morton described as Toltecan. This showed them that the Mound Builders comprised one and the same race, as did Central and South American Indians. Cranial evidence reinforced the hypothesis that populous agricultural peoples found in North America had migrated down the Mississippi River into Mexico and beyond. Squier and Davis removed the mystery about the origin and fate of the Mound Builders. Their research represented a significant step forward in science toward ultimate resolution of the Mound Builders' origins and the development of archaeology. Their investigations should have put the key issues of Indian origins versus those of the Mound Builders permanently to rest: that the Mound Builders were the American Indians. ${ }^{84}$

Neither source fully credits Squier and Davis for their achievement.

${ }^{82}$ Ephraim George Squier and Edwin Hamilton Davis, Ancient Monuments in the Mississippi Valley, pp. $301,302$.

${ }^{83}$ Ephraim George Squier and Edwin Hamilton Davis, Ancient Monuments of the Mississippi Valley, p. $186:$ " . . . The vast amount of labor expended upon these works and the regularity and design which they exhibit ... state ... a numerous agricultural people, ... over a vast extent of country, and having established habits, customs, and modes of life . . ."; Stuart J. Fiedel, Prehistory of the Americas, p. 4. Fiedel comments that Squier and Davis carefully mapped out the mounds and drew precise sketches of several Ohio mounds, along with excavation of these mounds.

${ }^{84}$ Robert E. Bieder, Science Encounters the Indian, 1820-1880, p. 116. 


\section{Section 6}

\section{Conclusion}

Attempts to resolve the controversy about the Mound Builders through serious scientific investigations did little or nothing to resolve it, or the pressing debate about Indian origins that the mounting controversy had brought to a climax by mid-nineteenth century. Nothing resulted for full acceptance of Bering Strait Theory. The controversy about the Mound Builders opened a new question about the unity or diversity of the native population. This question overshadowed Bering Strait Theory with a flurry of debate about the evolution of a separate rate antecedent to the Indians.

The results from the investigations of Squier and Davis clarified the evidence underlying the issues of the "Mound Controversy," because of their methods used to investigate the mounds and their contents. Previous, less experienced, less organized archaeologists conducted inconsistent, sporadic, and haphazard investigations. Their results and hypotheses increased the confusion surrounding origins of both Indians and Mound Builders. The meticulous and thorough investigations of the two sophisticated archaeologists, Squier and Davis, should have brought the entire origins question to a consensus by mid-nineteenth century. Squier and Davis, however, failed to clarify their exact position on one side of the debate or the other. Their conclusions represented a middle-of-the-debate resolution: Mound Builders were American Indians, but represented an extinct sub-group. This left open the question of whether or not this sub-group had been more advanced than the Indians of their day. If they had come down more precisely in favor of equality between Mound Builders and Indians, they might have convinced other scientific investigators, such as ethnologists, about a single origin for both. Squier and Davis indicated that both groups ultimately had crossed over the Bering Strait from northeastern Asia, 
perhaps, in a single major wave of migration coupled with minor ones elsewhere. With these implications they undermined the numerous theories about different origins for North and South American Indians favored by various types of researchers in the 1830s and 1840s. Phrenologists had played an important role in linking North and South American indigenous peoples together, because they had established the Mound Builders as ancestors to the Mexican and Peruvian civilizations. Their efforts destroyed the unity of humankind as one species, by presenting each race as a separate, unique species, especially the American Indians.

For various reasons, the controversy about the Mound Builders and the validity of Bering Strait Theory continued unresolved into the late nineteenth century. Researchers failed to form a consensus on these two accounts, because a combination of factors prevented such resolution. The phrenologists declined as a reputable empirical group of investigators by the 1850s, because of their consistently skewed observations and inconsistent conclusions about race and human subspecies. Science did not clarify the definition and differentiation of species until the publication of Charles Darwin's Origin of Species (1859), the year Humboldt died.

Phrenologists and other diverse antagonistic groups of investigators infiltrated the ranks of ethnology, and the efforts of the American Ethnological Society to proceed with investigations as an organized scientific discipline. With the death of its founder and president, Albert Gallatin, the American Ethnological Society fragmented, and members ignored relevant matters of investigation. During this interim period, the Smithsonian Institution had already organized efforts for scientific research, but it was still in its infancy. The renowned American physicist, Joseph Henry (1797-1878) had co-ordinated Squier and Davis's attempts to conduct more objective investigations.

The antebellum period of the 1850s found Americans and American scholars preoccupied 
with issues about live Indians versus Mound Builders, and the debate about the continuing existence of slavery as an institution. The heated controversies surrounding both issues distorted reasonable attempts to arrive at a consensus on the origins or species debate.

Humboldt had played an overriding role in the origins debate. He took an equivocal stance in Views and Monuments about the about the Mound Builders' origins and resolution of the controversy. His construction of a valid empirically based origin theory, Bering Strait Theory, represented Humboldt's most significant and lasting contribution to the origins debate. It formed a cornerstone of the debate on which empirical, speculative, and para-empirical researchers focused. These referred to his results frequently to support their own research. His emphasis on the origin, migration, and development of the major indigenous civilizations of the Mexicans and Peruvians left its mark in the work of investigators through mid-century. With Humboldt's death in 1859 , his influence declined and his researches on Indians were neglected. ${ }^{85}$ The problems associated with the origins debate and the "Mound Controversy" continued unresolved after Humboldt's death until the advent of new research efforts. The origins debate and the "Mound Controversy" produced a significant positive result for future scientific investigations: The flurry of scientific activity surrounding them helped to firmly establish new sciences, particularly archaeology and anthropology (derived from its parent discipline of ethnology) in the scientific community. What Humboldt had pioneered with his multi-discipline approach to the origins debate, resulted in a range of scientific disciplines that developed throughout the nineteenth century.

\footnotetext{
${ }^{85}$ Laura Dussow Walls, "'The Napoleon of Science': Alexander von Humboldt in Antebellum America," NineteenthCentury Contexts, Vol. 14: no. 1, Boston: Interdisciplinary Nineteenth-Century Studies, with the assistance of the College of Arts and Sciences and the Department of English of Northeastern University, 1990, p. 85: "Humboldt's fame was quickly eclipsed after his death. . . two events, the Civil War and the publication of Darwin's Origin of Species (1859), help account for the shift in attention away from Humboldt. . . . Humboldtian science was sliding
} 
During the remainder of his life, Squier continued to write about his investigations, and tried to preserve ethnology as a viable scientific discipline. His efforts in the latter proved futile. His optimism shared particularly with ethnologists, particularly Gallatin, and with Humboldt, about the Indians' potential capabilities for development of civilizations clashed with concurrent racist assumptions about the permanent status of the American Indians as an "inferior" separate species, incapable of further development. An ongoing antagonism between Squier and Schoolcraft further weakened Squier's arguments, and prevented any rapprochement between advocates of monogenesis and polygenesis.

Bieder maintains that Squier still upheld the theory about an advanced race of Mound Builders, which his investigations and writings did not appear to support. The idea of an "advanced" race of Mound Builders separate from the Indians lingered until the 1890s, when the American Bureau of Ethnology commissioned Cyrus Thomas (18251910), an Illinois entomologist to survey the mounds and prepare a documentary report on them. By the late 1890s, popular excitement and scholarly interest in the mounds had dwindled. Thomas destroyed the theory about an "advanced" race of Mound Builders through his investigations and publication of a formal report in 1894, "Report on the Mound Explorations of the Bureau of Ethnology," Bureau of Ethnology Annual Report for 1891 (1894). ${ }^{86}$ The American version of anthropology evolved from these

into the past...".

${ }^{86}$ Robert E, Bieder, Science Encounters the Indian, 1820-1880, pp. 140-143. Bieder mentions that more than any other thinker of his day, Squier tried to amalgamate competing theories. His love for progress combined with his optimistic view of humanity did not permit him to accept the racial results of polygenism, which guaranteed an inferior position for non-Caucasian races; Gordon R. Willey and Jeremy A. Sabloff, "The Classificatory Descriptive Period 1840-1914," Chap. 3, A History of American Archaeology, New York: W.H. Freedom and Company, 1993, pp. 47, 48. Thomas at first accepted the hypothesis about a "separate Mound Builder race," but after working in the field went over to the side of the opposition. John Wesley Powell, the Director of the Bureau of Ethnology and the United States Geological Survey, selected Thomas to head a Division of Mound Exploration in 
investigations of the Mound Builders and the American Indians. No ultimate conclusions about the American Indians' origins appeared on the horizon in the 1890s before the turn of the century, nor complete validation and acceptance of Bering Strait Theory as a viable scientific explanation for their origin.

1882. Under the auspices of the Bureau of Ethnology, the empirical foundations of archaeology in the United States we reestablished on a wide geographical scale. 


\section{CONCLUSION}

The first half of the nineteenth century ended with an impasse on American Indian origins. Many "armchair" or speculative theories prevailed despite the attempts of earlier scholars to discredit ideas about Atlantis or the Lost Tribes. Several new suppositions by scholars who had discarded earlier theories prevented serious investigators from reaching any consensus. The new suppositions included separate origins for North and South American Indians, which many scholars had not considered seriously before the 1830 s and 1840 s. The debate about American Indian origins peaked by the mid-nineteenth century, when the controversy about the Mound Builders intertwined with the issues of the origins debate, and undermined its resolution. More was at stake than just Indian origins, but humanity's single origin and unity, with the postulation of the Mound Builders as a separate race. The efforts to resolve the controversy also reached a climax by mid-century with the scientific investigations of Squier and Davis.

The turn of the nineteenth century opened optimistically with the initiation of new, systematic, scientific methods of investigation, such as the tool of philology, which showed promise for resolution of the origins dilemma. The nineteenth century introduced an Enlightenment legacy from the previous century. This legacy eroded traditional Christian concepts and ushered in new concepts about degeneracy and multiple origin possibilities for humans. It represented an age, when a fledgling American republic tried to resolve the dilemma of what to do with the American Indians. Many of the key governmental figures, influenced by Enlightenment principles, belonged to an elite group, the American Philosophical Society. They felt the origins dilemma related directly with the question of what to do with the Indians. For 
investigators of all of the previous centuries, the underlying reason for speculation on American Indian origins represented an attempt to justify how the Europeans treated the Indians. This point clearly came out in several of the works examined.

In this milieu of politicians and philosophers, Alexander von Humboldt stood out with a new approach for probing American Indian origins. He was the first to conduct an expedition through Meso- and South America, in which he purposely and systematically investigated remains, artifacts, traditions, and languages of the contemporary Indian peoples and past civilizations he found there. He meticulously collected data about these and formulated observations and hypotheses on his own upon his return to Europe. Before his return, he visited the United States and met with members of the American Philosophical Society. He discussed problems facing the young republic and its goal of western expansion, especially what to do with the Indians. Humboldt and the Americans may have discussed Indian origins, but no record of this exists. Certainly, origin of the American Indians was a topic uppermost in Humboldt's mind, when he published his work on Indian origins, Views and Monuments. In it he provided precise accounts of his findings in the Americas that culminated with the creation of his origin theory the Bering Strait Theory. His works persuasively influenced subsequent researchers directly and indirectly, if citations from Humboldt's Views and Monuments are any indication. Investigators and theorists from various perspectives deferred to his authority on many areas of concern about American Indians and their origins. Often opponents blatantly opposed his results, yet quoted him extensively, if only to achieve prestige by refuting such a renowned figure in natural science. He definitively played a dominant role in the concomitant origins debate he initiated during the first half of the nineteenth century. Twentieth-century dissenters to the Bering Strait Theory still cite him and connect him with it. 
Humboldt developed the Bering Strait Theory from earlier speculations about a northeastern Asian origin for the American Indians and the results of Humboldt's precedentsetting expedition to Meso- and South America. By the time of Humboldt's expedition, explorers such as James Cook had established the proximity of Asia to America in the far north via the Bering Strait. This single piece of evidence provided a stronger foundation on which Humboldt could build his theory.

A version of the Bering Strait Theory had already emerged in the early nineteenth century with key segments in place. Barton favored it in his work, New Views of the Origin of the Tribes and Nations of America (1797). He belonged to a new group of empirical investigators, the philologists, who searched for linguistic clues to Indian origins. It seemed only a matter of time for acceptance of such a theory. Humboldt, the renowned European natural scientist and intellectual, fully developed the concept and paved the way for its eventual acceptance. He possessed an advantage over American counterparts, since he was not directly involved with the pragmatic effects of any Indian origin theory. His outside perspective permitted him to assess evidence from a more unbiased perspective than possible for many American investigators.

To argue that he was the first investigator to systematically, objectively, and completely use the scientific method to probe Indian origins is the foremost emphasis of this dissertation. He certainly was the most prominent of the early nineteenth-century theorists to do so.

Almost all of the authors of the early nineteenth century knew about the Bering Strait Theory and referred to it in their own works, whether to discredit, replace, or support it. Several of these substantiated its validity. The attention given it formed a central focus for the ongoing origins debate among scholars, scientists, politicians, and theorists alike.

Investigators meanwhile discredited other theories that prevailed during the early 
nineteenth century. This opened up a wider field with fewer contenders so a better chance existed for the theory's acceptance. Mere exposure enhanced the possibility of its acceptance versus the other origin theories. By mid-nineteenth century, investigators interjected alternate hypotheses about separate origins for North American and South American Indians. They often reached conclusions from other researchers' evidence, and upon this indirect evidence reaffirmed a northeastern Asian origin for many American Indian tribes and a different set of origins for the rest. This effectively destroyed the possibility of a single origin and the homogeneity of all of the American Indians as one unified people, a key element of the Bering Strait Theory. Humboldt attempted to establish a single origin and homogeneity for all of the American peoples, though he himself noted individual differences.

Along with the introduction of new alternate hypotheses, earlier speculative theories from classical or mythological sources survived to form a speculative tradition that co-existed with the newer empirical one. Several authors expressed renewed interest in these theories. Amid the debate about Indian origins, the controversy about the Mound Builders' origins produced further confusion and fragmentation in the debate. Prior to the turn of the century, investigators, such as Bartram, Barton, and Jefferson sowed the seeds of the controversy that dominated the debate by mid-century. It developed into a phenomenon that threatened to undo all systematic investigative work on Indian origins up to that time, and undermine acceptance of the Bering Strait Theory in the scientific community. The hypothesis of the Mound Builders as a separate race from American Indians clouded all other aspects of the debate on origins. The debates with their unresolved issues reached a climax at the time of Gallatin's formation of the American Ethnological Society in 1842. This event signified the foundation of the new American science of ethnology. Many kinds of investigators joined the Society, including philologists, 
anthropologists, archaeologists, and phrenologists. The latter three represented fledgling disciplines, while philologists had evolved into a more comprehensive and sophisticated discipline by mid-century.

Origin theories reflected the increasing fragmentation and weakening of their tenets, because of the Mound Controversy, alternate hypotheses, development of new approaches and methods of investigation, and other reasons mentioned in the preceding chapters. Kuhn's model for scientific revolutions and scientific change allows for the existence of anomalies, which fail to support and consequently weaken the entire paradigm before a paradigm shift could take place. Resistance to acceptance of a new paradigm sometimes is the greatest before such a shift occurs. Anomalies did occur regarding Indian origins. Evidence accumulated by researchers undermined proposed Indian origins from various peoples, such as Atlanteans, Carthaginians, Phoenicians, Jews, Egyptians, Vikings, and Welsh. This research revealed inconsistencies or anomalies in these theories, which contrasted with the growing evidence in favor of the Bering Strait Theory. The anomalies, thereby, paved the way for extinction of these theories.

By mid-century the paradigm shift had not yet taken place; the Bering Strait Theory had not won general recognition. Humboldt certainly had led the way with his analysis of evidence and the dominant roles he played in the debate. Many investigators had settled on one approach for evaluation of evidence to assess Indian origins, whereas Humboldt considered multiple facets of evidence. Some of the investigators hypothesized from primary source evidence or analyses of researchers who had performed the investigations first-hand. This criticism took aim at philologists, such as Barton, who borrowed source material from missionaries in the field.

Humboldt showed himself in the forefront of investigation, as he designed and carried out an expedition during which he obtained evidence first hand and analyzed it with rigorous 
precision. In Views and Monuments, he submitted the evidence to precise analysis and counter analysis, as if to purposely discover the weaknesses of his own theory. He examined the evidence and consequent theory for inconsistencies, thus formulating a more critical account than his predecessors.

Later investigators relied on Humboldt's reputation for accuracy and authenticity. Acknowledgement of his authority and citations by theorists was unable to stave off the fragmentation of the origins' debate and the increasing resistance to the Bering Strait Theory. Full acceptance of the theory did not occur during Humboldt's lifetime. Humboldt had already turned to other interests and did not continue research in this area. Also, he never returned to America, but kept up a correspondence with various Americans on topics unrelated to Indian origins. Had he further pursued his interests in American Indians, he may have proved a powerful force for acceptance of the Bering Strait Theory. However, like his contemporary, Gallatin, he may have been historically dated with his Enlightenment principles. He, therefore, turned into an authority to refute, and whose hypotheses existed aside from the main current of mid-nineteenth century thought on Indian origins.

The historical perspective of the origins debate at mid-nineteenth century may also have little relevance to contemporary thought about origins. Conclusions reasonable and acceptable for Humboldt's generation may be severely outdated. The technology and approach between the two eras separated by over 140 years can render the historical conclusions and the debate itself as irrelevant. Humboldt, and others like him, were comprehensive, holistic generalists and gentleman scientists, well versed in a variety of subjects. By the 1840's, archaeology had arisen and would eventually dominate investigations on origins. Squier and Davis claimed to have been systematic and objective, but did not have the equipment and dating methods available to 
archaeologists in the late twentieth century. So, they could not properly date their findings in the mounds to put the controversy about the Mound Builders' origins to rest.

Today's scientists represent specialists from many fields who work systematically to gather and analyze evidence left by American Indian peoples. They work co-operatively at times and in opposition at other times. Present day Bering Strait Theory is basically an archaeological theory. Humboldt would have understood this well, as he examined monuments, artifacts, and hieroglyphics left by American Indian civilizations. And like the anthropologists of today, he would have filled in the gaps of concrete evidence with hypotheses about Indian origins that culminated in the Bering Strait Theory. Anthropologists (whose predecessors were the ethnologists of Humboldt's era) generally accepted the validity of the Bering Strait Theory amid supposed concrete evidence for the existence of a separate, superior race of Mound Builders. Also, like today's scientific expedition conducted for a particular research purpose, Humboldt's expedition had definitive purposes for research. Humboldt might have had little understanding of the way universities, museums, and governments fund research, though the Russian Czar funded Humboldt's last major expedition.

The search for Indian origins today derives from a different perspective than that in which even enlightened researchers (as Humboldt and Gallatin) contrasted Indians as savages, red men, copper-colored men, aborigines, inferior in culture and civilization to "white" EuropeanAmerican civilized society. A tendency exists to evaluate these researchers, especially Humboldt, from a "presentist" perspective of history. The historical search for origins carried with it the stigma of what to do with the Indians. Early nineteenth-century perspectives (and before) assessed the problem of American Indian origins, as just that: a problem that needed a solution. American Indians still suspect "white" researchers' motives in their search for origins 
as they unearth artifacts and remains. They continue to search for evidence to refute the Bering Strait Theory. With a new awareness about American Indians' rights, perhaps scientists' search for evidence to better comprehend the Bering Strait Theory is more directly associated with accumulation of scientific knowledge than for other agendas. American Indians still continue to oppose a scientific theory, no matter how well supported by empirical evidence, that makes them only first immigrants among others. This represents a point of legality for them, because bona fide indigenous inhabitants would have absolute first priority rights over land proprietorship. The Bering Strait Theory also targets their spirituality, which provides for an indigenous origin within America from within the Mother Earth. This sacred belief conflicts directly with the tenets of the Bering Strait Theory. Another source of conflict has arisen from archaeologists' past and present excavations of sacred sites with removal of bones and artifacts for scientific investigation. Members of the American Indian Movement are actively seeking restoration of remains from museums and laboratories to proper places of burial.

Resistance has also continued from the scientific community. For various reasons, scientific and non-scientific, these scientists oppose recognition of the Bering Strait Theory, while others discover new forms of evidence to counter or discredit its validity. Recent discoveries, such as Mesa Verde in Chile, have generated enough doubt to question its validity as a scientific origin theory, or enough opposing evidence to lead to another paradigm shift to eliminate it altogether as a viable origin theory. The controversy rages in the scientific and nonscientific communities about a theory created and refined by Humboldt that may already have been a theory in its day, which solved the problems of the day. Meanwhile, varied proposals about origins from other sources surface once more, but no single definitive theory, supported by 
firm empirical evidence, has arisen to take its place as the main theory of American Indian origins. 


\section{SELECTIVE BIBLIOGRAPHY}

\section{PRINTED PRIMARY SOURCES}

A Synopsis; or Complete System of the Indian Nations, Proving Them Out of All Doubt in Belief, to be Originally Jews, Sent into captivity by the Assyrian Kings . . London: c. 1800.

Acosta, Father Joseph de. The Natural and Moral History of the Indies. Vol 2.New York: Burt Franklin Publisher, 1880. Reprinted from Edward Grimston, 1604 ed.

Adair, James. The History of the American Indians. London: E. and C. Dilly, 1775.

Adams, Henry. The Writings of Albert Gallatin. Vols.1, 2, 3. Philadelphia and London: J.B. Lippincott \& Company, 1879.

Adelung, Johann Christoph. Mithridates oder allgemeine Sprachen Künde mit dem Vater Unser als Sprachprobe in bey nahe fünf hundert Sprachen und Mundarten. Dritter Theil. Berlin: Der Vossischen Buchhandlung, 1816.

Atwater, Caleb. "Description of the Antiquities Discovered in the State of Ohio and other Western States. Communicated to the President of the American Antiquarian Society".American Antiquarian Society Transactions and Collections. Circleville, Ohio: American Antiquarian Society of Ohio, 1820, pp. 105-299.

Atwater, Caleb. Remarks Made on a Tour to Prairie du Chien: Thence to Washington City in 1829. Columbus, Ohio: Isaac N. Whiting, 1831.

Barton, Benjamin Smith, M.D. "Hints on the Etymology of Certain English Words, and on their Affinity to Words in the Languages of Different European, Asiatic, and American (Indian) Nations." Vol. 6, pp. 145-157.

Barton, Benjamin Smith, M.D. New Views of the Origin of the Tribes and Nations of America. Philadelphia: John Bioren, 1797.

Barton, Benjamin Smith M.D. "Some Remains of Antiquity." Transactions of the American Philosophical Society, Held at Philadelphia for Promoting Useful Knowledge. Vol.4.No.23. Philadelphia: Thomas Dobson, 1799, pp. 181-215.

Bartram, William. Travels and Other Writings. Travels through North and South Carolina, Georgia and Florida, 1773-74: A Report to Dr. John Fathergill: Miscellaneous Writings. Edited by Thomas P. Slaughter. New York: Library of America, Inc., 1996.

Bartram, William. Travels through North and South Carolina, Georgia, East and West Florida. London,1792. Savannah, Georgia: Beehive Press, 1973. 
Bliss, Eugene. Diary of David Zeisberger, a Moravian Missionary among the Indians of Ohio. Vols.1, 2. Cincinnati: Robert Clarke and Company, 1884.

Boudinot, Elias. A Star in the West; or a Humble Attempt to Discover the Long Lost Ten Tribes of Israel, Preparatory to the Return to Their Beloved City, Jerusalem. Trenton, N.J.: D. Fenton, S. Hutchinson, \& J. Dunham, 1816.

Brackenridge, H. M. "On the Population and Tumuli of the Aborigines of North America." Transactions of the American Philosophical Society. Vol.1. Philadelphia: American Philosophical Society, 1819.

Bradford, Alexander. American Antiquities and Researches into the Origin and History of the Red Race. New York: Wiley and Putnam, 1843.

Burder, George. The Welch Indians; or a Collection of papaers Respecting a People Whose Ancestors Emigrated from Wales to America, in the Year 1170, with Prince Madoc, Three Hundred Years Before the First Voyage of Columbus, And Who Are Said Now to Inhabit a Beautiful Country on the West Side of the Mississippi. London: Printed for T. Chapman, 1797.

Cass, Lewis, 2. "Inquiries Respecting the History, Traditions, languages, within the United States." The North American Review. Vol.4.Art.2. Boston: Otis, Broaders, and Co., 1837, pp. 3459.

[Cass, Lewis.] Review of "Travels in the Central Portions of the Mississippi Valley; Comprising Observations on Its Mineral Geography, Internal Resources, and Aboriginal Population." Edited by Henry Rowe Schoolcraft. "A Vindication of the Rev. Mr. Heckewelder's History of the American Indian Nations." Edited by William Rawle. The North American Review. Vol.17.Art.3. Boston: Frederick T. Gray, 1828, pp. 357-403.

Coates, B.H., M.D. Annual Discourse, Delivered before the Historical Society of Pennsylvania, on the $28^{\text {th }}$ Day of April, 1834, On the Origin of the Indian Population of America. Philadelphia: Printed for McCarthy \& Davis, 1834.

Darwin, Charles. The Origin of Species (1859). Avenel, New Jersey: Randomhouse Value Publishing and Co., 1997.

Donnelly, Ignatius. Atlantis: The Antediluvian World. $18^{\text {th }}$ ed. New York: Harper and Brothers, 1880.

Du Ponceau, Peter S.; Corresponding Secretary of the Historical and Literary Committee of the American Philosophical Society. "A Correspondence between the Rev. John Heckewelder, of Bethlehem and Peter S. DuPonceau, Esq., Respecting the Languages of the American Indians." Transactions of the Historical and Literary Committee of the American Philosophical Society Held at Philadelphia, for Promoting Useful Knowledge. Vol.2.,1819, pp. 355-402. 
Eliot, John. A Grammar of the Massachusetts Indian Language, A New Edition with Notes and Observations, Edited by Peter S. Du Ponceau, LL.D. Boston: Phelps and Farnham, 1822.

Flint, Timothy. The History and Geography of the Mississippi Valley. Vol.1. Cincinnati: E.H. Flint and L.R. Lincoln, 1832.

Gallatin, Albert. "Notes on the Semi-Civilized Nations of Mexico Yucatan, and Central America." Transactions of the American Ethnological Society. Vol.1. Art.1. New York: Bartlett and Welford; London : Wiley and Putnam, 1845, pp. 147-157?

Gatlin, George. Letters and Notes on the Manners, Customs, and Condition of the North American Indians. Edited by Michael MacDonald Mooney. New York: Clarkson N. Potter, Inc., 1975.

Grotius, Hugo. Biblioteca Curiosa on the Origin of the Native races of America: A Dissertation. Translated from the original Latin by Edmund Goldsmid, F.R.H.S. Edinburgh: Privately Printed, 1854.

Guyot, Arnold. The Earth and Man: Lectures on Comparative Physical Geography in Its Relation to the History of Mankind. Boston: Gould, Kendall, and Lincoln, 1849.

Heckewelder, John. History, Manners, and Customs of the Indian Nations Who Once Inhabited Pennsylvania and the Neighboring States. Philadelphia: Publication Fund of the Historical Society of Pennsylvania, 1876.

Hill, Ira. Antiquities of America Explained. Hagerstown: William D. Bell, 1831.

Humboldt, Alexander von. Cosmos: A sketch of a Physical Description of the Universe. Translated from the German by E.C. Otté. Vols. 1, 2, 3, 4, 5. London: Henry G. Bohn, New York Street, Covent Gardens, 1849.

Humboldt, Alexander von. Letters of Alexander von Humboldt, Written between the Years 1827 and 1858, to Varnhagen von Ense, Together With Extracts from Varnhagen's Diaries, and Letters From varnhagen and Others to Humboldt. Authorized Translation from the German, with Explanatory Notes and a Full Index of Names. London: Trübner and Company, 60 Paternoster Row, 1860.

Humboldt, Alexander von. Personal Narrative of Travels to the Equinoctial regions of the New Continents during the Years 1799-1804. Translated by Helen Maria Williams )1792-1827). Philadelphia: M. Carey, 1815.

Humboldt, Alexander von. Political Essay on the Kingdom of New Spain. John Black Translation. (Originally Published in 1811.) Norman and london: University of Oklahoma press, 1972. 
Humboldt, Alexander von. Political Essay on the Kingdom of New Spain. Vols. 1, 2, 3, 4. Translated from the French by John Black. London: Longman, Hurst, rees, Orme, and Brown. Paternoster Row and Colburn, 1811. New York; AMS Press, 1966.

Humboldt, Alexander von. Researches, Concerning the Institutions and Monuments of the Ancient Inhabitants of the Americas, with Descriptions and Views of Some of the Most Striking Scenes in the Cordilleras! Translated by Helen Maria Williams. Vols.1, 2. London: Longman, Hurst, Rees, Orme, and Brown, J. Murray and H. Colburn, 1814.

Jefferson, Thomas. Notes on the State of Virginia. Edited by William Peden. Chapel Hill, N.C.: University of North Carolina Press, 1955.

Jefferson, Thomas. The Papers of Thomas Jefferson. Vol.2. (22 June to 31 Dec.) 1786. Edited by Julian P. Boyd. Princeton, N.J.: Princeton University Press, 1954.

Jefferson, Thomas. The Papers of Thomas Jefferson. Vol.10. (1 Jan. to 6 Aug.) 1787. Princeton, N.J.: Princeton University Press, 1954.

Jones, George. The Original History of Ancient America, Founded upon the Ruins of Antiquity: The Identity of the Aborigines with the People of Tyrus and Israel: and the Introduction of Christianity by the Apostle St. Thomas. London: Longman, Brown, Green \& Longmans, 1843.

Kennedy, James, Esq. LL.B. Probable Origin of the American Indians, with Particular Reference to that of the Caribs. A Paper Read before the Ethnological Society, the 15 March 1854, and Printed at Their Special Request. London: E. Lumley, 1854.

Mackintosh, J. The Discovery of America, By Christopher Columbus, and the Origin of the American Indians. Toronto: W.J. Coates, 1836.

McCulloh, J.H., Jr. M.D. Researches, Philosophical and Antiquarian, Concerning the Aboriginal History of America. Baltimore: Fielding Lucas, Jr., 1829.

McIntosh, John. The Origin of the North American Indians; with a Faithful Description of Their Manners and Customs, Both Civil and Military. Their Religions, Languages, Dress, and Ornaments. New York: Nafis and Cornish, 1843.

McIntosh, John. The Origin of the North American Indians; with a Faithful Description of Their Manners and Customs, Both Civil and Military. Their Religions, Languages, Dress, and Ornaments. New York: Nafis and Cornish, 1859.

Morton, Samuel George, M.D. "Account of a Craniological Collection with Remarks on the Classification of Some Families of the Human Race." Transactions of the American Ethnological Society. Vol.2. Art. 2. New York: Bartlett and Welford; London: Wiley and Putnam, 1848,p. 215. 
Morton, Samuel George, M.D. An Inquiry into the Distinctive Characteristics of the Aboriginal Race of America. Read at the Annual Meeting of the Boston Society of Natural History, April 27, 1842.

Murray, Hugh, Esq., F.R.S.E. Historical Account of Discoveries and Travels in North America, Including the United States, Canada, the Shores of the Polar Sea, and the Voyages in Search of a Northwest Passage; with Observations on Emigration. Vols.1, 2. London: Longman, Rees, Orme, Brown, and Green; and Edinburgh: Oliver and Boyd, 1829.

Newman, John B., M.D. Origin of the Red Men; An Authentic History of the Peopling of America by the Atlanteans and Tyrians; The origin of the Toltecs, the Description and History of Atlantis, An Island that Once extended from near the Coast of Africa to the West Indies. New York: John C Wells, 1849.

Noah, Mordecai Manuel. Discourse on the Evidences of the American Indians Being the Descendants of the Lost Tribes of Israel. New York: James van Norden, 1837.

Pickering, John, "An Essay on the Orthography for the American Indian Languages of North America, as Published in the Memoirs of the American Academy of Arts and Sciences," Cambridge, Mass.: Cambridge University Press, 1820.

Priest, Josiah. American Antiquities, and Discoveries in the West: Being an Exhibition of the Evidence that an Ancient Population of Partially Civilized Nations, Differing Entirely from Those of the Present Indians, Peopled America, many Centuries before Its Discovery by Columbus. Albany: Hoffman and White, 1833.

Rafinesque, C.S. The American Nations; or Outlines of their History, Ancient and modern: Including the Whole History of the Earth and Mankind in the Western Hemisphere, the Philosophy of American History: the Annals, Traditions, Civilization, Languages \& c. of All the American Nations, Tribes, Empires, and States. Vols.1, 2. Philadelphia: C.S. Rafinesque, 1836.

Ranking, John, Esq. Ruins at Palenque in Guatemala and the Origin of the North American Indians. (Newberry Library Collection), 1828.

Rio, Captain Don Antonio del. Descriptions of the Ruins of an Ancient City. (Newberry Library Collection), 1822.

Review of 1. "Report of the Corresponding Secretary (Peter S. DuPonceau, Esq.) to the Historical and Literary Committee of the American Philosophical Society, of His Progress in the Investigation of the General Character and Forms of the Languages of the American Indians." 2. "A Correspondence between the Rev. John Heckewelder, of Bethlehem, and Peter S. Duponceau, Esq., Corresponding Secretary of the Historical and Literary Committee of the American Philosophical Society, respecting the Languages of the American Indians." The North American Review and Miscellaneous Journal. Vol.9.Art.11. Boston: Cummings and Hilliard, 1819, pp. 179-187. 
Review of Morton, Samuel George, M.D. "Crania Americana; or a Comparative View of the Skulls of Various Aboriginal Nations of North and South America; to which is prefixed an Essay on the Varieties of the Human Species." Art. 8. The North American Review. Vol.51. Boston: Ferdinand Andrews, 1840, pp. 173-186.

Review of Gatlin, George. "Letters and Notes on the Manners, Customs, and Condition of the North American Indians." The North American Review. Vol.54.Art.2. Boston: James Munroe and Co. (April 1842), pp. 283-295.

Review of Bradford, Alexander, W. "American Antiquities and Researches into the Origin and History of the Red Race." The North American Review. Vol.54.Art.2. Boston: James Munroe and Co. (April 1842), pp. 295-299.

Schoolcraft, Henry R. 1. "Archaeologia Americana: Transactions and Collections of the American Antiquarian Society." The North American Review. Vol. 45. Art. 2. Boston: Otis, Broaders, and Co., 1837, pp. 34-59.

Schoolcraft, Henry R. An Address Delivered before the New York Historical Society, at Its FortySecond Anniversary, 17 November, 1846. New York: Press of the Historical Society, 1847.

Smith, Raoul. "The Interest in Language and Languages in Colonial and Federal America." Proceedings of the American Philosophical Society. Vol.123, No.1 (February 20, 1979), Philadelphia: The American Philosophical Society, 1979, pp. 29-45.

Squier, E.G.A.M., and Davis, E.H.M.D. Ancient Monuments of the Mississippi Valley. New York: Bartlett \& Welford; Cincinnati: J.A. and V.P. James, 1848.

Squier, E.G. "Observations on the Aboriginal Monuments of the Mississippi Valley." Vol.2.Art.2. Transactions of the American Ethnological Society. New York: Bartlett and Welford; London: Wiley and Putnam, 1848, p. 131.

Stevens, John Austin. American Statesman, Albert Gallatin. Boston and New York: Houghton Mifflin; Cambridge: The Riverside Press, 1883.

Terra, Helmut de. "Alexander von Humboldt's Correspondence with Jefferson, Madison, and Gallatin." Proceedings of the American Philosophical Society. Vol.103. No.6 (Dec. 1959), pp. 783-805.

Vater, Johann Severin. Untersuchungen über Amerika's BevÖlkerung, aus dem alten Kontinents. Leipzig: CFW, 1810.

Webb, Daniel, Esq. Selections from M. Pauw, with Additions by Daniel Webb. London and Bath: R. Cruttwell, 1795. 
Williamson, Hugh, M.D. LL.D. Observations on the Climate in Different Parts of America, Compared with the Climate in Corresponding Other Parts of the Other Continent. New York: T.and J.Swords, 1811.

Zeisberger, David. Grammar of the Language of the Lenni Lenape or Delaware Indians. Translated from the German manuscript of the Author by Peter S. Du Ponceau with a Preface and Notes by the Translator. Philadelphia: James Kay, June 1827.

\section{SECONDARY SOURCES}

Barnhart, Terry Allen, “Of Mounds and Men: The Early Anthropological Career of Ephraim George Squier.” A PhD Dissertation. Oxford: Miami University, 1989.

Berman, Myron. The Last of the Jews? Lecham, New York; Oxford: University Press of America, 1998.

Bieder, Robert E. Science Encounters the Indian, 1820-1880. The Early Years of Ethnology. Norman and London: University of Oklahoma Press, 1986.

Borch, Rudolf. Alexander von Humboldt, Sein Leben in Selbstzeugnissen, Briefen, und Berichten. Berlin: Verlag das Druckhauses Templehof, 1948.

Botting, Douglas. Alexander von Humboldt. Biographie Eines Grossen Forschungs Reisenden. München: Prestel verlag, 1989.

Bowen, Margarita. Empiricism and Geographical Thought from Francis Bacon to Alexander von Humboldt. London, New York, Sydney: Cambridge University Press, 1981.

Cannon, Susan Faye. Science in Culture: The Early Victorian Period. New York: Dawson and Science History Publications, 1978.

Ceram, C.W. The First American, A Story of North American Archaeology. Harcourt, Brace, and Janovich, 1971.

Cole, Richard, "Sixteenth-Century Travel Books as a Source of European Attitudes Toward NonWhite and Non-Western Culture." Proceedings of the American Philosophical Society. Vol.116, 1972, pp. 59-67.

Derry, T.K. A History of Scandinavia, norway, Sweden, Denmark, Finland, and Iceland. Minneapolis: University of Minnesota Press, 1979.

Fagin, Bryllion N. William Bartram. Interpreter of the American Landscape. Baltimore: The John Hopkins University Press; London: Humphrey Milford Oxford University Press, 1933. 
Fellows, Otis E. and Milliken, Stephen F. Buffon. New York: Twayne Publishers, Inc., 1972.

Fiedel, Stuart J. Prehistory of the Amereicas. Cambridge: Cambridge University press, 1987.

Foucault, Michel. The Order of Things, Archaeology of the Human Sciences. New York: New York Vintage Press, 1970.

Gerbi, Antonello. The Dispute of the New World. The History of a Polemic 1750-1900. Pittsburgh: University of Pittsburgh Press, 1983.

Glacken, Clarence C. Traces on the Rhodian Shore. Nature and Culture in Western Thought from Ancient Times to the End of the Eighteenth Century. Berkeley: University of California Press, 1967.

Hagen, Victor Wolfgang von. South America Called Them. Explorations of the Great Naturalists. La Condamine. Humboldt. Darwin. Spruce. New York: Alfred A. Knopf, 1945.

Horsman, Reginald, "Scientific Racism and the American Indian in the Mid-Nineteenth Century." American Quarterly. Vol.27. No.2

(May 1975). Philadelphia: University of Pennsylvania, pp. 152-168.

Huddleston, Lee Edward. Origins of the American Indian, European Concepts 1492-1729. Austin and London: University of Texas Press, 1967.

Kupperman, Karen Ordahl. American European Consciousness 1493-1750. Chapel Hill, N.C.: University of North Carolina Press, 1995.

Laughlin, Williams, and Harper, Albert B. The First Americans: Origins, Affinities, and Adaptations. New York: Gustav, Fischer, 1979.

Martin, Paul S., Quimbly, George I., Collier, Donald. Indians before Columbus. Twenty Thousand Years of North American History Revealed by Archaeology. Chicago and London: University of Chicago Press, 1965.

Oxenstierna, Eric. The Norsemen. Edited by Karen Hutler, Greenwich Company: New York Graphic Society, 1965.

Paul, Doris. The Navajo Code Talkers. 25 Anniversary Edition.

Powell, Adam. Address to the Atheneum of Philadelphia, 1946.

Pratt, Marie Louise. Imperial Eyes. Travel Writing and Transculturation. London and New York: Routledge, 1992. 
Sheehan, Bernard H. Seeds of Extinction. Jeffersonian Philanthropy and the American Indian. Chapel Hill, N.C.: University of North Carolina Press, 1973.

Swanton, John R. The Indians of Southeastern United States. Washington, D.C.: Smithsonian Institution of American Ethnology. Bulletin 137. United States Government Printing Press, 1946.

Terra, Helmut de, "Studies of the Documentation of Alexander von Humboldt: The Philadelphia Abstract of Humboldt's American Travels and Humboldt portraits and Sculptures in the United States." Proceedings of the American Philosophical Society. Vol.102. No.6(Dec.)1958, pp. 560573.

Walls, Laura Dassow, “'The Napoleon of Science': Alexander von Humboldt in Antebellum America." Nineteenth Century Contexts. Boston: Interdisciplinary Nineteenth Century Studies, with the Assistance of the College of Arts and Sciences and the Dept. of English of Northeastern University, 1987, pp. 71-98.

Wauchope, Robert. Lost Tribes and Sunken Continents, Myth and Method in the Study of American Indians. Chicago and London: University of Chicago Press, 1962.

Willey, Gordon R., and Sabloff, Jeremy A. A History of American Archaeology. $3^{\text {rd }}$. Edition. New York: W.H. Freeman and Company, 1993.

Williams, David. John Evans and the Legend of Prince Madoc 1770-1779. Cardiff: University of Wales Press, 1963.

Willis, John A.K., "Origins: Anthroplogical Perspectives." Encyclopaedia of North American Indians. Boston and new York: Houghton and Mifflin, 1996, pp. 445-447.

Woodford, Frank B. Lewsis Cass. The Last Jeffersonian. New Brunswick, N.J.: Rutgers University Press, 1950. 